\title{
Analytical Staining of Cellulosic Materials: A Review
}

\author{
Martin A. Hubbe, ${ }^{a}$ Richard P. Chandra, ${ }^{b}$ Dilek Dogu, ${ }^{c}$ and S. T. J. van Velzen ${ }^{d}$ \\ Numerous dyes and fluorescent compounds, as reported in the literature, \\ exhibit specificity in the staining of materials associated with lignocellulosic \\ fibers and their chemical components, including cellulose, hemicellulose, \\ and lignin. Such effects long have provided analysts with convenient ways \\ to identify cellulosic fiber types, products of different pulping methods, \\ degrees of mechanical refining, estimates of accessibility to enzymes, and \\ localization of chemical components within microscopic sections of \\ cellulosic material. Analytical staining procedures allow for the facile \\ estimation or quantification using simple methods such as light microscopy \\ or UV-vis spectroscopy. More recent developments related to confocal \\ laser micrometry, using fluorescent probes, has opened new dimensions \\ in staining technology. The present review seeks to answer whether the \\ affinity of certain colored compounds to certain cellulose-related domains \\ can improve our understanding of those stained materials - either in terms \\ of their fine-scale porous structure or their ability to accommodate certain \\ colored compounds having suitable solubility characteristics. It is \\ proposed here that successful staining ought to be viewed as being a \\ three-dimensional phenomenon that depends on both the physical \\ dimensions of the colored compounds and also on functional groups that \\ influence their interactions with different components of lignocellulosic \\ materials. Published information about the mechanisms of staining action \\ as well as characteristics of different stain types is reviewed.
}

Keywords: Dyes; Fiber identification; Affinity; Accessibility

Contact information: a: North Carolina State University, Department of Forest Biomaterials, Box 8005, Raleigh, NC 27695-8005 USA; b: University of British Columbia, Faculty of Forestry, 2424 Main Hall, Vancouver, BC V6T 1Z4, Canada; c: Istanbul Univ.-Cerrahpasa, Dept. Forest Biology \& Wood Protection Technol., Faculty of Forestry, TR-34473 Istanbul, Turkey; d: University of Amsterdam, Programme Conservation and Restoration of Cultural Heritage; *Corresponding author: hubbe @ncsu.edu

\section{Contents}

Introduction . . . . . . . . . . 7388

Purpose of the staining . . . . . 7389

Aims of the article ......... 7389

Background for staining of cellulosics. 7390

Coloration ... . . . . . . . . . . 7390

Chromophores ... . . . . . . . . 7390

Retention of colorant . . . . . . . . 7396

Chemical aspects of dye sorption. 7399

Physical aspects of dye sorption . 7405

Stain specificity \& cellulosic matter . . 7407

Cellulose . . . . . . . . . . . . . . . . 7407

Hemicelluloses . . . . . . . . . . . 7411

Lignin . . . . . . . . . . . . . . . . 7413

Pectin . . . . . . . . . . . . . . 7416

Extractives . . . . . . . . . . . 7416

Callose . . . . . . . . . . . . . 7416
Suberin . . . . . . . . . . . . 7417

Protein . . . . . . . . . . . 7417

Fungal matter . . . . . . . . . 7418

Phloem . . . . . . . . . . . . . 7418

Flavonols . . . . . . . . . . 7418

Starch . . . . . . . . . . . . . 7418

Fiber type identification . . . 7419

Stain specificity \& processing . . 7420

Chemical processing . . . . . . 7420

Mechanical processing . . . . 7423

Closing statements . . . . . . . . . . 7425

References cited . . . . . . . . . . . 7427 APPENDIX

Table A: Widely used stains . . 7450

Table B: Staining procedures . . 7458 


\section{INTRODUCTION}

Many years of trial and error have contributed to a rich body of knowledge of using colorants to reveal aspects of cellulosic fiber materials. Important aspects and milestones in this history have been captured in articles and monographs (Lee 1916; Graff 1935, 1940; Conn 1948; Isenberg 1967; van Velzen 2018). A peak of related research took place in the 1930s to 1950 s, followed by a decline in interest until recent decades, when there has been increasing attention to fluorescent dyes. As pointed out by Scott (1972) the field of analytical staining has suffered from episodes of unrealistic claims, sometimes leading to expectations of near-perfect specificity between a given staining procedure and the presence of a corresponding feature, chemical component, or identifiable condition within the tested material. On the other hand, there also has been a maturation of the field of analytical staining, such that certain staining procedures are now recognized as being more useful than others. The organization of this article, after this introduction, is based on three main sections. The first section deals with the mechanisms affecting analytical staining of cellulosics. The next section considers what stain specificity can reveal about cellulosic matter. The final section asks and what stain specificity can reveal about processing of the cellulosic material. The appendix to the article contains two tables. The first of these (Table A) lists key aspects of the more prominent colorants used in the analytical staining of cellulose fibers. The second table (Table B) provides information about some of the most widely used fiber staining procedures, often involving several chemical agents or more than one colorant.

The topic of this review article needs to be distinguished from the related field of histological staining, i.e. the staining of living tissues. Some notable reviews and monographs of the field of histological staining are as follows (Lillie 1977; Horobin 1982, 2002; James 1984; Lewis and Knight 1992). The field of histological staining overlaps the focus of the presence article, to some extent, when research specimens include either living cells in the outer layers or wood, or cells that still retain proteinaceous remnants from those phases of the life cycle (Woo 1970; Stockert et al. 1984; Oparka et al. 1994; Gutmann 1995; Kitin et al. 2000; Hamburger et al. 2002; Dubrovsky et al. 2006; Paredez et al. 2006; Bond et al. 2008; Mitra and Loque 2014; Soukup 2014). However, when using stains to investigate wood-based materials and their products, there is often little or no remnant of the proteinaceous materials associated with living cells.

Histological staining employs some specialized methods that generally fall outside of the present review scope, but which can be mentioned briefly. For example, living tissue commonly needs to be "fixed" (e.g. with ethyl alcohol) to enable its storage and long-term observations (Bond et al. 2008; Zelko et al. 2012). Another type of treatment known as "clearing" tends to make cellular tissue material more transparent so that the stained features can be observed more clearly in a microscopic observation (Ursache et al. 2018). For example, Lux et al. (2005) recommended the addition of lactic acid saturated with chloral hydrate as a clearing agent for living plant tissues. Another common procedure is embedding, in which the fragile living tissue becomes reinforced by the curing of an added material (Verhertbruggen et al. 2017). Such procedures can allow the specimen to be microtomed into thin sections for examination of the three-dimensional aspects. Gray (1954) discussed another common situation, in which one is examining living plant material, but the main interest is on the "skeletal" components, i.e. cellulose, hemicellulose, and lignin. It was recommended, in such cases, to treat the specimen with a solution of 
sodium or potassium hypochlorite (an oxidative bleach) to remove proteinaceous material before attempting to stain the lignocellulosic structures.

Why stain cellulosic material in the laboratory? Numerous reasons have emerged over the course of time, and some of the more important are listed in Table 1. As shown, it is possible to group the listed reasons into the three main categories of identification, detection, and either quantification or estimation. Each of the listed items will be examined in more detail in the course of this review.

Table 1. Purposes for the Laboratory Staining of Cellulosic Materials and Fibers

\begin{tabular}{|c|l|}
\hline Category & Selected References \\
\hline Identification & $\begin{array}{l}\text { Graff 1940; Hall 1976; Parham and Gray 1982; TAPPI } \\
\text { 1988; Woodward 2002; Jablonsky et al. 2015 }\end{array}$ \\
\hline Fiber type & $\begin{array}{l}\text { Cartwright 1929; Kitamura and Kyoshi 1971; Srebotnik } \\
\text { and Messner 1994; Gutmann 1995; Drnovsek and Perdih } \\
\text { 2005a; Donaldson and Vaidya 2017; Ursache et al. 2018 }\end{array}$ \\
\hline Chemical components & $\begin{array}{l}\text { Bahr 1954; Hagege et al. 1969; Hieta et al. 1984; Stein et } \\
\text { al. 1992; Fernando et al. 2011; Coiro and Tuernit 2017 }\end{array}$ \\
\hline Detection & $\begin{array}{l}\text { Heyn 1966; Inglesby and Zeronian 2002; Donaldson and } \\
\text { Frankland 2008 }\end{array}$ \\
\hline Microstructure & Cartwright 1929; Xiao et al. 1999; Dubrovsky et al. 2006 \\
\hline Fibrils & Ben Mlouka et al. 2016 \\
\hline Mycelia & $\begin{array}{l}\text { Simons 1950; Blanchette et al. 1992; Fernando and } \\
\text { Daniel 2010; Fernando et al. 2011 }\end{array}$ \\
\hline Biofilms & Graff 1940; Woodward 2002; Chandra et al. 2008 \\
\hline Quantification or estimation & $\begin{array}{l}\text { Inglesby and Zeronian 2002; Chandra et al. 2008, 2012; } \\
\text { Meng et al. 2013 }\end{array}$ \\
\hline Degree of fibrillation & Horvath et al. 2008; Meng et al. 2013; Yang et al. 2013 \\
\hline Changes due to processing & Ougiya et al. 1998; Chandra and Saddler 2012; \\
\hline Surface area &
\end{tabular}

Analytical staining methods can be regarded as relatively simple, rapid, low-cost, and widely practiced for identification of fibers. However, the procedures have problems including subjective error and low accuracy. A key challenge lies in the attempt to identify fiber types by color. The hue, saturation, and luminosity may vary due to unknown causes, leading to uncertainty in interpretation of the findings. For example, the colors of fibers after application of the well-known Herzberg stain (see later) have been stated as brilliant yellow for groundwood fibers, dark purplish green to deep reddish purple for bleached kraft fibers, and brilliant purplish pink to vivid red-purpose for rag fibers (Dubinyová et al. 2016).

\section{Aims of the Article}

The motivating premise for this article is that, considering all of the research that has been carried out to find which dyes best indicate certain fibers, chemicals, or pore structures, etc., there must be things that one can learn by reversing the perspective. In other words, if a certain dye compound stains a certain feature or fiber deeply, that fact may be trying to tell us something about the nature of the stained materials. In many cases the information might go beyond the as-received materials and involve changes in the 
nature of various cellulosic materials in response to such processes as pulping, bleaching, refining, or treatment with concentrated alkali, i.e. mercerization, etc. Also, a secondary goal of this work (located at the end of the document) is to provide an organized listing of some of the best-established dyes and staining procedures that have shown their utility for the analytical staining of cellulosic materials.

To lay the groundwork for all of the goals just mentioned, the following section considers what has been reported about the mechanisms by which various stains affect the color of cellulosic materials and features thereof.

\section{BACKGROUND FOR ANALYTICAL STAINING OF CELLULOSICS}

\section{Coloration Mechanisms}

The process of staining a material inherently involves several different aspects. Some of these involve the colorant, including why certain compounds absorb light of different wavelengths. One also needs to be concerned with how and to what extent the colorant is retained on the target material. Presumably the amount of uptake will be closely related to the depth of coloration. Uptake of dye clearly depends on both chemical and physical aspects, and such issues will be considered. Mechanisms of coloration and staining have been considered in the following articles (Griffiths 1982; Maekawa et al. 1989; Yu et al. 1995; El-Shafei et al. 2011). A search of the literature indicated a need for publication of general background information in this area.

\section{Chromophores}

Absorbance of light

Certain compounds, both organic and inorganic chromophores, have the ability to absorb light within the visible range, which lies roughly between the wavelengths of 400 and $700 \mathrm{~nm}$ (Harkin 1972; Schmidt and Heitner 1993; Mahapatra 2016). The topic of chromophores has been covered in various sources (Zollinger 1991; Clark 2011). The goal of this section is to provide basic information about this topic, as may be needed by researchers who are new to the field of analytical staining and to describe some related principles.

As diagramed in Fig. 1, one can visualize the incidence of one photon, having an energy of $h v$ (Planck's constant times frequency of the light) onto the colored object. If that amount of energy corresponds to the difference in energy between the outermost occupied molecular orbital and the next higher (usually "antibonding") molecular orbital of the chromophore, then the energy can be absorbed. Light absorbance takes place when the energy is then dissipated as heat rather than being re-emitted as light (Belgio et al. 2012). Ordinary non-fluorescent dyes, as frequently used in analytical staining, function according to this scheme.

As indicated in the figure, the content of vibrational energy, which varies from moment to moment, can have different values both in the ground state and in the elevated energy state of a valence electron. The presence of multiple vibrational energy levels has the effect of spreading out the energy associated with a given electronic transition. This explains why typical light absorbance spectra, even in the case of some pure chromophores, show very broad maxima in their light absorbance as a function of wavelength. The broadness of adsorbance spectra of typical dyes places limits on how many dyes can be used in a typical staining assay; as is evident from items in Table B of the Appendix, a 
majority of staining protocols employ a single dye, many employ two, but almost none employ more than three colored compounds.

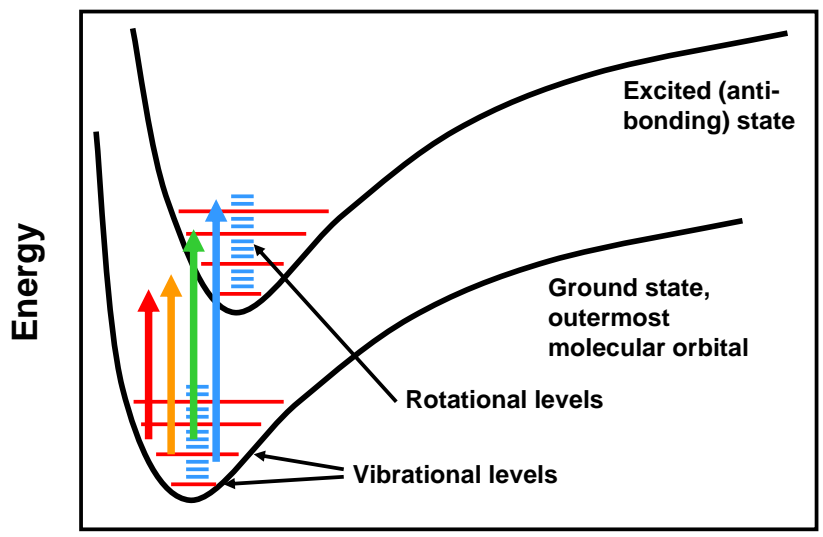

Internuclear separation

Fig. 1. Representation of the absorbance of light due to the presence of a chromophoric chemical group in which an outer electron is promoted from a bonding molecular orbital (often associated with highly conjugated and partly aromatic structures) to the next anti-bonding orbital with the dissipation of the energy as heat. Note that the line color represents the color of light associated with hypothetical promotion of an electron from a given vibrational and rotational condition in the ground state to another situation in the excited state.

\section{Factors affecting hue}

Though colored organic compounds play a major role in our daily life, the underlying mechanisms have not often been explained to general scientific audiences. Therefore, this section will describe some basic physical aspects of such phenomena and use some common examples, such as food items, for which the chromophores have relatively simple chemistry. As illustrated in Fig. 2, the addition of a dye or stain to an uncolored material will remove intensity from the transmitted or scattered (diffusely reflected) light.

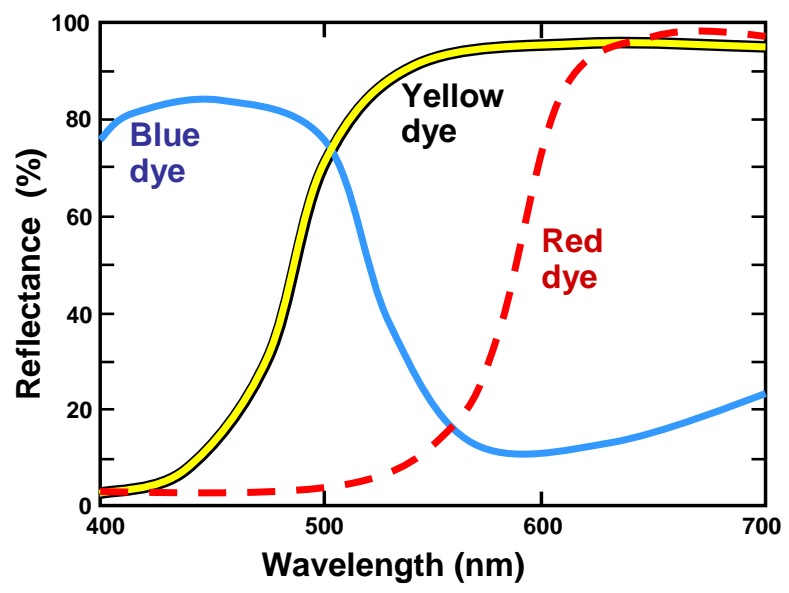

Fig. 2. Principle of subtractive coloration, whereby a chromophoric group preferentially absorbs some wavelengths of light while allowing other wavelengths to be scattered in all directions, allowing the net diffusely reflected light to be perceived as having a certain color 
Here, the word "transmitted" implies that the light proceeds forward, as through a window. The word "scattered" implies that the emitted light from a point of scattering goes in all directions, as in the case of light incident on a non-glossy sheet of paper (Hubbe et al. 2008). If, for instance, the incident light includes a steady mixture of all the wavelengths in the visual region (i.e. something that would be regarded by the viewer as an example of white light), then some of the energy would be removed from the transmitted or scattered beams. If the absorbed energy is at least somewhat selective, then the observer will sense that the light is no longer white but has a color. Because typical chromophoric (light-absorbing) groups have a wide assortment of vibrational states, separated by rather low differences in energy, it is very common for the absorbance of light to be spread out over a relatively wide range of wavelengths in a bell-shaped curve (Swofford et al. 1976).

Many factors affect the tendency of certain chemical compounds to absorb light energy within different ranges of wavelength. Most organic compounds, e.g. pure cellulose, do not absorb light in the visible range because it takes too much energy to move any of the electrons within them to the next higher energy state. It would require shorter wavelength radiation with higher energy, e.g. ultraviolet light, to move such electrons to the next energy level. By contrast, some organic compounds are chromophoric, meaning that they absorb energy in the visible light spectral range. In such cases the energy difference between the most weakly held molecular orbital and the next available level is in the same range as the wavelengths of visible light. This can happen, for instance, when there is a sufficient degree of conjugation, i.e. sufficiently long sequences of double and single carbon-carbon bonds (Frank et al. 1997). A good example of this is found in $\beta$ carotene (Decoster et al. 1992), which has the chemical formula shown in Fig. 3.

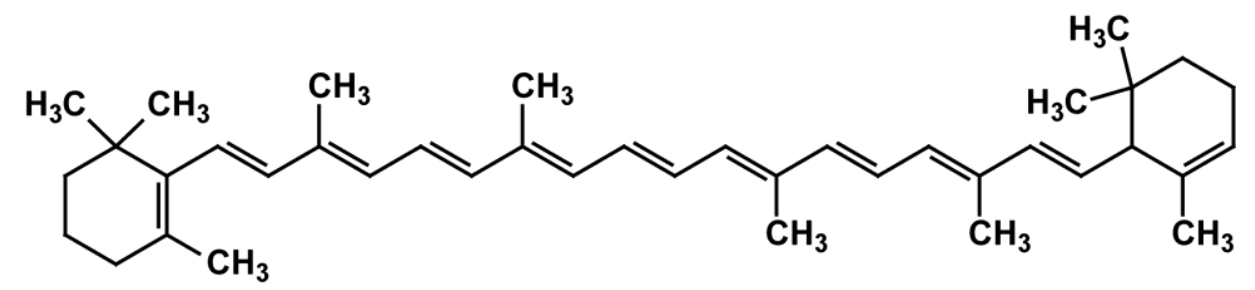

Fig. 3. Chemical structure of $\beta$-carotene, as found in carrots

Note that $\beta$-carotene has a series of ten conjugated double bonds in its structure. The fact that carotene strongly adsorbs in the blue region, while letting a mixture of green and red wavelengths reach the eye, accounts to the perception of the orange color associated with carrots. The next example, lycopene (Fig. 4), is a component of tomatoes. It has eleven conjugated double bonds, but in other respects the chemical structure is very similar. Thus, the red hue associated with tomatoes can be attributed to the fact that there is one more conjugated double bond in lycopene, in comparison to $\beta$-carotene.

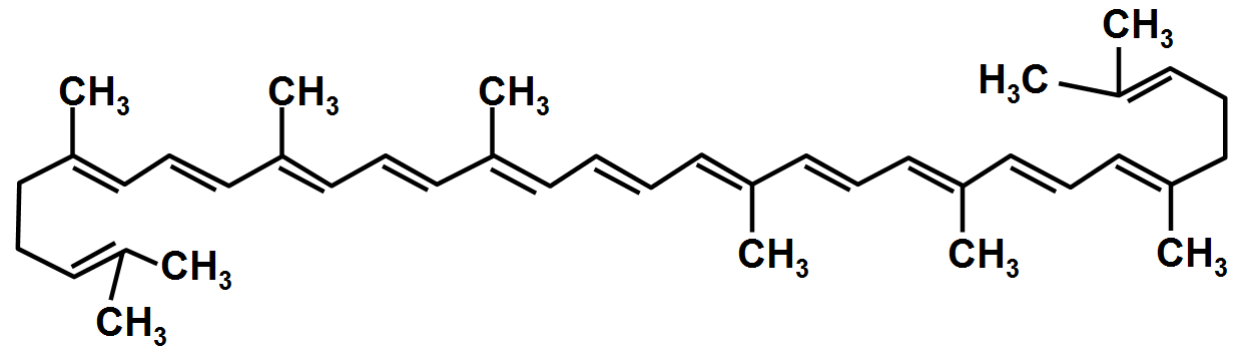

Fig. 4. Chemical structure of lycopene, as found in tomatoes 
The difference in color between carrots and tomatoes can be attributed to a difference in the number of conjugated double bonds. The fact that lycopene has one more double bond in the sequence than $\beta$-carotene allows it to absorb green wavelengths in addition to blue wavelengths, thus letting mainly just the red wavelengths to be diffusely reflected. Closely related to beta-carotene and lycopene is vitamin A (retinol), which is colorless (Fig. 5). The reason that retinol is colorless again can be attributed to the different lengths of the conjugated chain: The absorbance maximum of vitamin $\mathrm{A}$ is at shorter wavelengths (in the ultraviolet range) compared carotene and lycopene. Vitamin A plays an important role in vision, since it serves as a precursor to synthesis of chromophores in the eye (Duester 2000).

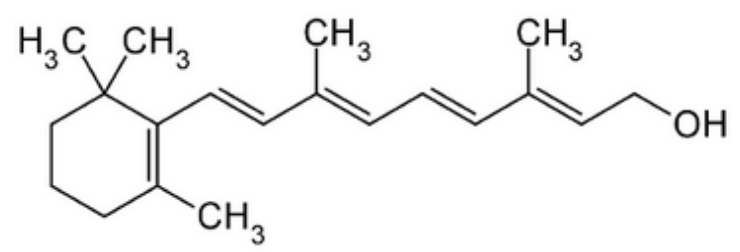

Fig. 5. Chemical structure of vitamin A (retinol), which does not absorb light in the visible range

\section{Color detection and specification}

Though color can be readily perceived by human observers, instrumental methods allow its objective quantification. The most widely employed system for color specification is known as CIE $L * a * b *$ (Johnson and Fairchild 2003). As may be surmised from the name of this system, it generally takes three parameters to specify a color. The parameter $L^{*}$ represents lightness, with 100 indicating a pure white and zero indicating a pure black. The parameter $a$ quantifies the red-to-green color coordinate (red being positive), and $b$ represents the yellow-to-blue coordinate (yellow being positive). The fact that an object's color can be specified by a set of three parameters is consistent with the presence of three color-sensing receptors in the cone cells of the majority of humans (Kolb 1991; Smith 2005).

\section{Kubelka-Munk analysis}

The $L^{*}, a^{*}$, and $b^{*}$ values are sufficient to specify any perceivable color of a nonfluorescent object. But to go a step further, often it can be important to have a measure of the relative concentration of chromophoric material in a certain specimen or part of a specimen. A mathematical approach to dealing with such issues was provided by Kubelka and Munk (1931). The Kubelka-Munk approach employs major simplifying assumptions, such as light traveling in only one dimension through a completely uniform, featureless medium. The reflectivity (proportion of diffusely reflected light compared to the incident light) at a specified wavelength can be evaluated in terms of the following equation,

$$
R_{\infty}=1+K / S-\left[(K / S)^{2}+(2 K / S)\right]^{0.5}
$$

where $K$ is the light absorbance coefficient and $S$ is the light scattering coefficient. Both $K$ and $S$ can be evaluated using suitable spectrophotometers, following standard methods (Molenaar et al. 1999). 
If one makes the assumption that a typical stain will have a large effect on light absorbance but a negligible effect on light scattering, then the relative amount of chromophoric material present on or in the stained materials will be proportional to the ratio $K / S$, where (Hubbe et al. 2008),

$$
K / S=(a S-S) /[0.5 \ln [(c+1) /(c-1)] /(W b)]
$$

where

$$
\begin{aligned}
& a=0.5\left[\left(1 / R_{\infty}\right)+R_{\infty}\right] \\
& b=0.5\left[\left(1 / R_{\infty}\right)-R_{\infty}\right] \\
& c=\left(1-a R_{\mathrm{O}}\right) /\left(b R_{\mathrm{o}}\right)
\end{aligned}
$$

Also in Eq. 2, $R_{0}$ is the reflectance of a single sheet or layer backed by a perfect black background (a black cavity), and $W$ is the mass per unit area (basis weight) of the sheet or layer.

Since the quantities in Eq. 2 all can be measured experimentally, there is a great opportunity to use these relationships for advanced evaluation of the results of various staining protocols based on instrumental measurements. A Kubelka-Munk analysis has been used, for instance, by Khatri et al. (2014), to account for the amount of dye uptake onto cellulosic fibers. The widespread availability now of powerful computing capabilities suggests that research ought to be done in this area. In addition, utilization of the mathematical relationships between optical characteristics and the amounts of chromophoric groups present have potential applications in the automatic evaluation and interpretation of the results of staining assays.

\section{Fluorescence}

The term "fluorescence" implies that light of one wavelength impinges on an object and that at least some of the incident energy is absorbed and re-emitted at a longer wavelength, representing a lower energy (Olmstead and Gray 1997; Donaldson and Bond 2005). In recent years there has been explosive progress in development of fluorescent staining for cellulose-based materials for purposes of analysis. Related studies are listed in Table 2, which gives some highlights of each study.

An inherent advantage of using fluorescent staining compounds is that the fluorescent emission can be easily distinguished from the scattered components of incident light, especially if the latter is monochromatic. Thus, as long as the specimen has little or no fluorescence of its own at the wavelength of interest, all of the detected intensity at that wavelength can be attributed to the fluorescent stain. These considerations have contributed to a recent high popularity of fluorescent compounds, together with confocal laser scanning microscopy, to obtain three-dimensional micrographs of cellulosic materials (Donaldson and Vaidya 2017; Hutterer et al. 2017).

To place these studies in proper context, it is important to note that lignin itself has fluorescent attributes (Olmstead and Gray 1997). In addition, safranin dye, which has been much used for many years to reveal the presence of lignin, has fluorescent character (Kitin et al. 2000; Bond et al. 2008). 
Table 2. Studies Using Fluorescent Staining of Cellulosic Fibers or Materials

\begin{tabular}{|c|c|}
\hline Notable Findings of the Work & Reference \\
\hline $\begin{array}{l}\text { Fluorescein was mixed with cellulase, then centrifuged. The } \\
\text { supernatant solution was dialyzed to retain the labeled enzyme. }\end{array}$ & Seibert et al. 1978 \\
\hline $\begin{array}{l}\text { Staining was with berberine. Analin blue was the counter-stain, } \\
\text { to remove background fluorescence and non-specific staining. }\end{array}$ & Brundrett et al. 1988 \\
\hline This review provides an overview of the topic. & Kasten 1989 \\
\hline $\begin{array}{l}\text { A highly soluble fluorescent dye was used to reveal movement } \\
\text { of fluid from the root tip and up specific channels in the plant. }\end{array}$ & Oparka et al. 1994 \\
\hline This article reviews the topic for conifer embryogenesis. & Fowke et al. 1995 \\
\hline $\begin{array}{l}\text { A simple method revealed pine lignin, cuticle material, } \\
\text { unsaturated lipids, and pectocellulosic components. }\end{array}$ & Mori and Bellani 1996 \\
\hline $\begin{array}{l}\text { The authors estimated the extent of delignification of single pulp } \\
\text { fibers by means of acridine orange fluorescent staining. }\end{array}$ & Liu et al. 1999 \\
\hline $\begin{array}{l}\text { Fungal colonizers were detected by immunofluorescent labeling } \\
\text { and confocal laser scanning microscopy. }\end{array}$ & Xiao et al. 1999 \\
\hline $\begin{array}{l}\text { Flocculation and adsorption processes in paper manufacturing } \\
\text { were visualized by fluorescence microscopy with tagged agents. }\end{array}$ & Whipple and Maltesh 2000 \\
\hline Filipin selectively stained sitosterol, a pitch component. & Speranza et al. 2002 \\
\hline Lignin was selectively stained with acridine orange. & Li and Reeve 2004 \\
\hline Hybrid poplar was transformed with a fluorescent protein. & Nowak et al. 2004 \\
\hline Rhodamine staining permitted 3D imaging of coated paper. & Ozaki et al. 2006 \\
\hline $\begin{array}{l}\text { Cellulose deposition in growing plant tissue was visualized by } \\
\text { fusion with fluorescent protein. }\end{array}$ & Paredez et al. 2006 \\
\hline $\begin{array}{l}\text { Fluorescent-labeled lectins were used to image spores and cell } \\
\text { walls. }\end{array}$ & Bouzon and Ouriques 2007 \\
\hline $\begin{array}{l}\text { A cationic fluorescent labeled dextrin of various molecular mass } \\
\text { was used to study diffusion into cell walls. }\end{array}$ & Horvath et al. 2008 \\
\hline $\begin{array}{l}\text { A cationic fluorescent labeled polyallylamine was used to study } \\
\text { diffusion into cell walls and resulting paper strength. }\end{array}$ & Gimaker and Wågberg 2009 \\
\hline $\begin{array}{l}\text { Glucuronoxylan was fluorescently labeled and used to study } \\
\text { effects of drying on the pore structure of kraft pulp fibers. }\end{array}$ & Kohnke et al. 2010 \\
\hline $\begin{array}{l}\text { Ovalbumin was fluorescently labeled and used to reveal } \\
\text { accumulation of the protein at pit membranes. }\end{array}$ & Neumann et al. 2010 \\
\hline Nanofibrillated cellulose surfaces were fluorescently labeled. & Orelma et al. 2012 \\
\hline $\begin{array}{l}\text { Fluorescent labeled bovine serum albumin was used to study } \\
\text { the biological decay of biomass. }\end{array}$ & He et al. 2013 \\
\hline $\begin{array}{l}\text { A fluorescent label system was used to study cellulose } \\
\text { enzymatic breakdown and cellulase enzyme binding. }\end{array}$ & $\begin{array}{l}\text { Luterbacher et al. 2013, } \\
2015 a, b\end{array}$ \\
\hline $\begin{array}{l}\text { Fluorescently labeled polyethylene glycol (PEG) was used to } \\
\text { study interactions between lignin and PEG within wood. }\end{array}$ & Donaldson et al. 2014 \\
\hline $\begin{array}{l}\text { Click chemistry was used to fluorescently label cellulose } \\
\text { nanofibrils for use in subsequent studies. }\end{array}$ & Navarro et al. 2015 \\
\hline $\begin{array}{l}\text { Fluorescently labeled monolignols were incorporated into } \\
\text { growing stems, revealing lignin biosynthesis details. }\end{array}$ & Pandey et al. 2016 \\
\hline Xylan structures were selectively fluorescent labeled. & Hutterer et al. 2017 \\
\hline $\begin{array}{l}\text { The alignment of microfibrils was revealed more clearly using } \\
\text { fluorescent dye adsorption. }\end{array}$ & Thomas et al. 2017 \\
\hline
\end{tabular}

\section{Metachromic staining}

The term "metachromic" implies that the color of a chromophore changes during the processes of staining (Boon 1986; Gutmann 1995; Li and Reeve 2004). Such changes, which might be due to changes in electronic environments or redox reactions, have the potential to reveal differences between different substrates. Gutmann (1995) observed that 
oxidation of cellulosic specimens either before or after their treatment with toluidine blue yielded strong changes in the resulting coloration; such changes were often helpful in efforts to obtain vivid and appealing contrasts in color micrographs of the specimens. In a case considered by Li and Reeve (2004), a change in fluorescence emission of acridine orange dye was attributable to in-situ dimerization of the dye when the addition level was excessive.

An example of a distinctive color change that can be brought about by a shift in the redox potential, in the competition between oxidizing and reducing agents, is illustrated in Fig. 6. The reagent potassium ferrocyanide is a yellow-colored compound that is specified in the recipes for several of the staining procedures listed in Table B of the Appendix (see Alexander stain, Graff 1940; Bright stain, Bright 1917; Boast stain, Franke 1993; Kantrowitz-Simmons stain, ASTM D 1030-95; Schwalbe stain, Isenberg 1967). Oxidation of this species, for instance by the addition of ferric iron species, gives rise to Prussian blue, wherein the iron is shifted from $a+2$ to $a+3$ valence state. It is worth noting that the presence of oxidizable groups in the cellulosic sample, such as in the case of groundwood, tends to give yellow coloration in the cited test protocols, which is consistent with the depletion of the oxidizing species by its reaction with the biomass (see notations for Boast stain).

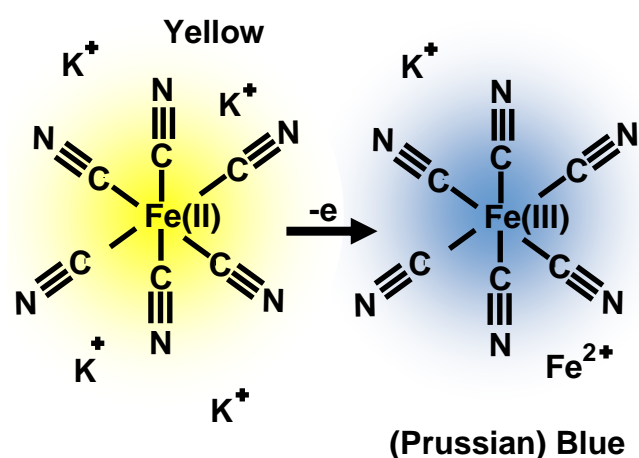

Fig. 6. Structures of potassium ferrocyanide (yellow) and Prussian blue and their interconversion by oxidation

\section{Electron density}

When transmission electron microscopy is being used to obtain very high resolution images, stronger contrast sometimes can be achieved by use of substances having high electron density (Hayat 1975; Lewis and Knight 1992; Stein et al. 1992; Harris 1997). In particular, metals having relatively high values of atomic number can be used to make the treated cellulose-related surfaces more opaque to electron beams (Kuga et al. 1983; Hieta et al. 1984; Righetti et al. 1986; Maurer and Fengel 1990; Kovarik et al. 1992; Hosoo et al. 2002; Kvien et al. 2005; McNeal et al. 2005). The degree of contrast within transmission electron micrographs is often improved by such staining treatments.

\section{Retention of the Colorant}

A second essential issue that underlies successful staining procedures is that there must be an effective mechanism of attachment. Evidence can be found in various published works to support two main mechanisms by which various dyes become retained onto or within cellulosic materials. The preposition "onto" can be used in cases where the 
interaction is best explained by a process of adsorption, i.e. the binding interaction of the dye onto a surface. The preposition "within" can be used in cases where it makes more sense to envision the dye as fully mixing with one or more chemical domains within cellulosic materials, especially in the cases of lignin, hemicellulose, and extractives, which are all non-crystalline. During the discussions that follow, it should be kept in mind that these two idealized mechanisms are likely to operate in parallel, even if, in a given case, one of them is predominant.

\section{Adsorption onto surfaces of cellulosic matter}

In many cases this attachment can be regarded as adsorption of molecules onto a surface. Bird et al. (2006) evaluated the adsorption of several different acid dyes onto cellulose and determined that binding forces (enthalpy) associated with van der Waals interactions played a dominant role. Such forces are well known to provide attraction between all substances, including uncharged compounds and surfaces (Dzyaloshinskii et al. 1961). Adsorption of dyes very often conforms to a Langmuir isotherm model (Langmuir 1918; Hubbe et al. 2012a). The Langmuir model assumes that the dye molecules independently interact with energetically equivalent sites of adsorption.

An inherent limitation in adsorption mechanisms dominated by van der Waals force components is their non-specific nature. This is contrary to the frequent goal of staining technologists, who generally want to identify a certain type of chemical group or type of tissue. For instance, a review of adsorption of dyes onto cellulose surface, for purposes of water treatment, showed that ionic charges of the dyes and the substrates often play a prominent role relative to the uptake of a selected dye (Hubbe et al. 2012a).

Many of the colorants that have been employed for the analytical staining of cellulosic materials and fibers have an ionic charge. Table 3 lists some examples of colored compounds that are either cationic (positive ionic charge) or anionic (negative charge) under typical conditions of application.

Table 3. Well Known lonically Charged Stains for Cellulosic Materials or Fibers

\begin{tabular}{|l|l|l|}
\hline Sign of Charge & Compound & Selected References \\
\hline \multirow{5}{*}{ Cationic (+) } & Acridine orange (lignin stain) & Li \& Reeve 2004 \\
\cline { 2 - 3 } & Alcian blue & Benes 1968 \\
\cline { 2 - 3 } & Anilinium sulfate & Herzberg 1902 \\
\cline { 2 - 3 } & Astra blue FM & Srebotnik \& Messner 1994 \\
\cline { 2 - 3 } & Auramine O & Ursache et al. 2018 \\
\cline { 2 - 3 } & Malachite green & Isenberg 1967 \\
\cline { 2 - 3 } & Methylene Blue & Korn \& Burgstaller 1953 \\
\cline { 2 - 3 } & Rhodamine B & Navarro \& Bergstrom 2003 \\
\cline { 2 - 3 } & Safranin (lignin dye) & Bond et al. 2008 \\
\cline { 2 - 3 } & Toluidine blue O & Matsumura et al. 1998 \\
\hline & Acid fuchsin & Kitin et al. 2010 \\
\cline { 2 - 3 } & Calcofluor white (purified cellulose) & Choi \& Oday 1984 \\
\cline { 2 - 3 } & Chlorazol black E & Robards \& Purvis 1964 \\
\cline { 2 - 3 } & Direct Blue 1 & Inglesby \& Zeronian 1996 \\
\cline { 2 - 3 } & Direct Yellow 11 -$)$ & Kwok et al. 2017 \\
\cline { 2 - 3 } & Direct Orange 15 & Chandra \& Saddler 2012 \\
\cline { 2 - 3 } & Lignin pink & Chen et al. 2006a \\
\cline { 2 - 3 } & Trypan blue & Williams 1983 \\
\hline
\end{tabular}


In principle it is reasonable to expect a greater tendency for cationic chromophores to adsorb onto negatively charged surfaces, which includes most cellulosic substances. In practice, as may become apparent from other topics to be considered in this review, ionic charge is just one among several factors that can play a major role governing uptake of stains.

Much greater specificity can be achieved by various forms of immunological staining. The term immunological implies that one takes advantage of a highly specific interaction between an antibody and an antigen protein, usually with one of them attached to a fluorescent chromophore or "label". There are many examples of such staining for the analysis of lignocellulosic materials or fibers (Xiao et al. 1999; Hutterer et al. 2017; Paes et al. 2017; Verhertbruggen et al. 2017).

Sometimes conditions need to be adjusted with care in order to achieve selective adsorption of a dye onto a component of choice. As noted by Boon (1986), one can expect that the more suitable sites for dye adsorption will be filled first and less-suitable sites would be filled if the dye is present in sufficient excess. Li and Reeve (2004) observed such a relationship with adsorption of acridine orange dye onto wood pulp. Only at sufficiently low concentration, the dye preferentially becomes associated with lignin.

In staining procedures involving more than one dye, a higher-affinity compound may displace another colorant. For instance, Gutmann (1995) describes treatment of thin sections of plant tissue successively with safranin (a lignin-indicating dye) followed by other dyes. It was observed that in areas where the surface was composed of cellulose, the safranin could be effectively displaced by subsequent application of azure II dye, yielding a good visual contrast between the cellulose-covered areas and the lignin-covered areas.

\section{Solubilization of dye within cellulosic matter as a mechanism of dye retention}

In some situations it may be more appropriate to envision the staining matter as becoming dissolved in the target substrate, rather than its being attached to surfaces. This way of describing the situation is especially appropriate in cases where the substrate of interest is liquid-like or behaves like a swellable gel. In such cases the principles of solubility can be expected to govern the extent of uptake of a stain. In general terms, solubilization tends to be favored when the affinity characteristics such as the Hildebrand coefficient, polar nature, and hydrogen bonding tendency are most similar between the two compounds to be combined (Hansen 2007). The Hildebrand parameter, determined as the square-root of the cohesive energy density (Hildebrand et al. 1970), has been found to be a good predictor of mutual solubility, especially when just considering nonpolar substances. When comparing various organic solvents, Schuerch (1952) found increasing solubilization of lignin as the Hildebrand parameter became near to 11 and also with increasing hydrogen bonding ability. In addition, one can expect there to be an additional contribution to solubilization when a dye and a target material have contrasting acid-base character such that they attract each other electrostatically (Fowkes and Mostafa 1978; Fowkes 1990).

The extent of coloration of a cellulosic specimen sometimes has a high dependency on factors contributing to mutual solubilization of the colorant and the target specimen. It has been shown that substances that each tend to be soluble in a certain test liquid also tend to mix well with each other at a molecular scale (Hansen 2007). The best examples of this are the highly hydrophobic and non-polar dyes that can be used as indicators of the presence and location of wood extractives, which also contain hydrophobic alkyl chains or aromatic groups (Boon 1986; Brundrett et al. 1991; Mori and Bellani 1996; Fernando et 
al. 2005; Ursache et al. 2018). Another good example is acid phloroglucinol, which resembles lignin with respect to its phenolic composition; staining with acid phloroglucinol is known to be a quick and reliable way to determine the location of lignin within a specimen (Wick 1970).

\section{Chemical Aspects of Dye Sorption}

Charge interactions

When considering chemical aspects of the adsorption of stains, $\mathrm{pH}$ responses can be an important clue to the mechanism. Boon (1986) provides a chart describing the different $\mathrm{pH}$ behaviors of dyes that fall into the categories of acid, basic, and amphoteric. Among these, the acid dyes adsorb best at low $\mathrm{pH}$, which tends to protonate many types of acidic groups and render the dye compounds less soluble in water. Similarly, basic dyes tend to be adsorbed more efficiently at high $\mathrm{pH}$, consistent with the deprotonation of amine groups, rendering neutral charge. Amphoteric materials, having both acidic and basic groups, exhibit intermediate adsorption behavior. However, all of these tendencies can be shifted depending on the relative amount and state of ionization of acidic or basic groups present on the specimen to be examined (Boon 1986).

Charge phenomena appear especially evident in the case of cationic dyes, which would reasonably have an affinity for the negatively charged (acidic) groups present on a wide range of cellulosic materials when wet (Thomaneck et al. 1991; van de Ven et al. 2007; Horvath et al. 2008; Gimaker and Wågberg 2009). For instance, Drnovsek and Perdih (2005a) observed that cationic dyes, as a group, generally have a preferential affinity for lignin. This may be at first a surprising finding, since published models to represent lignin structure generally do not show groups that would become negatively charged below a pH of about 9 (Pearl 1967; Sakakibara 1980; Glasser and Sarkanen 1989). The explanation may lie in the close association of lignin with certain hemicellulose moieties, due to lignin-polysaccharide complexes (Lawoko et al. 2004, 2013). Indeed, high affinity of cationic dye has been reported for glycans (Ghinea 1986), which often contain carboxylic acid functions.

Gutmann (1995) found increased uptake of cationic dye to plant tissues after oxidation with sodium hypochlorite. This finding is again consistent with a role of negatively charged acidic groups. The oxidation can be expected to increase the amount of carboxylic acid groups on the cellulosic material, unless they thereby become solubilized and released from the substrate. The binding between cationic dyes and the negatively charged groups on pulp fibers is sufficiently stoichiometric in some cases that it can be used as a means of determining the amount of fiber charge (Fardim et al. 2002; Mathews et al. 2004). Caution is required, however, when making such assumptions; according to Smith and McCully (1978) the specificity of a cationic dye for negatively charged groups was not as great as they had assumed.

As noted by Hall (1976), acid dyes are effective for coloration of wool and silk, since the proteins that compose such fibers have positively charged amine groups. Though lignocellulosic fibers are not noted for having amine groups, there certainly will be proteinaceous materials present in growing plant tissue (Hamburger et al. 2002; Soukup 2014). Also, lignocellulosic materials might be optionally treated with a variety of cationic agents, which then can promote their staining with the use of anionically charged dyes (Gurr 1965; Thomaneck et al. 1991). As noted by Gurr (1965), the cations of aluminum or iron can be used as effective mordants for anionic dyes. Alternatively, Grigsby et al. (2005) used a staining procedure to reveal the presence of a cationic resin used to treat 
medium-density fiberboard material. Thomaneck et al. (1991) used an anionic dye (anthralan blue B) to reveal the effect of cationic modification of cellulose membranes.

Effects of salt concentration can provide further mechanistic evidence to understand staining. For instance, Gimaker and Wågberg (2009) found that the addition of $\mathrm{NaCl}$ in solution promoted the penetration of a cationic fluorescent polyelectrolyte into the interior of lignocellulosic fibers. The effect was attributed to a contraction of the extended conformation of the polyelectrolyte and a weakening of the binding interactions. As a consequence, the colorant was more able to diffuse into the mesopores in the cell walls of the fibers. The same colorant, when added in the absence of salt, remained mainly on the outsides of the fibers and did not stain them deeply. According to Horvath et al. (2008), the uptake of the polyelectrolyte (a cationic dextran with fluorescent labeling) increased monotonically with increasing salt concentration. Likewise, Goodrich and Winter (2007) soaked cellulose and chitin nanocrystals in salt buffer to neutralize the charge sites (sulfated cellulose) on the nanocrystals to focus the adsorption of Congo red.

\section{Hydrophobic interactions}

The term "hydrophobic interactions" has been used in scientific publications to refer to a tendency of non-polar chemical groups, of sufficient size, to self-associate (SanchezRuiz 1996; Hillyer and Gibb 2016). However, one needs be cautious regarding the driving force for such association. Although the London dispersion component of the van der Waals forces is no-doubt acting to bring the materials together (Bijma et al. 1998; Farina et al. 1999), those forces are acting between all molecules and structure at the nanoscale, not just the nonpolar ones. It appears that a main driving force for self-association of hydrophobic groups and structures would involve an increased net amount of polar interactions, especially hydrogen bonding that can occur in systems where the hydrophobic groups have been segregated into the core of micelles, emulsion droplets, or other assemblies of non-polar entities (Walstra 1993; Kronberg 2016). Since the polar interactions involve greater energy, thermodynamics favors segregation of the phases.

A tendency for non-polar chromophoric compounds to become solubilized into hydrophobic domains of a specimen can help to explain the role of stains that are used to identify oily and fatty substances in a specimen. For example, Speranza et al. (2002) used filipin staining as a selective method to show the location of sitosterol, a pitch-like materials present in wood. This is an example in which a non-polar stain preferentially becomes mixed with, and possibly dissolved in, similarly nonpolar components of the wood.

\section{Dye self-association}

Self-association among dye molecules is another process having the potential to affect staining outcomes. The term "laking" has been used to describe formation of agglomerates of dye molecules (Gurr 1965; Boon 1986). Anionic dyes are expected to form lakes when treated with various trivalent or divalent metal ions (Gurr 1965). According to Boon (1986), lakes can be formed by reaction of the $\alpha$ - $\beta$ keto-enol groups present in some dyes with $\mathrm{Al}^{3+}$ ions. Gurr (1965) likewise referred to a charge-based mechanism, suggesting that dyes with both positive and negative charged groups can selfassociate in various ways, including interactions with other dyes. It makes sense that neutralization of negatively charged sulfonate groups by the metal ions would cause the dyes to lose their solubility in water. Inglesby and Zeronian (2002), who were focused on the usage of direct dyes, noted that dye agglomeration tends to increase with increasing slat 
concentrations, increasing temperatures, and sometimes with decreasing temperatures. They suggested that some amphoteric dyes may adsorb as dimers due to formation of ion pairs.

Salts also are known to promote the uptake of dyes in some cases. For instance, the adsorption of certain direct dyes onto cotton can be promoted by salt addition to the aqueous solution (Venkataraman 1952). Presumably by increasing the ionic strength of the solution, the contribution of charged groups on the dyes to their solubilization is reduced. In other words, they are salted out due to decreased solubility. The term "laking" is used when such insolubilization is brought about intentionally, usually by adding divalent metal ions (Hunger and Herbst 2012). However, such precipitation tends to be non-specific, not depending on the nature of the substrate. Alternatively, the laked dye may remain as a stable colloidal suspension rather than depositing on a solid surface. Thus, laking would not generally be recommended in situations where preferential dye adsorption onto certain chemical domains or physiological structures is the goal.

\section{Chemical pretreatments of the specimen, then staining}

Sometimes a two-step process may be involved in staining procedures, the first step involving some kind of modification of the cellulosic material. Borzynski et al. (1972) first treated the substrate with the oxidant periodic acid, enabling staining with basic fuchsin, in a system that was specific for glycoproteins. Also, the carboxylate groups resulting from oxidation can increase the intensity of coloration with cationic dyes (Gutmann 1995).

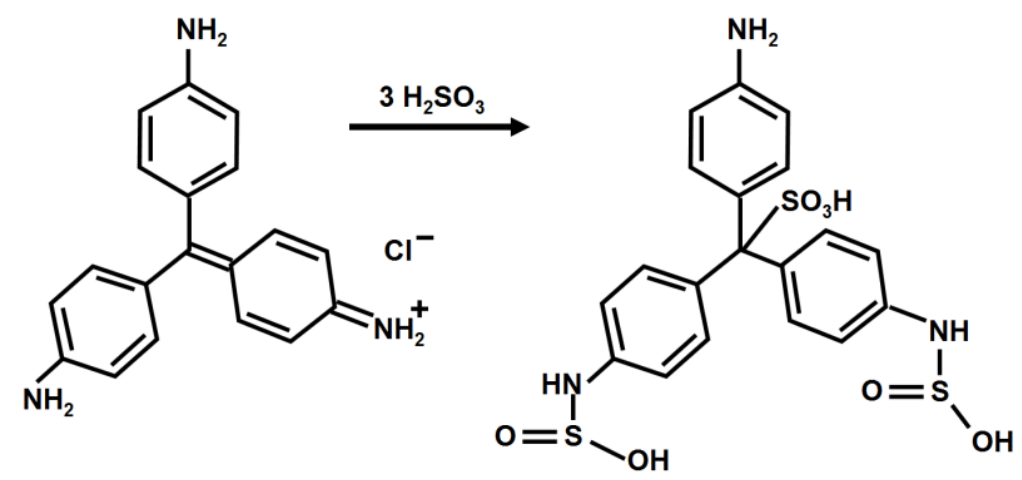

Fig. 7. Activation of pararosanilin red with sulfurous acid to generate the Schiff reagent

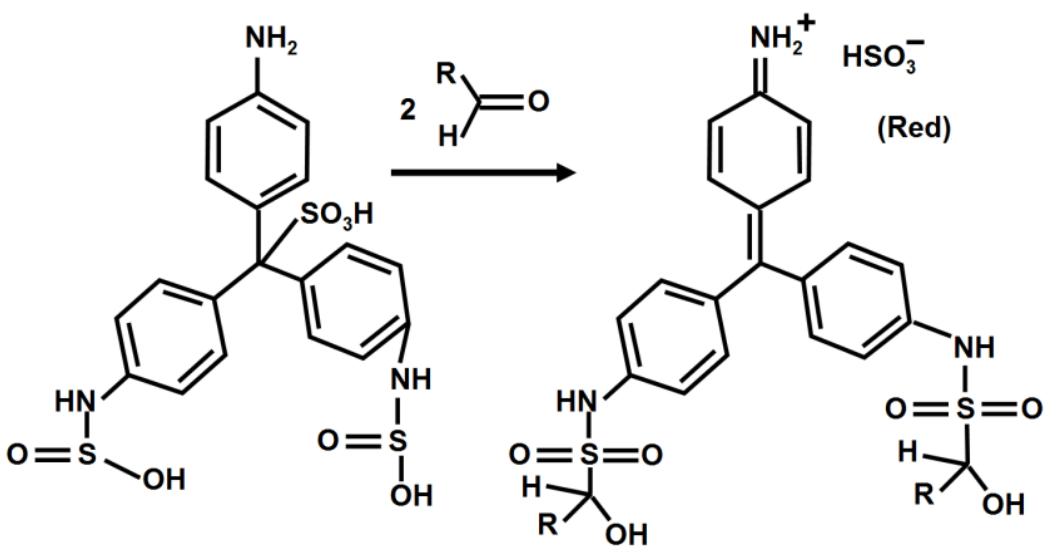

Fig. 8. Reaction of Schiff reagent with aldehyde groups, restoring the red coloration 
Treatment with periodic acid can be used as an efficient way to generate aldehyde groups by reaction with hydroxyl groups $(-\mathrm{OH})$. The adjacent $-\mathrm{OH}$ groups on the $\mathrm{C} 2$ and C3 carbons of polysaccharides and sugars are susceptible to such oxidation. Thus, subsequent evidence of staining with Schiff's reagent reveals the polymeric material to have been a polysaccharide (Boon 1986). As illustrated in Fig. 7, to bring about the Schiff reaction, pararosanilin red is treated with sulfurous acid, giving a colorless intermediate. Reaction with an aldehyde group (Fig. 8) restores the red coloration.

Knebel and Schnepf (1991) and Coiro and Truernit (2017) extended similar chemistry, as in the Schiff reaction, to covalently bind a fluorescent group to cell walls. Such preparations can be examined by confocal scanning laser microscopy.

\section{Enzymatic, immunological binding}

Much greater specificity can be achieved by various forms of immunological staining. The term immunological implies that one takes advantage of a highly specific interaction between an antibody and an antigen protein, usually with one of them attached to a fluorescent chromophore or "label". The forces and energies that are responsible for immunological and enzymatic bonding mechanisms are fundamentally the same as those acting between ordinary materials, but they involve relatively large protein structures having shapes and detailed structures that can facilitate high specificity. There have been many related publications, especially in recent decades, as shown in Table 4.

Many of the cited studies employed confocal laser scanning microscopy, together with fluorescent-tagged immunological stains, to characterize the three-dimensional microstructure of cellulosic materials (Beamesderfer et al. 1952; Abe et al. 1995; Xiao et al. 1999; Nowak et al. 2004; Paredez et al. 2006; Truernit et al. 2008; Anderson et al. 2010; Neumann et al. 2010; He et al. 2013; Gourlay et al. 2015; Luterbacher et al. 2015a,b; Donaldson and Vaidya 2017; Hutterer et al. 2017; Ursache et al. 2018). Notably, cellulosebonding modules associated with many cellulase enzymes provide a mechanism of specific bonding to cellulose; the usage of fluorescently labeled cellulose-bonding modules has been reported (McCartney et al. 2006; He et al. 2013; Luterbacher et al. 2013, 2015b; Gourlay et al. 2015).

\section{Covalent bonding}

The use of covalent derivatization is not a common preparatory step before analytical staining. Exceptions to this rule are found in the work of Yang and Pan (2010), and Navarro and Bergstrom (2014). The first-listed authors carried out a silanization reaction of cellulose nanocrystals (CNCs) as a means of attaching amino groups to the cellulose surfaces. The amino groups were then reacted with either 1-pyrenebutyric acid $\mathrm{N}$-hydroxy succinimide ester or fluorescein isothiocyanate, resulting in fluorescent CNCs. The fluorescent-tagged CNCs then could be imaged by various methods. Navarro and Bergstrom (2014) prepared cellulose nanofibrils with grafted rhodamine B, which has fluorescent properties. Such treatment helped them to obtain 3D images of the nanocellulose by means of confocal laser scanning microscopy. While neither of the approaches here represent a system for directly staining a multi-component cellulosic material, one can easily imagine using such fluorescently labeled nanocellulose as a means of determining how well the nanocellulose can be mixed in forming a composite, for instance. 
Table 4. Key Findings of Studies Using Immunological Staining of Cellulosic Specimens

\begin{tabular}{|c|c|}
\hline Notable Findings of the Work & Reference \\
\hline $\begin{array}{l}\text { Aminoaldehyde dehydrogenase activity was revealed using } \\
\text { stain. }\end{array}$ & Seibert et al. 1978 \\
\hline $\begin{array}{l}\text { Antibodies gave a specific reaction with arabinogalactan- } \\
\text { proteins. }\end{array}$ & Kikuchi et al. 1991 \\
\hline $\begin{array}{l}\text { Microtubules in conifer tracheids were revealed by } \\
\text { immunological staining. }\end{array}$ & Abe et al. 1995 \\
\hline $\begin{array}{l}\text { Cinnamyl alcohol dehydrogenase, a catalyst for lignin synthesis, } \\
\text { was revealed by staining. }\end{array}$ & Feuillet et al. 1995 \\
\hline $\begin{array}{l}\text { Conifer embryonic cells were studied by immunofluorescence } \\
\text { methods. }\end{array}$ & Fowke et al. 1995 \\
\hline $\begin{array}{l}\text { Fungal hyphae in wood were located by immunofluorescence } \\
\text { labeling. }\end{array}$ & Xiao et al. 1999 \\
\hline $\begin{array}{l}\text { This article describes preparation and use of antibody probes to } \\
\text { study plant cell walls. }\end{array}$ & Willats et al. 2000 \\
\hline $\begin{array}{l}\text { Enzyme labeling was used to locate aminoaldehyde } \\
\text { dehydrogenase activity. }\end{array}$ & Sebela et al. 2001 \\
\hline $\begin{array}{l}\text { Endoclonal cells became stained by interaction with beta- } \\
\text { glucuronidase. }\end{array}$ & Hamburger et al. 2002 \\
\hline $\begin{array}{l}\text { Immuno-gold staining revealed day-night differences in } \\
\text { glucomannan content. }\end{array}$ & Hosoo et al. 2002 \\
\hline $\begin{array}{l}\text { Jellyfish fluorescent protein was used as a stain to study poplar } \\
\text { hybrids. }\end{array}$ & Nowak et al. 2004 \\
\hline $\begin{array}{l}\text { Tagged cellulose synthase was used to visualize microtubules in } \\
\text { Arabidopsis. }\end{array}$ & Paredez et al. 2006 \\
\hline Xylan-binding modules were synthesized. & Filonova et al. 2007 \\
\hline $\begin{array}{l}\text { Phloem structure was studied using staining to visualize gene } \\
\text { expression. }\end{array}$ & Truernit et al. 2008 \\
\hline $\begin{array}{l}\text { Direct dye staining revealed the progress of enzymatic } \\
\text { processes. }\end{array}$ & Anderson et al. 2010 \\
\hline $\begin{array}{l}\text { Immunological staining was used to reveal accumulation of } \\
\text { protein at pit openings. }\end{array}$ & Neumann et al. 2010 \\
\hline $\begin{array}{l}\text { Biodegradation of woody material was observed by fluorescently } \\
\text { labeled protein. }\end{array}$ & He et al. 2013 \\
\hline $\begin{array}{l}\text { Carbohydrate binding modules were used to study } \\
\text { decomposition of woody tissue. }\end{array}$ & Gourlay et al. 2015 \\
\hline $\begin{array}{l}\text { Labeled cellulase was used with confocal microscopy to study } \\
\text { biodegradation. }\end{array}$ & Luterbacher et al. 2015a,b \\
\hline $\begin{array}{l}\text { Fluorescently labeled cellulase was used to study pine } \\
\text { degradation. }\end{array}$ & Donaldson and Vaidya 2017 \\
\hline $\begin{array}{l}\text { Xylan was located on the surfaces of pulp and viscose fibers } \\
\text { using antibodies. }\end{array}$ & Hutterer et al. 2017 \\
\hline $\begin{array}{l}\text { Immunological labeling was used to study effects of } \\
\text { pretreatments of poplar cell walls. }\end{array}$ & Paes et al. 2017 \\
\hline $\begin{array}{l}\text { Three methods involving immunological staining were } \\
\text { compared. }\end{array}$ & Verhertbruggen et al. 2017 \\
\hline
\end{tabular}

Related work has involved click chemistry, i.e. derivatization leading to certain functional groups that can be reacted with selected agents at near-100\% efficiency under mild and dilute conditions (Liebert et al. 2006; Filpponen and Argyropoulos 2010). For instance, Navarro et al. (2015) first modified cellulose nanofibrils (CNF) with furan and maleimide groups. The presence of these groups enabled subsequent click reactions 
involving either Diels-Alder cycloaddition or the thiol-Michael reaction. The staining facilitated imaging by confocal laser scanning. Pandey et al. $(2015,2016)$ incorporated a click-compatible monolignol analog into developing Arabidopsis thaliana stems. Later, the stems could be specifically labeled with a click reaction, providing clear evidence of the location of the lignin that had incorporated the tagged monolignols during biosynthesis.

\section{Iodine-containing stain formulations}

Iodine has been a key component in several of the most widely used protocols aimed at distinguishing between different classes of woodpulps (Herzberg 1902; Graff 1940; Isenberg 1967; AATCC 1990; Jia et al. 2016). The popularity of iodine appears to be related to two complementary properties. On the one hand, iodine is a weak oxidizing agent (Togo and lida 2006), such that its valency state can change from zero $\left(I_{2}\right)$ to minus one $\left(\mathrm{I}^{-}\right)$in the presence of easily oxidizable chemical species (see later discussions associated with the oxidation of certain groups within lignin and extractives). In addition, the elemental iodine under certain environmental conditions tends to form linear chains having three or more iodine atoms (Bluhm and Zugenmaier 1981; Svensson and Kloo 2003). The linear iodine oligomers are expected to be stable only in the presence of suitable complexing system and when stabilized by $\mathrm{H}_{3} \mathrm{O}^{+}$ions (Calabrese and Khan 2000). A wide range of polysaccharides, including xylan and cellulose, have been found to stabilize polymeric iodine, leading to a staining effect (Swanson 1948; Moulay 2013). For instance, it is well known that highly colored iodine species are stabilized in the presence of starch (Minick et al. 1991; Gutmann 1995; Woodward 2002). In the case of amylose and amylopectin, the iodine chains appear to be stabilized within helices of aqueous starch solutions (Minick et al. 1991; Davis and Khan 1994). Swanson (1948) showed that by varying the linear portion of polysaccharide chain length, iodine colors can be obtained ranging from red to lavender, to purple, and ultimately to blue at relatively high linear chain lengths. This finding is consistent with the principle that the complex becomes darker and darker with increasing length of the polyiodide chain (Svensson and Kloo 2003). The strong coloration of iodine complexes can be attributed to the energy levels associated with the molecular orbitals within species of the type illustrated in Fig. 9. The fact that polyiodine complexes are stabilized by various cations (Svensson and Kloo 2003) is consistent with the use of such salts as aluminum chloride, calcium chloride, and zinc chloride in various staining procedures (see Graff "C" stain in Table B of the Appendix). It is unclear from the literature whether or not the use of various salts in the course of staining assays removes the need for polysaccharide stabilization of the colored complexes.

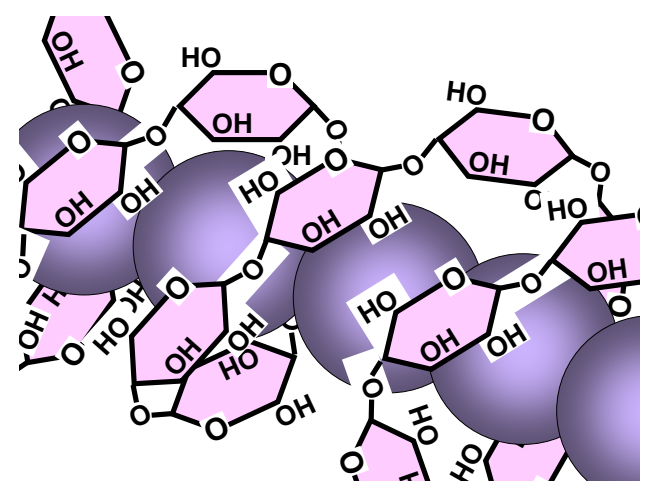

Fig. 9. Schematic illustration of chromophoric polyiodide chain stabilized within a polysaccharide helix in aqueous solution 


\section{Physical Aspects}

Certain physical aspects of a lignocellulosic substance can be expected to influence the degree of uptake of various chromophoric compounds (Peters and Ingamells 1973). This section reviews research related to the effects on staining phenomena of pore size at the site of interest, permeability of any material in the way of the adsorption site, time of dyeing, surface area, swelling ability, and the dye molecule's size. The location of the prospective adsorption site within a lignocellulosic material can be presumed to make a difference because the chromophoric compound needs to physically fit within the available space, be able to diffuse to that position without insurmountable physical barriers, and also have enough time to accomplish such ends.

\section{Pore size}

Gurr (1965) proposed that the relative size of dye molecules, compared to that of mesopores within the cellulosic material structure, ought to determine whether or not significant coloration of internal surfaces can take place. Several studies have used dye adsorption as a means to estimate the pore size of cellulosic material (Inglesby and Zeronian 1996; Yu and Atalla 1998). In principle, successful dying implies that the nanoscale domains within the material at least need to be as large as the dye molecules for strong coloration to result. Evidence of dye molecules being too large to reach or fit into adsorption sites have been found (Drnovsek and Perdih 2005a,b).

Notably, Direct Orange 15 has been found to have a unique relationship between molecular size and adsorption; a higher-mass fraction of dye molecules has been found to have a strong tendency to adsorb within fibrillated cellulose domains ( $Y u$ and Atalla 1998). The preference for larger molecules suggests that the physical ability to occupy the sites cannot be the whole explanation for adsorption. Rather, it appears that the mechanism must be related to the greater interaction energy between a larger molecular structure of a dye at an adsorption site. This is consistent with the larger dye molecules likely being associated with larger van der Waals forces of attraction. Ingelesby and Zeronian (2002) also expressed doubt regarding whether, in typical circumstances, the size of a dye molecule plays a determining role regarding whether or not it adsorbs on the internal surfaces of cellulosic material; the cited authors proposed that dye structure can be more important.

\section{Permeability}

In some other studies the researchers made the assumption that the depth of staining depended more on whether or not the presumed adsorption sites could be reached by a diffusion mechanism, rather than being obstructed by dead-end pores or pores too small to allow passage (Maekawa et al. 1989; Kim et al. 2004; Yang et al. 2013; Khatri et al. 2014; Luterbacher et al. 2015a). For instance, Luterbacher et al. (2015a) used confocal laser scanning microscopy to support a mechanism by which the enzymatic widening of pores within lignocellulosic substrates tended to increase the rate at which dyes were able to permeate into the material.

\section{Time and temperature of dyeing}

Equations and theories have been proposed to characterize the related rates of diffusion into porous materials (Weber and Morris 1963; Ho and McKay 1999; McKay and Ho 1999; Wu et al. 2009; Yang et al. 2011). One of the most useful approaches to accounting for rates of permeation of dyes into porous substrates, including cellulosic 
materials, is that of Weber and Morris (1963), the so-called interparticle diffusion theory. According to this concept, after an initial adsorption onto the external surface of a material, the rate of subsequent permeation involves diffusion within the void spaces of the material and temporary adsorption along the way. This step can be represented by the following rate law (Yang et al. 2011),

$$
Q=k t^{0.5}+I
$$

where $Q$ is the amount adsorbed per unit mass of sorbent, $k$ is the rate constant governing diffusion into the particle, $t$ is the elapsed time after combining the solution and the sorbate, and $I$ is the intercept of a plot of $Q$ versus $t^{0.5}$.

Differences in rates of diffusion sometimes can be used advantageously to achieve better discrimination between adjacent lignocellulosic materials exposed to staining treatments. For instance, Gutmann (1995) observed that short-term dying can be used as a way to better discriminate between different types of lignocellulosic material; a $15 \mathrm{~s}$ exposure period of a mixture of toluidine blue $\mathrm{O}$ (an indicator for cellulose) and safranin $\mathrm{O}$ (an indicator for lignin) resulted in deep staining of just the cellulosic domains, leaving the phenolic areas lightly stained.

Temperature affects a variety of processes related to analytical staining. A useful review of this topic is provided by Singer (1952). For instance, increasing temperatures can be expected to speed up the rates of diffusion of dyes into mesopores within the cell wall of a cellulosic fiber (Weber and Morris 1963). Changes in temperature also can change the relative solubility of a dye in water, which thereby can influence its tendency to come out of solution in the process of adsorbing onto a surface (Karst and Yang 2005).

\section{Surface area}

From a broad view, if the substrate is acting like a non-swelling solid, then the amount of dye taken up by a substrate hypothetically could be proportional to surface area. The best support for this view comes from studies of Simons' stain (Direct Orange 15) in systems where the degree of fibrillation of cellulose was systematically varied (Chandra $e t$ al. 2008). Though the cited article shows that the detailed mechanism is more complicated than previously had been supposed, a correlation between accessible surface area and color depth was confirmed. Whipple and Maltesh (2000) observed a very similar relationship when using fluorescently labeled polymers, the uptake of which on cellulosic materials appeared to be related to surface area; thus the fines and fibrils took up more colorant per unit mass than the larger fibers. Inglesby and Zeronian (2002) found a strong correlation between the specific surface area of cellulose and the uptake of Direct Blue 1. This concept will be pursued further when considering such processes as mechanical fibrillation of cellulosic materials.

\section{Displacement of smaller dye molecules}

Aside from the issue of whether a dye molecule has sufficient space to occupy a proposed site of adsorption, another consideration is whether or not the dye molecule is big enough to be able to resist being pushed away by other competing adsorbate molecules. Such mechanisms can be important in a variety of staining procedures in which a substrate is treated simultaneously or successively with different colorants. Examples of such effects have been reported in use of Simons' stain, which has been used to reveal differences in the degree of internal fibrillation of cellulose domains (Jayme and Harders-Steinhauser 1955; Akhtar et al. 1995; Yu and Atalla 1995, 1998; Chandra et al. 2008). Yu and Atalla 
(1998) used such an approach to examine the pore structure of microcrystalline cellulose; in the cited study Direct Orange 15 was able to displace Direct Blue 1 that had been added earlier. However the blue dye remained adsorbed in places that were too small for the larger Direct Orange 15 molecules to reach.

\section{WHAT STAIN SPECIFICITY REVEALS ABOUT CELLULOSIC MATTER}

If all the materials took up stains equally, acquiring the same depth of coloration, then it is unlikely that analytical staining of cellulosic materials would have generated so much interest and such a rich reservoir of publications. Research has shown, in general, that different fiber types, the chemical nature of different tissues, and different processing conditions can make large differences in the depth of staining, with some staining protocols leading to completely different colors of different regions and components within a specimen. Examples to support this statement are listed in Table 5.

For instance, Gray (1954, see pp. 391-393) lists about seven dye combinations that earlier researchers had used to produce sharp differences in coloration of lignified and other tissues in plant material. Two types of question will be addressed in this section. First, what types of colorants, usually under specified conditions, have been used as evidence of the presence or location of certain chemical species of microscopic domains or structures within the material. Then, after having answered the first question, the goal is to consider various explanations to account for any observed specificity of dye uptake. Different types of lignocellulosic materials will be considered in turn, and the literature will be examined in a search for what the results of staining protocols may be trying to tell us about the nature of each class of the cellulosic materials.

\section{Cellulose}

Because cellulose is the most prominent polymer within woody materials, it makes sense to start by considering what dyes are attracted to it. There are many references indicating a preferential adsorption of direct dyes onto cellulose, either in the pure form of cellulose or when it is believed to be exposed at surfaces accessible to the aqueous media (Peters and Vickerstaff 1948; Simons 1950; Kitamura and Kyoshi 1971; Choi and Oday 1984; Maekawa et al. 1989; Bairathi 1993; Gutmann 1995; Drnovsek and Perdih 2005a; Lewis 2009; Anderson et al. 2010; Chandra and Saddler 2012; Ursache et al. 2018). Factors affecting the adsorption of direct dyes onto cellulose-based materials have been reviewed (Safa and Bhatti 2010; Hubbe et al. 2012a).

Direct dyes, which are widely used in papermaking, can be described as relatively large (molecular mass often in the range $500 \mathrm{~g} / \mathrm{mole}$ or greater) and having a planar shape (Venkataraman 1952; Zollinger 1991). They have a net negative ionic charge, usually due to the presence of sulfonate groups. The larger size of the direct dyes, together with their greater tendency to adsorb onto cellulose, distinguishes them from acid dyes, which generally require a mordant such as aluminum sulfate to adsorb effectively onto cellulose (El-Molla et al. 2011; Hubbe et al. 2012a). High uptake on cellulose also has been reported for alcian blue and similar dyes (Benes 1968; Tolivia and Tolivia 1987; Srebotnik and Messner 1994); these dyes can be described as having a copper atom in the center of a symmetrical, four-part planar ring structure. 
Table 5. Findings of Studies Showing Dependencies of Staining Results on Fiber Type, Chemical Nature of the Specimen, and Processing Conditions

\begin{tabular}{|c|c|}
\hline Notable Findings of the Work & Reference \\
\hline $\begin{array}{l}\text { Fixing with a saturated solution of nigrosin in picric acid } \\
\text { gave better staining results. }\end{array}$ & Lee 1916 \\
\hline $\begin{array}{l}\text { Kraft and sulfite fibers were distinguished from each other } \\
\text { by staining. }\end{array}$ & Lofton and Merritt 1921 \\
\hline $\begin{array}{l}\text { Quicker staining methods were developed to distinguish } \\
\text { bleached vs. unbleached fibers. }\end{array}$ & Kantrowitz and Simmons 1934 \\
\hline $\begin{array}{l}\text { Graf's "Color Atlas" describes a wide range of stains and } \\
\text { shows examples. }\end{array}$ & Graff 1940 \\
\hline $\begin{array}{l}\text { The } p, p \text { '-azodimethylanaline dye reacted specifically with } \\
\text { lignosulfonate groups. }\end{array}$ & Green and Yorston 1952 \\
\hline $\begin{array}{l}\text { Describes the dependencies of acid, basic, and direct dyes } \\
\text { relative to substrate charge. }\end{array}$ & Kitamura and Kyoshi 1971 \\
\hline $\begin{array}{l}\text { Gives a detailed description of many staining methods } \\
\text { intended for fiber identification. }\end{array}$ & Hall 1976 \\
\hline $\begin{array}{l}\text { Describes oxidation of the 1-2-glycol group in } \\
\text { polysaccharides with periodic acid, followed by the Schiff } \\
\text { reaction. }\end{array}$ & Boon 1986 \\
\hline $\begin{array}{l}\text { A set of stains is used to differentiate different kinds of } \\
\text { wood-pulp fibers. }\end{array}$ & CPPA 1988 \\
\hline $\begin{array}{l}\text { A set of stains is used to differentiate different kinds of } \\
\text { wood-pulp fibers. }\end{array}$ & TAPPI 1988 \\
\hline $\begin{array}{l}\text { Phloroglucinol is employed in a standard test for the } \\
\text { presence of lignin. }\end{array}$ & AATCC Test Method 201990 \\
\hline $\begin{array}{l}\text { A dual stain with safranin and phthalocyanine tetracarboxylic } \\
\text { acid gave good contrast. }\end{array}$ & Achar et al. 1993 \\
\hline $\begin{array}{l}\text { Fuchsin basic and astra blue were used to stain specimens } \\
\text { in glycol methacrylate. }\end{array}$ & deBrito and Alquini 1996 \\
\hline $\begin{array}{l}\text { Safranin } O \text { and astra blue dissolved in ethyl alcohol were } \\
\text { used to differentiate lignified and unlignified tissues. }\end{array}$ & Vazquez-Cooz and Meyer 2002 \\
\hline $\begin{array}{l}\text { Staining protocols were recommended for determining } \\
\text { paper components and defects. }\end{array}$ & Woodward 2002 \\
\hline $\begin{array}{l}\text { Dyes were recommended to separately determine lignin, } \\
\text { hemicellulose, and cellulose. }\end{array}$ & Drnovsek and Perdih 2005a \\
\hline $\begin{array}{l}\text { The Graff "C" staining test was shown to be adequate to } \\
\text { distinguish different fiber types. }\end{array}$ & Adamopoulos and Oliver 2006 \\
\hline $\begin{array}{l}\text { Safranin fluorescent staining was used to indicate lignified } \\
\text { tissues. }\end{array}$ & Bond et al. 2008 \\
\hline Dyes for used in identification of textile fibers are described. & Lewis 2009 \\
\hline $\begin{array}{l}\text { Herzberg staining was used to determine fibers present in } \\
\text { ancient currency paper. }\end{array}$ & Shi and Li 2013 \\
\hline $\begin{array}{l}\text { Staining with safranin and alcian blue was used to reveal } \\
\text { lignin domains in maize stems. }\end{array}$ & Zhang et al. 2013 \\
\hline $\begin{array}{l}\text { Color vector analysis was used to achieve more objective } \\
\text { and accurate interpretation of staining protocols for fiber } \\
\text { identification. }\end{array}$ & Jablonsky et al. 2015 \\
\hline $\begin{array}{l}\text { Lignocellulosic components' fluorescence spectra were } \\
\text { differentiated using conjugated oligothiophenes. }\end{array}$ & Choong et al. 2016 \\
\hline $\begin{array}{l}\text { Ramie and cotton fibers were differentiated using an iodine } \\
\text { reaction. }\end{array}$ & Jia et al. 2016 \\
\hline $\begin{array}{l}\text { Fluorescent proteins and histological stains can be used to } \\
\text { stain diverse cell wall components. }\end{array}$ & Ursache et al. 2018 \\
\hline
\end{tabular}


The preferential adsorption of various direct dyes onto cellulose can be rationalized, first of all, by the generally uncharged nature of the cellulose polymer. Direct dyes typically have anionic sulfonate groups, and they would not be electrostatically repelled by the neutral cellulose domains. Some aspects of the cellulose phase within a typical fiber that might affect dye uptake include the generally uncharged nature of the cellulose macromolecule (Hubbe and Rojas 2008), the sizes of pores that are associated with cellulose domains, especially after lignin removal and application of mechanical energy (Stone and Scallan 1966), the directionality and orientation of cellulose in natural fibers (Kadla and Gilbert 2000), and a tendency for development of planar surfaces (Fernando and Daniel 2010, 2011).

\section{Pore size and shape}

The reason that the pore size and shape are highly relevant is that the external surfaces of cellulosic materials are often just a minor fraction of their internal surface area, depending on how each of these quantities is determined. When never-dried bleached kraft or sulfite fibers are refined and then subjected to specialized drying conditions to minimize loss of surface area, subsequent surface area analysis by nitrogen gas adsorption (BET tests) often shows surface areas of more than a hundred $\mathrm{m}^{2} / \mathrm{g}$ (Ingmanson and Andrews 1959; Herrington and Midmore 1984; Moser et al. 2016). By contrast, once the same fibers are dried, so that their mesopores have closed due to capillary action (Stone and Scallan 1966; Weise 1998; Weise and Paulapuro 1999), only the external surfaces are accessible, and the surface area is of the order of magnitude of $1 \mathrm{~m}^{2} / \mathrm{g}$. Pores within water-swollen kraft fibers have been estimated to be in the diameter range of about 2 to $100 \mathrm{~nm}$ (Stone and Scallan 1966, 1968; Li et al. 1993; Alince and van de Ven 1997; Berthold and Salmén 1997; Alince 2002; Park et al. 2006). This is approximately the range defined as mesopores and somewhat larger pores. Based on the structures of some of the most widely used direct dyes (Willis et al. 1945; Zollinger 1991; Inglesby and Zeronian 2002; Shi et al. 2007), their typical dimensions can be estimated as about $2 \mathrm{~nm}$ long by about $0.5 \mathrm{~nm}$ wide (or more) and about $0.2 \mathrm{~nm}$ thick. Thus it is reasonable to expect that typical direct dyes could occupy positions adsorbed at the surfaces of pores within delignified fiber walls.

Another distinguishing aspect of cellulosic structures within delignified fibers is alignment. It is well known that cellulose fibrils within plant material tend to be aligned with each other within layers of the cell wall (Kadla and Gilbert 2000). It follows that the spaces created within cell walls as a result of delignification also will tend to have a strong directionality. Iodine staining has been used to characterize such orientation (Donaldson and Frankland 2008). The cited authors reported that treatment with iodine followed by nitric acid caused the iodine to become deposited in the void spaces adjacent to fibrils in the S1 layer of their specimens, making the fibril orientation easy to see. Thomas et al. (2017), who used a direct dye having polarization-dependent fluorescence, observed an angular dependence of optical effects, which again is consistent with the alignment of cellulose microfibrils within the sublayers of cell walls. It was possible to determine microfibril orientation by this means. Verbelen and Kerstens (2000) took advantage of polarization-dependency of Congo red fluorescence to detect microfibril orientation using confocal laser scanning microscopy.

\section{Planarity}

Because direct dyes generally have a planar shape, one can consider a hypothesis that their preferential adsorption onto cellulose is related to a relatively flat nature of 
cellulosic surfaces. Also, one can consider concepts related to relatively flat spaces opened up within cellulose due to delamination, especially in the case of refined kraft fibers (Simons 1950; Blanchette et al. 1992; Akhtar et al. 1995; Yu et al. 1995; Chandra et al. 2008; Fernando and Daniel 2010, 2011). Such a hypothesis is supported, first of all, by reports of strong adsorption of direct dies onto kraft fibers, from which much of the lignin and some of the hemicellulose has been removed (Peters and Vickerstaff 1948; Beamesderfer et al. 1952; Johnson et al. 1974; Hall 1976; Inglesby and Zeronian 2002; Abbott et al. 2004a,b; Drnovsek and Perdih 2005a; Thomas et al. 2017). The chemical structures of Direct Orange 15 and Direct Yellow 11, which are often used in studies of refined kraft fibers, include linear oligomeric species, in which the molecular structure still has a flat, ribbon-like shape (Chandra et al. 2008; Kwok et al. 2017). Table A in the Appendix shows the reported chemical structures of Direct Orange 15 and Direct Yellow 11. As noted by Zollinger (1991), the affinity of direct dyes of cellulose surfaces can be increased by enlarging the planar, conjugated double-bonded system; this can be done by extending the molecule with additional azo groups.

Possibly contradictory evidence comes from studies in which strong uptake of direct dyes onto cellulose was observed in cases where other chemical components of woody materials were still present. For instance, Anderson et al. (2010) used direct dye to indicate the location of cellulose within growing roots. In such cases it is not clear that there would be water-filled spaces available for dyes to adsorb adjacent to the cellulose domains. According to Wood (1980) there is an affinity between direct dyes and a wider class of polysaccharides, not just cellulose. In particular, Congo red and Calcofuor were found to have affinity for polysaccharides containing contiguous $(1 \rightarrow 4)$ - $\beta$-linked glucopyranose units, including cereal glucans, xyloglucans, and substituted celluloses. Notably, all such compounds contain extended linear chains. So it is reasonable to hypothesize a mechanism involving linear association between relatively straight polysaccharide chains and the generally flat and planar dye structures. Such a mechanism would also be consistent with the findings that different crystal faces of cellulose have distinctly different hydrophilic or hydrophobic character (Yamane et al. 2006), thus providing aspects that could provide binding of compounds having a range of solubility properties, as long as they have a suitable shape. Wood (1980) concluded, based on various evidence, that conformation was the key factor leading to suitability of different polysaccharides for the direct dyes, with the most favorable association found for glucans (such as cellulose) having an "extended, ribbon-like conformation".

\section{Crystallinity and different cellulose crystal habits}

Another hypothesis to consider is that direct dyes, being planar, have some kind of specific requirement related to the crystalline nature of the cellulose surfaces to which they adsorb. Accordingly, Inglesby and Zeronian (1996) observed the effects of mercerization (swelling treatment with concentrated alkaline solution) on the uptake of Direct Blue 1. Mercerization is known to reduce the crystallinity of cellulose (Bredereck and Weckmann 1978; Inglesby and Zeronian 1996; Langan et al. 2001). The mercerization increased the swelling of cotton and also increased dye uptake. Contrary to the hypothesis just stated, the dye was found to become associated mainly with the non-crystalline regions. Hall (1976) reported deeper staining following both regeneration of cellulose or mercerization, which is again consistent with a greater proportion of non-crystalline cellulose.

By negative staining with an aqueous solution of uranyl acetate, followed by transmission electron microscopy (TEM), Heyn (1966) was able to observe thin sections 
of cotton and jute fibers cell walls at very high resolution, such that the original crystalline nature of the material could be discerned. Individual fibrils were clearly evident in the reported micrographs, and effects such as the swelling of the cellulose in alkaline media were clearly shown. The authors present sketches to account for their observations in terms of crystalline and amorphous domains within individual microfibrils of cellulose.

Because of the manner of its biosynthesis, all chains of natural cellulose in plants are aligned in the same direction, giving rise to cellulose I crystals (Brown 1996; Guerriero et al. 2010; Kim et al. 2013; Ahvenainen et al. 2016). By contrast, regenerated cellulose, which can be prepared by precipitating the polymer from various different solvent systems, always has an alternating pattern of chain direction (Hieta et al. 1984; Langan et al. 2001, 2005; Chen et al. 2006b; Jiang et al. 2012; Hubbe 2014). A staining method has been used to provide evidence of the unidirectional nature of cellulose I (Kuga et al. 1983; Hieta et al. 1984). The cited authors used a heavy metal stain, which attached only at the ends of microfibrils associated with the reducing ends of cellulose chains. Treatment with polyethyleneimine-phosphotungstic aid was found to provide the most distinctive transmission electron micrographs, clearly demonstrating the unidirectional nature of cellulose obtained from plants. In the staining protocol employed, the polyethyleneimine provides the positive charge and the phosphotungstic acid provides the electron density.

\section{Dispersion forces vs. hydrogen bonding as a main explanation for adsorption}

Ratee (1974) discusses various explanations to account for the observed affinity of direct dyes for cellulose surfaces. A hypothesis that such affinity can be explained by hydrogen bonds can be rejected for two main reasons. First, the structures of direct dyes that have been used to stain the cellulose domains in fiber specimens generally do not match the structure of cellulose in such a way as to allow a consistent pattern of hydrogen bonding between the two. Second, in an aqueous mixture, any formation of a hydrogen bond between a dye molecule and a cellulose surface will require the breakage of at least one hydrogen bond between a water molecule at that surface site. Since the water molecules are much more numerous, and there is no reason to expect hydrogen bonds associated with the dye to be stronger than the water-cellulose hydrogen bonds, there is no driving force for dye adsorption based on hydrogen bonds. By default, Ratee (1974) concluded that the relatively large size and planar character of direct dyes provides a sufficiently large van der Waals dispersion forces contribution to account for the adsorption from aqueous solution onto cellulose surface, even when the latter are hydrated with a layer of adsorbed water molecules.

Another possibility is raised by the more recent work of Yamane et al. (2006). These authors found evidence to support a hypothesis that the 110 crystal face of cellulose has a more hydrophobic character than the other crystal planes. It follows that, depending on which crystal face or faces are exposed within the interlamellar spaces resulting from pulping and bleaching of cellulose fibers, there may be favorable sites for adsorption of the relatively hydrophobic dye molecules.

\section{Hemicelluloses}

General considerations

Hemicelluloses differ from cellulose in several ways, so it is reasonable to expect different behavior in how they take up colorants (Mori and Ballani 1996). Compared to cellulose, hemicelluloses generally have lower molecular mass, irregular side-groups that inhibit the formation of crystalline zones, and the presence of groups that can provide 
negative ionic charge (Niemelä 1989; Buchert et al. 1995; Hubbe et al. 2012b). Though not all native hemicellulose contains significant amounts of carboxylic acid groups, the acetate ester groups common in hemicelluloses are relatively easy to hydrolyze, especially under strongly alkaline pulping conditions, giving rise to negatively charged carboxylate groups (Niemelä 1989).

It has been reported that hemicellulose readily takes up cationic phthalocyanine dyes (Drnovsek and Perdih (2005a). Williams (1983) used the affinity between hemicelluloses and either the Grams iodine medium, Congo red, and tryan blue to as means to study the degradation of hemicellulose. Though the work of Drnovsek and Perdih (2005a) helps to reinforce the concept that the negatively charged character of hemicellulose in typical cellulosic fibers plays an important role in its behavior, it is clear that more research is needed to having a specific focus on the staining characteristics of hemicelluloses.

Immunological labeling is another mechanism that has been used for staining of hemicellulose (Kikuchi et al. 1991; Hutterer et al. 2017). For instance, Hutterer et al. (2017) used the indirect staining of xylan structures by selective binding of monoclonal primary antibodies and a fluorescent dye carrying secondary antibodies. Blockage of nonspecific staining sites was achieved with bovine serum albumin.

In related work, Kohnke et al. (2010) used fluorescent-labeled glucuronoxylan (a hemicellulose) to study its adsorption onto fibril surfaces. Bouzon and Ouriques (2007) employed fluorescent labeling of lectins having a specific affinity for carbohydrates in mucilage. Szewczyk (1983) used the specific interaction between acidic polysaccharides and bovine serium albumin as a means of specific staining.

\section{Iodine-based staining assays and hemicellulose}

Though results from the many iodine-based staining assays (see Table B in the Appendix) provide evidence of the importance of redox reactions (see earlier discussion), it appears that their specificity also can be largely attributed to the differing nature of hemicelluloses present in different specimens. As already noted, the coloration of iodine complexes has been found to be strongly dependent on the chain length of the polysaccharides involved in the complexes (Swanson 1948; Jia et al. 2016). It is notable that iodine-type assays have been used to distinguish between softwood and hardwood fibers (Korn and Burgstaller 1953; Isenberg 1967). The corresponding test procedures, as shown in Table B, are the Klemm stain and the Mäule stain. The two classes of fibers have very different types of hemicellulose (Ebringerova et al. 2005). Although it is reasonable to expect that such differences would lead to different propensities and colors of iodine complex formation, there has been a lack of related research in the case of hemicelluloses. The fact that iodine complexes can allow visual differentiation between different types of cellulosic fibers suggests that at least some of the hemicellulose chains extend outwards, in helical fashion, from the wetted fibers, thus allowing them to form complexes with iodine oligomers.

\section{Amorphous and charged nature of hemicellulose}

Two hypotheses can be considered relative to the amorphous and charged nature of hemicellulose. First it can be proposed that dye uptake by hemicellulose ought to be related to its non-crystalline nature (Gatenholm 2003). This would be consistent with the alreadymentioned findings of Inglesby and Zeronian (1996) in the case of cellulose, in which the amorphous domains stained more deeply. Likewise, hemicellulose would be expected to 
accept colorants that depend on the ability of the material to swell in water to be able to accommodate them (Dutta and Chakraborty 2016). Though such a concept seems reasonable, not enough published literature dealing with hemicellulose was found in this study to be able to judge its validity.

A second hypothesis is that the negatively charged nature of hemicelluloses plays the dominant role in determining what dyes are taken up, thus allowing discrimination between different lignocellulosic components. Notably, an assumed approximately stoichiometric uptake of cationic dye onto the negatively charged groups of pulp fibers is the basis for a published method to determine the charge of single wood-pulp fibers (Mathews et al. 2004). In related work, Ghinea (1986) showed that a cationic heme dye could be used to detect glycosaminoglycans in cellulose acetate strips. Borzynski et al. (1972) reported a strong uptake of basic fuchsin dye onto polysaccharides that had been treated with the oxidant periodic acid. Though not specific to hemicellulose, these findings are consistent with the proposed mechanism. A few published works have shown evidence of affinity of cationic (basic) dyes for hemicellulose (Drnovsek and Perdih 2005a; Choong et al. 2016).

Much of the evidence pertaining to a possible role of hemicellulose in dye uptake refers to larger categories of material, such as non-lignin components, "holocellulose", or "polysaccharides". None of these terms exclude cellulose, except that it is well known that cellulose tends not to have a strong negative charge, even after pulping and bleaching (deBrito and Alquini 1996; Vazquez-Cooz and Meyer 2002; Bond et al. 2008; Zhang et al. 2013). Though some carboxylic acid groups can be expected at some ends of cellulose polymer chains after alkaline pulping, due to the peeling reaction (Green et al. 1977), such groups would not involve other positions on the cellulose chains.

Some studies have reported affinity of negatively charged dyes for polysaccharides, which may include hemicelluloses. According to Mitra and Loque (2014), Congo red and calcofluor white are specific to polysaccharides; notably, both of these compounds have pairs of sulfonate groups, providing a net negative charge over essentially the whole range of $\mathrm{pH}$. As already noted, Williams (1983) reported specificity of both Congo red and trypan blue for hemicellulose. Likewise, Achar et al. (1993) reported that metal phalocyanine dyes, when used in combination with the lignin-specific safranin dye, stained the non-lignin material. Since the metal phalocyanine dyes are anionic, those observations are not supportive of a charge-based attraction to hemicellulose, which is the most anionic major component of lignocellulosic matter.

The next section, dealing with lignin staining, will consider an alternative view in which safranin's propensity to be taken up by "lignin" is actually due to highly negative carbohydrate complexes covalently bound to lignin.

\section{Lignin}

Preferential adsorption onto lignin

There has been much interest in determining the location or the amount of lignin in cellulosic specimens by means of staining methods. For instance, the acid phloroglucinol reagent is specified in a standard method for identification of lignin (AATCC Test Method 20, 1990). Tests by Wick (1970) showed this dye, which has an aromatic ring with three symmetrically-placed phenolic groups, to be the most specific stain for lignin. Presumably the common phenolic nature of both phoroglucinol and lignin contributes to their mutual affinity. As discussed earlier in this article, there will be a general expectation of mutual solubility when a solid and a solvent have similar chemical structures (Hansen 2007). This 
concept is consistent with the strong uptake of phlorogulcinol (Wick 1970; AATCC Test Method 20, 1990), which, like lignin, is an aromatic compound having phenolic groups. A more quantitative analysis of this idea will require estimation of Hildebrand solubility coefficients; such estimates can be carried out without difficulty in cases where the chemical compositions are known (Hansen 2007).

Another standard test of lignin is the Graff " $\mathrm{C}$ " stain (Graff 1940). This stain consists of an aqueous mixture of $\mathrm{AlCl}_{3}, \mathrm{CaCl}_{2}, \mathrm{ZnCl}_{2}, \mathrm{KI}$, and iodine (Adamopoulos and Oliver 2006). As mentioned earlier in this article, it is also reasonable to expect that the resulting color will depend on the extent of an oxidation reaction between the iodine present and susceptible groups, such as aldehydes within the cellulosic material (Boon 1986; Knebel and Schnepf 1991).

Many studies have used cationic (basic) dyes as indicators for the presence of and location of lignin. The dye mostly widely used as a stain for lignin is safranin, a basic dye (Cartwright 1929; Tolivia and Tolivia 1987; Achar et al. 1993; Srebotnik and Messner 1994; Gutmann 1995; Vazquez-Cooz and Meyer 2002; Drnovsek and Perdih 2005a; Bond et al. 2008; Zhang et al. 2013). Gutmann (1995) and Park et al. (2003) used toluidine blue$\mathrm{O}$, another basic dye with affinity for lignin. Mitra and Loque (2014) used toluidine blue$\mathrm{O}$ to differentiate between polysaccharides and lignin. Acridine orange, a basic dye with fluorescent emission, has been used as an indicator for lignin (Liu et al. 1999; Li and Reeve 2004). Also, fuchsin basic dye has been used as an indicator of lignin (deBrito and Alquini 1996). Kitamura and Kyoshi (1971) stated that basic dyes in general have affinity for "components other than cellulose". Ursache et al. (2018), who were working with a new system to reduce the effects of chlorophyll autofluorescence, demonstrated the following cationic dyes to be effective stains for lignin under the new conditions: basic fuchsin and auramine O. Donaldson et al. (2014) used fluorescent-labeled polyethylene glycol to provide contrast in lignified areas of thermomechanically modified pine wood.

\section{Hemicellulose chains co-located with lignin}

A puzzling aspect of the effects just described is the fact that the best-known molecular models of lignin structure show few if any groups that would take on a negative charge at pH values below about 9 (Pearl 1967; Sakakibara 1980; Glasser and Sarkanen 1989). This is in contrast to the situation with hemicellulose, as discussed in the previous subsection. A possible way to resolve this dilemma is to envision that what really is being observed is a tendency of cationic dyes to associate with lignin-polysaccharide complexes (Lawoko et al. 2005; Lawoko 2013). Remnants of such complexes can remain even after alkaline pulping (Lawoko et al. 2004). More study would be needed in order to show whether such complexes have sufficient negatively charged character to account for the strong adsorption of cationic dyes onto parts of plant-based structures identified as lignin.

The fact that cationic dyes have been widely used as indicators for the presence of lignin is difficult to explain based on solubility considerations. It is well known that strongly polar groups can play a major role with respect to solubility behavior (Hansen 2007). But the cationic charges associated with basic dyes such as safranin would be expected to promote mutual solubility with lignin only if there were a charge-charge attraction. Native lignin, as well as the lignin remaining after kraft pulping, does not contain many acidic groups other than phenolic groups, and phenolic groups are uncharged at near-neutral $\mathrm{pH}$ values. Thus, attaching of cationic dyes to lignin makes sense only if one is regarding anionic groups, such as lignin-carbohydrate complexes, as being part of the lignin to be stained. Other negative ionic groups that can be closely associated with 
certain types of lignin; for instance sulfite pulping results in sulfonate groups on the lignin (El Mansouri and Salvado 2007). Though such considerations are consistent with solubility principles, the lignin structures represents a more complicated analytical problem compared to other systems that have been most often evaluated using solubility principles (Schuerch 1952; Hildebrand et al. 1970; Hansen 2007).

\section{Factors affecting lignin's dye-affinity}

There is also evidence of substantial affinity of lignin towards certain negatively charged dyes. A negatively charged dye associated with lignin staining is lignin pink, the ionic charge of which is dominated by sulfonic acid groups (Robards and Purvis 1964; Chen et al. 2006a). In an effort to show the high specificity of direct dyes for cellulose, Chandra and Saddler (2012) showed that the $>100 \mathrm{kDa}$ fraction of Direct Orange $15 \mathrm{had}$ a negligible amount of adsorption when incubated with kraft lignin. Since direct dyes, which have structures not much different from lignin pink, generally have little affinity for lignin, there appears to be a need for further investigation.

Certain of the most-trusted staining methods to determine the presence of lignin rely upon lignin's ability to be oxidized, with the formation of aldehyde groups (Wu et al. 1994; Sales et al. 2006). Schiff's reagent can be regarded as a system to reveal the presence of aldehyde groups (Boon 1986). Kengel and Schnepf (1991) differentiated between asreceived wood material and the same material after it had been oxidized with periodic acid. The as-received specimens were stained by Schiff's reagent only in the lignified areas, whereas all components of the specimens became stainable after oxidation.

As an alternative to adding a dye, some studies have instead relied on lignin's autofluorescence as a way of revealing its location within woody tissues (Olmstead and Gray 1997; Nowak et al. 2004; Donaldson and Vaidya 2017). An inherent advantage of using such approaches, when successful, is that it may be possible to avoid unintended consequences of staining procedures. On the other hand, the signals due to lignin's autofluorescence are usually weak in comparison to typical stains and fluorescent labeling strategies.

Another approach taking advantage of lignin's ability to be oxidized consists of treatment with the strong oxidizing agent $\mathrm{KMnO}_{4}$ (Maurer and Fengel 1990). Due to the relatively high atomic mass of manganese (55 g/mole), the cited authors used such treatment to increase the electron-density adjacent to lignin in plant cell walls. This, in turn, enhanced images obtained using transmission electron microscopy.

One of the most innovative strategies reported for the localization of lignin involved the incorporation of a click-modified monolignol during the biosynthesis and early growth of Arabidopsis thaliana stems (Pandey et al. 2015, 2016). Such treatment allowed the subsequent use of click chemistry to specifically derivatize the lignified areas with a fluorescent tag. Confocal laser scanning microscopy was then used to show the spatial positioning of the fluorescence.

\section{Solubility characteristics of dyes in lignin domains}

Various hypotheses can be advanced in an effort to explain the affinity of certain dyes for lignin. One such approach is to assume that the affinity is dominated by issues affecting mutual solubility (Schuerch 1952; Hansen 2007). This view is consistent with the high aromatic group content of lignin, giving it different solubility characteristics compared to other components of wood, as well as the non-crystalline nature of lignin (Glasser and Sarkanen 1989). Presumably a non-crystalline nature would allow lignin 
domains to swell and accommodate a molecule having a suitable match of solubility properties. The solubility of lignin breakdown products in various solvents is evident from the results of organosolv pulping (Aziz and Sarkanen 1989; McDonough 1993).

\section{Pectin}

Pectins are anionic polysaccharides that are predominantly deposited in the primary cell wall, middle lamellae, and the tori of bordered pits of higher plants (Bauch et al. 1968). Pectin provides rigidity to the cell walls and adheres the adjacent cells to each other (Hornatowska 2005; Kameshwar and Qin 2018). D-galactopyranosyluronic acids (Galacturonans) are the basic component of pectin. Galacturonan may be partially methyl esterified, non-esterified, or both in cell walls (Hornatowska 2005; Dixon 2008). The middle lamella between lignified wood cells contains both methyl esterified and unesterified pectin (acidic pectin), but methyl esterified pectin is dominant (Hornatowska 2005). Pectins can be visualized by staining with ruthenium red and hydroxylamine-ferric chloride dyes (Ruzin 1999; Chaffey 2002); these are used to detect the location of unesterified and methyl esterified pectins, respectively (Hornatowska 2005). Red or pink color reaction indicates the presence of unesterified pectins in case of staining with ruthenium red. The dye of hydroxylamine-ferric chloride produces a distinct red color in the presence of esterified pectins. The intensity of the color reaction is proportional to the degree of esterification in pectin. Since the some cellulose and lignin might stain red, a nonspecific staining is obtained with ruthenium red (Ruzin 1999; Hornatowska 2005). Therefore, hydroxylamine-ferric chloride is regarded as superior to ruthenium red.

\section{Extractives}

Though the extractives component of woody materials often amounts to only a few percentage points by mass (Sjöström 1993; Back and Allen 2000), sometimes there is an interest in revealing its presence by use of staining methods. In general, oleophilic dyes have been used for such purposes (Boon 1986; Brundrett et al. 1991; Mori and Bellani 1996; Fernando et al. 2005; Ursache et al. 2018). Some oleophilic dyes mentioned in the just-cited work include Sudan III, Sudan black, Sudan red 7B, Nile red, and Fluorol yellow 088. The listed dyes mainly are comprised by nonpolar aromatic structures having few if any polar groups.

More specific identification can be made in the case of certain extractives having unsaturated alkyl chains. Examples include oleic, linoleic, and linolenic acids. These can be stained by osmium tetroxide or ruthenium tetroxide (Bahr 1954). The staining effect appears to be a consequence of the reduction of the metals by the $\mathrm{C}=\mathrm{C}$ double bonds. Hagege et al. (1969) extended this type of approach by using unsaturated polymers as a probe for cellulosic materials. Striking cross-sectional images were obtained in which dark stained bands of poly-isoprene were interposed between cellulosic domains.

\section{Callose}

Callose can be defined as a $\beta-1,3$ glucan (Pearce 1986). It appears to regulate the permeability of cells (Currier 1957), and thus it is likely to be present in specimens of living plant tissue. In addition to its natural occurrence, it also can be generated in response to wounding (Pearce 1986; Luna et al. 2011). Brundrett et al. (1988) described a staining system for callose in which berberine was used as the main staining agent. Berberine is a multi-ring dye that has just a single quaternary ammonium cationic site. Aniline blue was used as a counter-stain to quench unwanted background fluorescence. Pearce (1986) 
showed a specific staining of callose by chloratine fast green-BLL. Other callose-specific stains include coralline (rosolic acid), benzoasurine, ponceau $\mathrm{S}$, and aniline blue (fluorochrome) (Ulrychova et al. 1976; Pearce 1986). Alternatively, Eschrich and Currier (1964) showed that callose could be revealed by its diachrome and fluorochrome uptake. In the case of phloem, Cheadle et al. (1953) observed callose to take on a blue or greenishblue color, consistent with the uptake of lacmoid (resorcin blue).

\section{Suberin}

Suberin is a relatively hydrophobic plant material that is best known as a major component of cork (Pereira 2015; Leite and Pereira 2017). It can be described as a rubbery complex polyester having fatty acid chains as a major component (Vishwanath et al. 2015). Oleophilic dyes have been found to stain suberin effectively (Brundrett et al. 1988; Vaughn and Lulai 1991; Ursache et al. 2018). For example, suberin was made clearly apparent by staining with the oleophilic berberine dye, followed by counterstaining with crystal violet to quench lignin's fluorescence (Vaughn and Lulai 1991).

\section{Protein}

In mature wood it may be difficult to find vestiges of the proteinaceous cellular organelles that were essential during biosynthesis and growth. In examination of growing tips and roots, it may be of interest to reveal the presence and location of proteins. General methods of protein staining have been widely described (Heathcote et al. 1970; Boon 1986; Allen 1999). Such studies have been reported for plant materials (Yasuma and Itchikawa 1953; Woodward 2002; Fester et al. 2008). Because proteins contain positively charged groups associated with certain amino acids, acid dyes (having a negative charge in solution) have been used for selective staining (Hall 1976; Boon 1986; Lewis 2009). Many of the investigations have been realized on flowering plants, vegetables, and fruits while a few numbers of studies have been done on wood material (Hornatowska 2005). The cited author reported that the amido black, mercuric bromophenol blue, and aniline blue-black were tested on microscopic wood sections for protein localization. The proteins in the cell walls became positively charged by acetic acid and reacted with amido black and stained in blue color. However, the results of the staining in mercuric bromophenol blue and in aniline blue-black were found either doubtful or too weak for light microscope observation. Hamburger et al. (2002) reported an enzymatic staining procedure to reveal a gene in wood development. Abe et al. (1995) used immunofluorescent staining to reveal microtubules during differentiation of conifer tracheids. Certain non-cellulosic fibers, such as wool and silk, give strong positive staining evidence as proteins, thus providing a way to clearly show that these are not from plant materials (Hall 1976).

Colloidal gold was used as a stain to increase the contrast after gel electrophoresis in cellulose-acetate membranes (Righetti et al. 1986). The depth of coloration indicating the location of protein bands in such specimens was enhanced to a much greater degree than other staining methods considered up to that point.

In addition to the stains to identify the location of protein, Neumann et al. (2010) used a fluorescent version of ovalbumin to study the ability of proteins in general to be transported within woody tissue. There was a progressive decrease in permeability in the course of continued flow, which appeared to be related to buildup of the protein at pit junctions. Adsorption of protein, followed by its staining, also has been used as a means of detecting acidic polysaccharides (Szewczyk 1983). 


\section{Fungal Matter}

Sometimes a specimen of lignocellulosic nature may be in the presence of fungal material. Early work in that regard was reported by Cartwright (1929). A combination of safranin (basic dye having affinity for lignin) and picro-analine blue (a direct dye) was found to be effective to make the rhysomal structure of the fungi more visible under the microscope. It was also suggested for highlighting the presence of bacterial attack (Jensen 1962). The wood cell walls appear pink, and hyphae or bacterial attack appear blue with this method. Although safranin is particularly used in conjunction with a counterstain such as fast green (Johansen 1940; Gram and Jǿrgensen 1951; Sass 1958; Berlyn and Miksche 1976; O'Brien and McCully 1981; De Micco and Aronne 2007) or astra blue (Srebotnik and Messner 1994; Vazquez-Coos and Meyer 2002; De Micco and Aronne 2007) to detect the lignified and unlignified tissues, those procedures can help also to understand chemical composition of the decayed wood. According to Jensen (1962), Azure B exhibits bluegreen staining in advanced stages of wood decaying. Houtman et al. (2016) reported that staining with Acridine orange can detect wood oxidation occurred by the colonization of brown and white rot fungi under fluorescent microscope. When lignin is mildly oxidized, the association between acridine orange and lignin is reduced greatly but the dimer association is left largely unchanged. Thus, the color of the microscopic wood sections under fluorescent microscope changes from green to yellow to red as oxidation progresses. More recently, Xiao et al. (1999) used immunofluorescent labeling to reveal fungal colonies in decaying wood.

\section{Phloem (bark)}

The phloem or bark of trees also has received some attention with respect to staining (Harrar 1928; Cheadle et al. 1953; Schneider 1960). Many of the components of bark are similar to those of wood, except that the structure tends to be looser and other components such as suberin may be present. Schneider (1960) found a good differentiation between lignin and the cellulose of living or nonliving cells by treating first with hematoxylin (a poly-phenolic compound) and lacmoid (a poly-phenolic compound with an amine group, also known as resorcin blue), and then fixing with ferric ammonium sulfate. The hematoxylin is known to undergo oxidation. Cheadle et al. (1953) achieved differential staining of the cellulosic wall material (blue or blue-green) versus the protoplasmic contents of phloem (light brown) with a mixture of tannic acid and ferric chloride, followed by $\mathrm{NaHCO}_{3}$ in a water-alcohol solution, staining with lachmoid, and then dehydration and mounting.

\section{Flavonols}

Flavonols are a natural component of certain lignocellulosic tissue that are comprised of three rings, two of which are aromatic, and which can be substituted with different amounts and positions with phenolic -OH groups. Feucht et al. (2012) noted that flavinoids associate strongly with $p$-dimethylaminocinnamaldehyde reagent. Presumably the reaction could also take place with lignin, depending on the degree to which phenolic groups of lignin are accessible to such a reaction.

\section{Starch}

Starch is often present within plant material as a stored food source. It is well known that linear starch (amylose) in aqueous solution interacts strongly with iodine, creating a dark purple or black complex. Such evidence has been used to indicate the 
presence of starch in specimens of lignocellulosic origin (Gutmann 1995; Woodward 2002).

\section{Fiber Type for Identification}

Much of the same information, as already discussed in previous subsections, also can be used as the means of differentiating between different types of fibers (Graff 1940; Proksch and Keser 1970; Hall 1976; Parham and Gray 1982; TAPPI 1988; Mlynar 1999; Lai 2002; Woodward 2002; Adamopoulos and Oliver 2006; Jablonsky et al. 2015). Some of these publications place an emphasis on identification of textile fibers (AATCC Test Method 20, 1990; Lai 2002; Anheuser and Roumeliotou 2003). Some issues related to fiber identification, such as the use of acid dyes to reveal wool and silk, which are composed of protein, already have been noted (Hall 1976). Some standard tests for fiber identification are briefly described in Table B in the appendix. Notably, however, many of these tests are expected to reveal effects due to fiber processing, which is the subject of the next main section of this article.

\section{Staining for Wood Anatomy}

The specialized area of "wood anatomy" focuses on macroscopic and microscopic investigations of the structure of wood and wood-based materials. Macroscopic investigations are performed with the naked eye and hand lens, while different microscopic techniques are available for microscopic investigations. The fundamental differences between wood species are based on the types, sizes, proportions, and arrangements of different cells that compose the wood. Therefore, scientifically reliable and accurate studies on wood anatomy require microscopic techniques. Light (optical) microscopy is the most frequent method to study wood materials (Daniel 2016). The accuracy and speed of microscopic analysis are closely linked to the quality of microscopic sections to obtain high-resolution images (von Arx et al. 2016). The quality of microscopic sections are influenced by a range of variables including the specimen itself, specimen preparation, softening technique, the sharpness of microtome blade, cutting angle, and the treatment procedure of the sections. The treatment procedure can include bleaching (if needed), staining, dehydrating, and clearing of the microscopic sections before mounting on slides (Jansen et al. 1998; Gärtner and Schweingruber 2013; Tardif and Conciatori 2015).

The purpose of the staining process is to provide strong contrast among the various cell types and/or cell components and thus to identify wood species, emphasize microstructure, visualize cell contents and, reveal the presence of microbial attack, etc. There are a great number of stains and staining recipes using for these purposes (Gärtner and Schweingruber 2013; Tardif and Conciatori 2015; Daniel 2016). Anatomical staining and histochemical staining are different from each other. The anatomical staining performed primarily for the purpose of wood identification and the determination of morphological properties might also provide substantial and easily accessible information on cell wall composition, and tissue development and differentiation (Soukup 2014; Tardif and Conciatori 2015). However, the affinity to a target structure is much more important for the histochemical staining, and the success of staining depends highly on some specific conditions such as $\mathrm{pH}$, polarity of solvent, temperature, staining time, etc. (Soukup 2014; Ruzin 1999).

The most commonly used stains by wood anatomists are Safranin O, astra blue, aniline blue, Fast Green FCF, lactophenol blue, toluidine blue, cresyl violet acetate, and their combinations (Gärtner and Schweingruber 2013; Tardif and Conciatori 2015; von Arx 
et al.2016; Daniel 2016), and some of the factors are effective in the success of anatomical staining. The optimal thickness of microscopic wood sections is usually between 10 and $20 \mu \mathrm{m}$ to obtain a sufficient contrast with staining. Analyzing thick sections may cause over- and underestimation of anatomical features such as cell wall thickness and cell lumen area. However, too thin sections can result in excessively weak staining and insufficient contrast in wood microstructure. In the case of poor staining, extending the duration of the staining process can improve the staining contrast to a certain extent. In a wood research project, microscopic sections having consistent thickness are needed to supply a homogenous staining and the accurate analyses of cell sizes (von Arx et al. 2016). Staining intensity can also exhibit differences in sections obtained from different wood species and from different parts of individuals such as sapwood and heartwood, juvenile and mature wood, early- and latewood zones of the growth rings, and reaction wood. These variations are probably related to different proportions of cell wall contents in the different parts of wood (Kutscha and Gray 1972; von Arx et al. 2016).

The brownish color in unstained microscopic sections indicates that the wood specimens contain phenolic substances. Therefore, bleaching treatment may be required before the staining process for removing phenolic substances, gums, and resins, which may prevent to clear observation under the microscope (Jansen et al. 1998; Tardif and Conciatori 2015; Gärtner and Schweingruber 2013). Since this treatment enhances the brightness and contrast (Jansen et al. 1998; Gärtner and Schweingruber 2013; Tardif and Conciatori 2015), bleaching is also preferred for sections with the thickness of 25 to $30 \mu \mathrm{m}$ (Jansen et al. 1998).

The staining process is completed with dehydration, cleaning, and mounting procedures, respectively. To obtain a good color distribution, water should be removed completely from the microscopic sections. When treating with clearing agent, if the solution appears milky, it means that the sections are not completely dehydrated and the dehydration process should be repeated in absolute ethanol (Jansen et al. 1998; Gärtner and Schweingruber 2013; Tardif and Conciatori 2015).

\section{WHAT STAIN SPECIFICITY CAN REVEAL ABOUT PROCESSING}

This section will consider references describing ways in which the industrial modification of cellulosic material affects results of staining tests. The topic will be divided into two parts - chemical processing and mechanical processing.

\section{Chemical Processing}

Chemical processing can include pulping (separation of cellulosic fibers from each other, usually with partial or full removal of the lignin), bleaching (which often entails further removal of lignin and/or changes to its chromophoric nature), and other chemical treatments such as mercerization (exposure to strong alkaline conditions), enzyme treatments, regeneration from cellulose-solvent systems, and plasma treatments. A common feature is that the chemical composition of the material is altered in each such process. 


\section{Pulping}

The effects of chemical pulping operations on staining have been considered in earlier documents (Graff 1940; CPPA 1988; Woodward 2002). Kraft pulping can be briefly described as a lignin-removal method based on cooking wood chips in a highly alkaline solution that contains sodium sulfide. Standard staining methods enable an analyst to discriminate between kraft pulp fibers and those prepared by other means, such as mechanical pulping, semichemical pulping, or sulfite pulping (Lofton and Merritt 1921; CPPA 1988). As noted by Woodward (2002), the results can be expected to depend on the extent of lignification, with a gradual reduction of yellow coloration after treatment with Graff " $\mathrm{C}$ " stain, consistent with less and less lignin remaining. When following the standard procedures of Graff (1940), one can compare stained samples with standard images, showing the expected colors for fibers that have been modified in specified ways. Sulfite pulps can be identified in mixed pulp suspensions by staining with $p, p$ 'azodimethylaniline (Green and Yorston 1952).

\section{Bleaching}

Bleaching processes can be regarded as an extension of chemical pulping, generally continuing the purification of the cellulose fibers by removal of much of the remaining lignin, as well as some of the hemicellulose. Early work by Kantrowitz and Simmons (1934) showed that such differentiation could be achieved by staining with a combination of ferric chloride and potassium ferricyanide in solution, i.e. the so-called Bright stain. The ferricyanide ion is sensitive to the presence of oxidizable materials. Unbleached fibers stain green in such a solution, whereas fully bleached fibers remain colorless. In a second step the fibers are treated with benzopurpurine 4B concentrate, which causes the unbleached fibers to become green or blue, and the bleached fibers to turn red. Because fully bleached fibers generally do not contain significant amounts of oxidizable matter, Graff (1940) recommends usage of analine dyes to reveal the degree of pulping, bleaching, and in general purification of chemical pulps. The recommended recipes, as given in Table B of this report, correspond to the modified Bright stain, the cooking or bleachability stain, and the pulp purity stain.

Permanganate, a strong oxidizing agent, is used in the well-known Kappa test to determine the proportion of lignin remaining in pulp fibers after different conditions of chemical pulping and bleaching (Li and Gellerstedt 1998). According to the cited article, the groups within lignin that are susceptible to such oxidation include all the aromatic double bonds, aliphatic double bonds, aldehyde groups, and alpha-keto carboxylic acids. Taking advantage of such interactions, Stein et al. (1992) used $\mathrm{KMnO}_{4}$ as a stain to determine the location of lignin within transmission electron micrographs (TEM). Though such an approach appears reasonable, it is worth noting that chemical pulps also are known to contain other species, such as certain carbohydrate structures, that are also oxidizable by $\mathrm{KMnO}_{4}$ (Sevastyanova et al. 2006).

The Herzberg reagent can be described as an iodine-iodide mixture in solution with zinc chloride (Shi and Li 2013). According to the cited authors, the resulting color makes it possible to distinguish between fiber specimens with different contents of lignin. Ligninfree fibers give a red wine color. With increasing lignin, the color goes through different shades of grey-blue, to grey-yellow, to yellow, consistent with the gradual reduction of the iodine. In addition to reactions with lignin, one also can expect iodine to react with the reducing-end groups of cellulose and hemicellulose; it has been shown that reaction with 
iodine can be used as an initial oxidation step to quantify reducing ends in polysaccharides (Hashimoto et al. 1991).

Some of the most important bleaching treatments involve oxidation, such as with chlorine dioxide, oxygen, ozone, or hydrogen peroxide (Sjöström 1993; Dence and Reeve 1996; Suess 2010). In cases where oxidation proceeds only as far as the production aldehyde groups, and not converting all of them to carboxylic acids, such a condition can be revealed by the Schiff reagent (Boon 1986). Gutmann (1995) observed a strengthening of staining with cationic dyes upon oxidation with $\mathrm{NaOCl}$; this observation is consistent with charge attraction between the dye and the increasingly anionic cellulosic material. Thus, the depth of Schiff staining would be expected to increase with increasing amounts of oxidizable components such as lignin.

\section{Enzyme treatment of fiber}

Enzymes provide options for fiber modification, and some such modifications have been shown to affect staining results. Bond et al. (2008) noted contrasting effects upon treatment of wood with either brown-rot fungus (which mainly degrades cellulose) or white-rot fungus (which mainly degrades lignin). The results were in parallel to the expected affinities of dyes for cellulose and lignin, as discussed earlier in this article.

Blanchette et al. (1992) noted that treatment of wood chips with white-rot fungus caused a major change in the staining behavior of pulp, giving results that were equivalent to those of fibrillation brought about by refining.

\section{Mercerization}

Mercerization can be defined as a treatment of cellulosic material in very strong alkali solution (generally 20 to $30 \% \mathrm{NaOH}$ ), such that the crystal habit is substantially changed from cellulose I to cellulose II (Marsh 1942; Langan et al. 2001; Dinand et al. 2002). Because such treatment generally decreases the degree of crystallinity of cellulose, it can be expected that dyes can more easily diffuse into the material. Increased rates of dye uptake have been reported relative to un-mercerized cotton (Bredereck and Weckmann 1978; Chrastil et al. 1990; Fu et al. 2013). Such effects relative to textile manufacture from cotton have been reviewed (Patel and Varghese 1983). Inglesby and Zeronian (1996) confirmed this expectation in tests of with Direct Blue 1 before and after mercerization. It was noted that dye uptake was mainly in non-crystalline regions. Drying of the mercerized cellulose under tension tended to decrease subsequent dye uptake. As a further way to increase uptake of anionic dyes, it was shown that cellulose can be derivatized by attachment of quaternary ammonium groups during mercerization (Tarbuk et al. 2014).

\section{Regeneration}

Regeneration can be defined as a process in which the cellulose is first completely solubilized or made into a soluble chemical derivative that can be subsequently converted back into cellulose (Woodings 2001). When solution characteristics are changed in such a way as to kick the material out of solution, regenerating the cellulose, the chains in the regenerated cellulose are anti-parallel, meaning that half of them are in each direction in a regularly alternating pattern (Hindeleh and Johnson 1974; Langan et al. 2005; Chen et al. 2006b; Jiang et al. 2012). However the degree of crystallinity is typically lower than that within the starting cellulose I. Kim et al. (2004) used staining as a means to study the porosity of regenerated cellulose fibers. Landells and Whewell (1955) used iodine staining to study rayon that had been prepared together with vinyl polymers. The iodine was used 
to reveal the presence and location of condensation resins. Azoic dyes and direct dyes have been reported to have good affinity for viscose cellulose (regenerated from cellulose xanthate) (Lewis 2009).

\section{Mechanical Processing}

Though mechanical processing does not significantly change the chemical composition of cellulosic material, it can change the degree of swelling and the structure or porosity on a microscopic size scale, thus affecting stain uptake. Categories of mechanical processing to be considered in this subsection include generalized "damage", effects of refining (subjection of wet fibers to shear and compression in a tight gap between a rotor and stator), steaming, drying (hornification), and general contamination.

\section{Damage}

Mechanical stresses and strains have the potential to disrupt cellulose structure at the nano scale, possibly creating spaces that can be occupied by colorants. At a macro scale it is well known that cracks and other such defects in wood will affect the uniformity of stains applied to affect the appearance (Budakci and Cinar 2004). In general, the cracked places take up more wood stain. Wear in cotton fabric also has been studied by means of staining (Loeb et al. 1964). Increased coloration was correlated to increased damage. The staining system used in the cited work was Simons' stain, which is the next topic to be considered.

\section{Refining}

Uptake of certain compounds related to Direct Orange 15 have been found to correlate strongly to the degree of mechanical refining of pulp fibers (Simons 1950; Blanchette et al. 1992; Akhtar et al. 1995; Yu et al. 1995; Chandra et al. 2008; Fernando and Daniel 2010, 2011). As already noted, similar effects can be brought about by certain fungal treatments, which appear to internally fibrillate the material (Blanchette et al. 1992). According to $\mathrm{Yu}$ et al. (1995) the mechanism of action appears to involve the delamination of fiber cell walls to the extent that dye molecules are able to diffuse and occupy adsorption sites within the fiber walls. Higher molecular mass (oligomeric) Direct Orange 15 dye molecules displace lower-mass molecules of Direct Blue 1, thus providing a strong visual contrast.

Chandra et al. (2008) introduced a modification of the Simons' stain test in which the Direct Orange 15 dye was first fractionated to remove the lower-mass molecules. It was shown that the higher-mass molecules of direct dye, consisting of longer linear chain oligomers, were responsible for the staining effect in response to fibrillation. More recently, Kwok et al. (2017) found that Direct Yellow 11 can be used in the Simons' stain method as a substitute for Direct Orange 15. As shown in Table A (see Appendix), both Direct Orange 15 and Direct Yellow 11 dyes typically contain an oligomeric fraction.

A closely related topic to refining is accessibility of lignocellulosic materials to relatively large molecules, such as enzymes (Drnovsek and Perdih 2005b). The Simons' staining method, as just described, was found to be useful as a way to predict enzyme accessibility, for purposes of saccharification (Chandra and Saddler 2012). Simons' stain results earlier had been shown to correlate strongly with rates of enzyme digestion of cellulose following different levels of peroxide pretreatment of Douglas fir wood (Estaghlalian et al. 2001; Arantes and Saddler 2011). Related work, using Simons' stain, 
has shown the beneficial effect of acid pretreatment on the accessibility of poplar wood (Meng et al. 2013).

Uptake of dye molecules has been used as a criterion of accessibility, as in the already-cited work of Inglesby and Zeronian (1996, 2002). Dye molecules of different size have been used to judge the sizes of pores (Drnovsek and Perdih 2005b). Likewise, Donaldson et al. (2014) labeled polyethylene glycol chains with a fluorescent tag as a way to probe the accessibility of steam-exploded pine specimens to relatively large molecules, representing enzymes. Later, Donaldson and Vaidya (2017) used fluorescent-tagged cellulase enzymes as a more direct way to quantify similar effects of the steam explosion of pine wood. Enzymatically degraded lignocellulose, after anaerobic digestion, was stained by adsorption of fluorescent-labeled bovine serum albumin, making it possible then to clearly show the pore structure by means of confocal laser scanning microscopy (He et al. 2013). Luterbacher et al. (2013) used fluorescently labeled cellulase to track cellulase binding onto bacterial microcrystalline cellulose. Related work by Luterbacher et al. (2015a) showed that cellulase action could be characterized generally as a widening of long slit pores in the biomass. In follow-up work, the adsorption of cellulase was observed to take place in areas where lignin had been removed during a previous pretreatment step (Luterbacher et al. 2015b). Related work was done by Neumann et al. (2010), using fluorescent-tagged bovine serum albumin, together with evaluation of flow rates through the biomass specimens. Confocal laser scanning microscopy revealed the accumulation of the protein at pit junctions, and this was consistent with observations of reduced flow. In the absence of the albumin, no decrease in permeability with time was observed. These results are consistent with a tendency of large molecules or particles to plug channels in porous material (Hubbe et al. 2009).

Another useful strategy can be to study the kinetics of uptake of dyes, since the rate at which molecules can enter cellulosic material is sometimes a determining factor relative to the feasibility of subsequent processes. Khatri et al. (2014) judged the rate of uptake of a reactive dye by monitoring the absorbance and applying a Kubelka-Munk analysis of the light absorbance. Paes et al. (2017) studied the dynamics of uptake of fluorescent-tagged dextran molecules to study the rates of access to pretreated poplar wood material.

At a larger scale, Kitin et al. (2010) stained poplar wood specimens with acid fuchsin dye as a means of studying the conducting pathways such as lumens and pits. Cryofluorescence microscopy was used to reveal the location of the dye. Collapsed cells in genomically modified wood were shown to be responsible for impaired transport of fluids within the wood material.

\section{Hornification}

It is well known that the drying of kraft pulps leads to a partly irreversible closure of pores in the fiber cell walls (Stone and Scallan 1966; Yamagishi and Oye 1981; Weise and Paulapuro 1999). In other words, immersion of the dried fibers in water does not result in the opening of the original mesopores to the same extent as before the specimen was dried. Such effects were shown using Simons' staining tests after softwood kraft pulp was subjected to drying at different temperatures (Esteghlalian et al. 2001). The staining results, indicating a loss of "fibrillation" upon drying, were consistent with tests of enzyme digestability. A related approach was used to show the beneficial effect of xylan in decreasing the drying-induced effects on kraft pulps (Kohnke et al. 2010). In the cited work the hemicellulose was fluorescently labeled, make it possible to study the microstructure by confocal laser scanning microscopy. 


\section{Contamination}

The topic of contamination, which might be regarded as either a chemical or a mechanical effect, is worth mentioning, since the presence of contaminants may call into question various conclusions that have been made based on staining methods. Commercially manufactured paper products can be expected to contain a wide range of substances in addition to lignocellulose-derived fibers. Staining methods can be used to detect materials such as aluminum ions (Varriano-Marston and Cheeseman 1986) and starch (Gutmann 1995; Woodward 2002) in such products. Recycled paper can contain a wide variety of contaminants. Such possibilities need to be kept in view when employing staining protocols developed for native or somewhat purified lignocellulose specimens.

\section{CLOSING STATEMENTS}

In the course of gathering information for preparation of this review article, it became clear that much can be learned by studying the results of individual efforts of many researchers, each of whom has worked with complex lignocellulosic samples and with dyes that might also vary in composition or purity. Although this review article has attempted an integration of findings, showing in particular how results of such work can cast light upon the character of the lignocellulosic materials themselves and the effects of various processes to which they are subjected, there is a need for cautious reexamination of many issues. Development and use of stains having greater purity, in combination with modern methods such as confocal laser scanning microscopy, better quantification of color depths, and kinetic analysis can be expected to reveal important information in the coming years. Though staining methods are inherently indirect - drawing conclusions about a specimen based on its interactions with a probe - there appear to be a great many situations in which staining is an ideal way to learn about lignocellulose and its products resulting from pulping, bleaching, refining, and other processes.

At the beginning of this article it was suggested that the differential uptake of dyes might be trying to tell us something about the inherent nature of various components of lignocellulose or about the contrasting effects imparted by various processes, such as pulping and refining. Detailed contributions with respect to answering such questions already have been discussed in the sections of this article dealing with reported findings for cellulose, hemicellulose, lignin, and extractives. Table 6 addresses the same questions from a less focused view, attempting to integrate the general findings of many studies to provide summary comments.

Based on the literature cited in this article, a case can be made that uptake of stains onto cellulose is primarily a matter of surface adsorption, with the extent of coloration dependent on the presence of slit-like pores. The pore structure within the cellulose domains of the fibers follows from the high regularity of cellulose itself; removal of the lignin, as well as refining, have a tendency to internally delaminate the material within or adjacent to cellulose domains, giving rise to slit-like spaces in the mesopore (2 to $50 \mathrm{~nm}$ ) scale or larger. Such structures have been found to favor adsorption of direct dyes, especially the oligomeric fractions of Direct Orange 15 and Direct Yellow 11, which have a shape suitable for such spaces and also a flat, linear conformation. The concept that such adsorption is favored by structural affects and non-specific London dispersion forces is supported by the fact that direct dyes have a net negative charge, which otherwise would 
tend to discourage their adsorption onto cellulosic material, which often has negatively charged carboxylic acid groups associated with it.

Table 6. Summary of What Can be Learned about Predominant Features of Chemical Domains in Lignocellulosic Fibers and Materials Based on an Integration of Published Findings Involving Staining

\begin{tabular}{|l|l|}
\hline Chemical Domain & Main Characteristics Reveals by Staining Results \\
\hline Cellulose & $\begin{array}{l}\text { Linear mesopore structure is a dominant characteristic. } \\
\text { Highly crystalline character keeps dyes at the surface. } \\
\text { Lack of charge allows dispersion forces to dominate. }\end{array}$ \\
\hline Hemicellulose & $\begin{array}{l}\text { Location together with lignin is a key characteristic. } \\
\text { Negative charged character is often evident. } \\
\text { Non-crystallinity favors uptake of cationic, polar dyes. } \\
\text { Tails of hemicellulose extend from the fiber surface. }\end{array}$ \\
\hline Lignin & $\begin{array}{l}\text { Location together with hemicellulose is a key feature. } \\
\text { Appears to solubilize dyes having suitable solubility. } \\
\text { Uptake of cationic dyes likely due to the hemicellulose. }\end{array}$ \\
\hline Extractives & Solubilizes non-polar dyes having matching solubility. \\
\hline
\end{tabular}

The affinity of cellulose for direct dyes can be contrasted with that of the staining characteristics of the amorphous components of cellulose-based fibers. As proposed earlier in this review, the literature findings generally support a concept in which uptake of stains can be viewed as being mainly dependent on solubility phenomena rather than involving adsorption onto surfaces. Thus, the extent of coloration sometimes tends to be governed by such factors as solubility properties and ionic charge. Notably, certain basic dyes, having a net positive charge, are the most popular for indicating the presence of lignin. It is proposed in this review that the use of cationic dyes such as safranin to reveal the presence or location of "lignin" may be actually attributable to a natural close association of the lignin with some hemicellulose components, in the form of lignin-polysaccharide complexes. Such complexes, which involve covalent bonding between lignin and the negatively charged hemicellulose chains or fragments of chains, can help to explain the high uptake of cationic dyes. Since the evidence to support such a concept is generally indirect and circumstantial, there is a need for mechanistic studies to further evaluate the underlying mechanisms.

In the coming years there will continue to be opportunities to use modern instrumentation to achieve more sensitive or more specific results from staining procedures. Microspectrophotometry already is an important tool for color analysis and correct identification of fibers in cultural heritage research, forensic analysis, and in the pulp and paper industry (Macrae et al. 1979; Hartshorne and Liang 1987; Hartley et al. 1990; Koch and Kleist 2001; Massonnet et al. 2012). The most critical step is to be able to reach reliable conclusions. For better identification, it is possible to make better use of statistical methods to minimize subjective aspects of human attempts at interpretation of fiber staining results.

Though the emphasis in this article has been on the use of staining methods, there is a range of modern analytical procedures that also can be utilized. One such tool worth highlighting is time-of-flight surface ionization mass spectrometry (ToF-SIMS) (Mou et al. 2016). This method involves directing a beam of selected ions (

Hubbe et al. (2019). "Analytical staining review," BioResources 14(3), 7387-7464. 
selected points on the surface of a specimen. Charged fragments of molecules released from the top few molecular layers of the specimen, at that location, are evaluated by mass spectrometry, giving a highly precise analysis of what was present at the tested microscopic location of on the specimen. In principle, such results could be used for more definitive assignment of components present within the first few molecular layers on the outside of a specimen. These components reasonably could include fatty acids, terpenes, polysaccharides, and lignin-related structures, which can be readily distinguish by ToFSIMS (Mou et al. 2016).

Many of the reported procedures for differentiation of different zones within cellulosic material, reflecting fiber sources, local compositions, and effects of processing, have shown an ability to be used in a reliable manner for purposes of fiber identification. Staining tests also can be used to indicate whether or not the material has been processed in a certain way, such as pulping or refining. An underlying message, based on such findings, is that cellulosic material, depending on its source and processing, tends to be predictable in its responses, compositions, and structures. This is certainly good news from the perspective of manufacturers who depend upon predictability when attempting to meet the specifications of their customers for cellulose-based products. Reported effects of differential staining by combinations of colorants suggest a subtle dependency on minor differences in different domains or due to treatments of the cellulosic material. Whether or not such reported specificity of coloration ever can be predicted in detail, it points to a predictable nature of the cellulosic material itself, consistent with its biosynthesis and inherent responses to such processes has pulping, bleaching, and refining.

\section{ACKNOWLEDGMENTS}

The authors are grateful for the following volunteers who studied an earlier version of this document and indicated the need for corrections and clarifications, as well as providing insightful suggestions for improvements: Andreas Bommarius, Georgia Inst. Technol., School of Chemical \& Biomol. Engn., Atlanta, GA 30332 USA, and Petit Inst. Bioengn. \& Biosci., Krone Engn. Biosyst. Bldg., Atlanta, GA 30332 USA; Came Sistach, Retired from Arxiu Corona D'Aragon in Barcelona, Spain; and Michal Jablonsky, Inst. Natural \& Synthetic Polymers, Dept. Wood Pulp \& Paper, Radlinskeho 9, Bratislava 81237, Slovakia. The work of Martin A. Hubbe is supported by the Buckman Foundation.

\section{REFERENCES CITED}

AATCC Test Method 20. (1990). "Fiber analysis: Qualitative," American Association of Textile Chemists and Colorists, Research Triangle Park, NC.

Abbott, L. C., Batchelor, S. N., Jansen, L., Oakes, J., Smith, J. R. L., and Moore, J. N. (2004a). "Spectroscopic studies of Direct Blue 1 in solution and on cellulose surfaces: Effects of environment on a bis-azo dye," New J. Chem. 28(7), 815-821. DOI: $10.1039 / \mathrm{b} 401055 \mathrm{~h}$

Abbott, L. C., Batchelor, S. N., Oakes, J., Smith, J. R. L., and Moore, J. N. (2004b). "Spectroscopic studies of the intermolecular interactions of a bis-azo dye, direct blue 1, on di- and trimerization in aqueous solution and in cellulose," J. Phys. Chem. B 108(36), 13726-13735. DOI: 10.1021/jp0485542 
Abe, H., Funada, R., Imaizumi, H., Ohtani, J., and Fukazawa, K. (1995). “Dynamic changes in the arrangement of cortical microtubules in conifer tracheids during differentiation," Planta 197(2), 418-421. DOI: 10.1007/BF00202666

Achar, B. N., Bhandari, J. M., and Urs, H. G. V. G. (1993). “A rapid safranin-metal phthalocyanine double staining technique for plants," Biotechnic Histochem. 68(3), 127-131. DOI: 10.3109/10520299309104681

Adamopoulos, S., and Oliver, J. V. (2006). "Fiber composition of packaging grade papers as determined by the Graff "C" staining test," Wood Fiber Sci. 38(4), 567-575.

Ahvenainen, P., Kontro, I., and Svedstrom, K. (2016). "Comparison of sample crystallinity determination methods by X-ray diffraction for challenging cellulose I materials," Cellulose 23(2), 1073-1086. DOI: 10.1007/s10570-016-0881-6

Akhtar, M., Blanchette, R. A., and Burnes, T. A. (1995). "Using Simons stain to predict energy savings during biomechanical pulping," Wood Fiber Sci. 27(3), 258-264.

Alince, B. (2002). "Porosity of swollen pulp fibers revisited," Nordic Pulp Paper Res. J. 17(1), 71-73. DOI: 10.3183/NPPRJ-2002-17-01-p071-073

Alince, B., and van de Ven, T. G. M. (1997). "Porosity of swollen pulp fibers evaluated by polymer adsorption," in: The Fundamentals of Papermaking Materials, Transactions of the $11^{\text {th }}$ Fundamental Research Symposium, Cambridge, UK., Pira International, Vol. 2, pp. 771-788.

Allen, R. C. (1999). Protein Staining and Identification Techniques, BioTechniques Books, Natick, MA.

Anderson, C. T., Carroll, A., Akhmetova, L., and Somerville, C. (2010). 'Real-time imaging of cellulose reorientation during cell wall expansion in Arabidopsis roots," Plant Physiology 152(2), 787-796. DOI: 10.1104/pp.109.150128

Anheuser, K., and Roumeliotou, M. (2003). "Characterisation of mineralized archaeological textile fibres through chemical staining," The Conservator 27(1), 2333. DOI: 10.1080/01410096.2003.9995187

Arantes, V., and Saddler, J. N. (2011). "Cellulose accessibility limits the effectiveness of minimum cellulase loading on the efficient hydrolysis of pretreated lignocellulosic substrates," Biotechnology for Biofuels 4(1), 3. DOI: 10.1186/1754-6834-4-3

Aziz, S., and Sarkanen, K. (1989). "Organosolv pulping - A review," TAPPI J. 72(3), 169-175.

Back, E., and Allen, L. H. (eds.) (2000). Pitch Control, Wood Resin and Deresination, TAPPI Press, Atlanta, GA, pp. 392.

Bahr, G. F. (1954). "Osmium tetroxide and ruthenium tetroxide and their reactions with biologically important substances - Electron stains III," Exp. Cell. Res. 7(2), 457-479. DOI: $10.1016 / \mathrm{S} 0014-4827(54) 80091-7$

Bairathi, A. (1993). "Dyeing sorption isotherms of 3 direct dyes and their mixtures on purified cotton," Textile Chemist and Colorist 25(12), 41-46.

Bauch, J., Liese, W., and Scholz, F. (1968). "Üher die Entwickslung und stoffliche Zusammensetzung der Hoftupfelmembranen von Längstracheiden in Coniferen," Holzforschung 22, 144-153.

Beamesderfer, J. W., Thode, E. F., Chase, A. J., and Hubbard, R. E. (1952). "Dye adsorption on wood pulp. 1. Adsorption of direct dye on unbeaten sulphite pulp," Tappi 35(8), 374-379.

Belgio, E., Johnson, M. P., Juric, S., and Ruban, A. V. (2012). "Higher plant photosystem II light-harvesting antenna, not the reaction center, determines the excited-state 
lifetime - Both the maximum and the nonphotochemically quenched," Biophys. $J$. 102(12), 2761-2771. DOI: 10.1016/j.bpj.2012.05.004

Ben Mlouka, M. A., Cousseau, T., and Di Martino, P. (2016). “Application of fluorescently labelled lectins for the study of polysaccharides in biofilms with a focus on biofouling of nanofiltration membranes," Aims Molec. Sci. 3(3), 338-356. DOI: 10.3934/molsci.2016.3.338

Benes, K. (1968). "On the stainability of plant cell walls with alcian blue," Biol. Plant 10, 334-346. DOI: 10.1007/BF02921018

Berlyn, P. G., and Miksche, J. P. (1976). Botanical Microtechnique and Cytochemistry, Iowa State University Press, Ames, Iowa, pp. 326.

Berthold, J., and Salmén, L. (1997). "Effects of mechanical and chemical treatments on the pore-size distribution in wood pulps examined by inverse size-exclusion chromatography," J. Pulp Paper Sci. 23(6), J245-J253.

Bijma, K., Blandamer, M. J., and Engberts, J. B. F. N. (1998). "Effect of counterions and headgroup hydrophobicity on properties of micelles formed by alkylpyridinium surfactants. 2. Microcalorimetry," Langmuir 14(1), 79-83. DOI: 10.1021/la970216n

Bird, J., Brough, N., Dixon, S., and Batchelor, S. N. (2006). "Understanding adsorption phenomena: Investigation of the dye-cellulose interaction," J. Phys. Chem. B 110(39), 19557-19561. DOI: 10.1021/jp063730n

Blanchette, R. A., Akhtar, M., and Attridge, M. C. (1992). "Using Simons stain to evaluate fiber characteristics of biomechanical pulps," TAPPI J. 75(11), 121-124.

Bluhm, T. L., and Zugenmaier, P. (1981). "Conformation and packing analysis of polysaccharides and derivatives. 7. Detailed structure of the vh-amylose-iodine complex - A linear polyiodine chain," Carbohyd. Res. 89(1), 1-10. DOI:

10.1016/S0008-6215(00)85224-6

Bond, J., Donaldson, L., Hill, S., and Hitchcock, K. (2008). "Safranine fluorescent staining of wood cell walls," Biotech. Histochem. 83(3-4), 161-171. DOI: $10.1080 / 10520290802373354$

Boon, M. E. (1986). Routine Cytological Staining Techniques, Elsevier, New York, NY, pp. 238. DOI: 10.1007/978-1-349-18250-3

Borzynski, L. J., Norton, D. A., and McDougall, W. J. (1972). "Basic fuchsin in acid alcohol as a stain for glycoproteins after electrophoresis on cellulose polyacetate," Stain Technol. 47(6), 317-318. DOI: 10.3109/10520297209116561

Bouzon, Z. L., and Ouriques, L. C. (2007). "Characterization of Laurencia arbuscula spore mucilage and cell walls with stains and FITC-labelled lectins," Aquatic Bot. 86(4), 301-308. DOI: 10.1016/j.aquabot.2006.10.010

Bredereck, K., and Weckmann, R. (1978). "Dyeing properties and structure of cotton materials after treatment with liquid-ammonia and $\mathrm{NaOH}$ mercerization," Melliand Textilber. Intl. Text. Rep. 59(2), 137-142.

Bright, C. G. (1917). "Method of staining to distinguish between bleached and unbleached sulfite pulps," Indust. Eng. Chem. 9(11).

Brown, R. M. (1996). "The biosynthesis of cellulose," J. Macromol. Sci. - Pure Appl. Chem. A33(10), 1345-1373. DOI: 10.1080/10601329608014912

Browning, B. L. (1977). Analysis of Paper, $2^{\text {nd }}$ Ed., Marcel Dekker, New York, NY. Brundrett, M. C., Enstone, D. E., and Peterson, C. A. (1988). "A berberine-aniline blue fluorescent staining procedure for suberin, lignin, and callose in plant tissue," Protoplasma 146(2-3), 133-142. DOI: 10.1007/BF01405922 
Brundrett, M. C., Kendrick, B., and Peterson, C. A. (1991). "Efficient lipid staining in plant material with Sudan red 7B or Fluorol yellow 088 in polyethylene glycolglycerol," Biotechnic and Histochemistry 66, 111-116. DOI: 10.3109/10520299109110562

Budakci, M., and Cinar, H. (2004). "Colour effects of stains on wood with knots, cracks and rots," Prog. Organic Coatings 51(1), 1-5. DOI: 10.1016/j.porgcoat.2004.04.001

Buchert, J., Teleman, A., Harjunpaa, V., Tenkanen, M., Viikari, L., and Vuorinen, T. (1995). "Effect of cooking and bleaching on the structure of xylan conventional pine kraft pulp," TAPPI J. 78(11), 125-130.

Calabrese, V. T., and Khan, A. (2000). "Polyiodine and polyiodide species in aqueous solution of iodine plus KI: Theoretical and experimental studies," J. Phys. Chem. A 104(6): 1287-1292. DOI: 10.1021/jp992847r

Cartwright, K. S. (1929). "A satisfactory method of staining fungal mycelium in wood sections," Ann. Botany 43(170), 412-413. DOI: 10.1093/oxfordjournals.aob.a090177

Chaffey, N. (2002). "Wood Microscopical Techniques," in: Wood Formation in Trees; Cell and Molecular Biology Techniques, N. Chaffey (ed), Taylor \& Francis, London, pp. 17-40.

Chandra, R., Ewanick, S., Hsieh, C., and Saddler, J. N. (2008). "The characterization of pretreated lignocellulosic substrates prior to enzymatic hydrolysis, Part 1: A modified Simons' staining technique," Biotech. Prog. 24(5), 1178-1185. DOI: 10.1021/bp.33

Chandra, R. P., and Saddler, J. N. (2012). "Use of the Simons' staining technique to assess cellulose accessibility in pretreated substrates," Ind. Biotechnol. 8(4), 230-237. DOI: 10.1089/ind.2012.0016

Cheadle, V. I., Gifford, E. M., and Esau, K. (1953). "A staining combination for phloem and contiguous tissues," Stain Technol. 28(2), 49-53. DOI: 10.3109/10520295309105101

Chen, S. F., Li, Y. F., and Huang, C. Z. (2006a). "Spectral assignments of the light emissions of fluorescent organic small molecules in aqueous medium," Talanta 70, 52-57. DOI: 10.1016/j.talanta.2006.01.044

Chen, X. M., Burger, C., Fang, D. F., Ruan, D., Zhang, L., Hsiao, B. S., and Chu, B. (2006b). "X-ray studies of regenerated cellulose fibers wet spun from cotton linter pulp in NaOH/thiourea aqueous solutions," Polymer 47(8), 2839-2848. DOI: 10.1016/j.polymer.2006.02.044

Choi, A. H. C., and Oday, D. H. (1984). "Calcofluor staining of cellulose during microcyst differentiation in wild-type and mutant strains of polysphondyliumpallidum," J. Bacteriology 157(1), 291-296.

Choong, F. X., Back, M., Steiner, S. E., Melican, K., Nilsson, K. P. R., Edlund, U., and Richter-Dahlfors, A. (2016). "Nondestructive, real-time determination and visualization of cellulose, hemicellulose and lignin by luminescent oligothiophenes," Scientific Reports 6, article no. 35578. DOI: 10.1038/srep35578

Chrastil, J., Reinhardt, R. M., and Blanchard, E. J. (1990). "Influence of mercerization and cross-linking of cotton fabrics on dyeing kinetics of direct dyes from finite baths," Textile Res. J. 60(8), 441-446. DOI: 10.1177/004051759006000802

Clark, M. (ed.). (2011). Handbook of Textile and Industrial Dyeing, Vol. 1, Principles, Processes and Types of Dyes, Woodhead Publ. Textiles, Ch. 17. DOI: 10.1533/9780857093974.1.225

Coiro, M., and Truernit, E. (2017). "Xylem characterization using improved pseudoSchiff propidium iodide staining of whole mount samples and confocal laser-scanning 
microscopy," in: Xylem: Methods and Protocols, M. DeLucas and J. P. Etchells (eds.), Book Ser.: Methods in Molecular Biology, Vol. 1544, pp. 127-132. DOI: 10.1007/978-1-4939-6722-3_11

Conn, H. J. (1948). A History of Staining, Biotech. Publ., Geneva, NY, pp. 143.

CPPA (1988). "Wood fiber identification according to pulping process," CPPA Standard B.3P, $11 \mathrm{pp}$.

Cross, C. F., and Bevan, E. J. (1907). A Text Book of Papermaking, E\&FN Spon., London.

Currier, H. B. (1957). “Callose substance in plant cells,” Amer. J. Bot. 44(6), 478-488. DOI: $10.2307 / 2438916$

Daniel, G. (2016). "Microscope techniques for understanding wood cell structure and biodegradation," in: Secondary Xylem Biology; Origins, Functions, and Applications, Y.S. Kim, R. Funada, and A.P. Singh (eds), Academic Press, London, pp. 309-343.

Davis, H., and Khan, A. (1994). "Determining the chromophore in the amylopectin iodine complex by theoretical and experimental studies," J. Polym. Sci. Part APolym. Chem. 32(12), 2257-2265. DOI: 10.1002/pola.1994.080321207

deBrito, C. J. F. A., and Alquini, Y. (1996). "A new method for staining botanical material embedded in glycol methacrylate (GMA)," Arquivos de Biologia e Technologia 39(4), 949-951.

Decoster, B., Christensen, R. L., Gebhard, R., Lugtenburg, J., Farhoosh, R., and Frank, H. A. (1992). "Low-lying electronic states of carotenoids," Biochem. Biophys. Acta 1102(1), 107-114. DOI: 10.1016/0167-4838(92)90504-7

De Micco, V., and Aronne, G. (2007). "Combined histochemistry and autofluorescence for identifying lignin distribution in cell walls," Biotechnic \& Histochemistry 82(4-5), 209216.

Dence, C. W., and Reeve, D. W. (1996). Pulp Bleaching: Principles and Practice, TAPPI Press, Atlanta, GA, pp. 868.

Dinand, E., Vignon, M., Chanzy, H., and Heux, L. (2002). "Mercerization of primary wall cellulose and its implication for the conversion of cellulose I $\rightarrow$ cellulose II," Cellulose 9(1), 7-18. DOI: 10.1023/A:1015877021688

Dixon, D. W. (2008). Characterization of Commercial Pectin Preparations by Spectroscopic and Chromatographic Techniques, Master's Thesis, East Tennessee State University, Johnson City, TN.

Dodge, C. R. (1897). A Descriptive Catalogue of Useful Fiber Plants of the World: Including the Structural and Economic Classifications of Fibers, Government Printing Office, Washington, DC. DOI: 10.5962/bhl.title.63977

Dogu, A. D., and Grabner, M. (2010). "A staining method for determining severity of tension wood," Turkish J. Agric. For. 34(5), 381-392. DOI: 10.3906/tar-0906-209

Donaldson, L. A., and Bond, J. (2005). Fluorescence Microscopy of Wood, Scion, Rotorua, New Zealand. CD-ROM.

Donaldson, L., and Frankland, A. (2008). "Ultrastructure of iodine treated wood," Holzforschung 58(3), 219-225. DOI: 10.1515/HF.2004.034

Donaldson, L. A., Newman, R. H., and Vaidya, A. (2014). "Nanoscale interactions of polyethylene glycol with thermo-mechanically pre-treated Pinus radiata biofuel substrate," Biotech. Bioeng. 111(4), 719-725. DOI: 10.1002/bit.25138

Donaldson, L., and Vaidya, A. (2017). "Visualising recalcitrance by colocalisation of cellulase, lignin and cellulose in pretreated pine biomass using fluorescence microscopy," Scientific Reports 7, article no. 44386. DOI: 10.1038/srep44386 
Drnovsek, T., and Perdih, A. (2005a). "Selective staining as a tool for wood fibre characterization," Dyes Pigments 67(3), 197-206. DOI: 10.1016/j.dyepig.2004.10.013

Drnovsek, T., and Perdih, A. (2005b). "Fibre surface characteristics determined by the method of selective staining, ESCA measurements and charge determinations," Wood Res. 50(3), 37-46.

Dubinyová, L., Jablonský, M., Varga, Š., Fikar, M., and Katuščák, S. (2016). “Cellulose materials identification: The effect of dimensionality of colour photography data," BioResources 11(1), 71-86.

Dubrovsky, J. G., Guttenberger, M., Saralegui, A., Napsucialy-Mendivil, S., Voigt, B., Baluska, F., and Menzel, D. (2006). "Neutral red as a probe for confocal laser scanning microscopy studies of plant roots," Ann. Bot. 97(6), 1127-1138. DOI: 10.1093/aob/mcl045

Duester, G. (2000). "Families of retinoid dehydrogenases regulating vitamin A function Production of visual pigment and retinoic acid," Eur. J. Biochem. 267(14), 43154324. DOI: 10.1046/j.1432-1327.2000.01497.x

Dutta, S. K., and Chakraborty, S. (2016). "Pore-scale dynamics of enzyme adsorption, swelling and reactive dissolution determine sugar yield in hemicellulose hydrolysis for biofuel production," Sci. Reports 6, article 38173. DOI: 10.1038/srep38173

Dzyaloshinskii, I. E., Lifshitz, E. M., and Pitaevskii, L. P. (1961). "The general theory of van der Waals forces," Advances in Physics 10(38), 165-209. DOI:

$10.1080 / 00018736100101281$

Ebringerova, A., Hromadkova, Z., and Heinze, T. (2005). "Hemicellulose," in: Polysaccharides 1: Structure, Characterization and Use, T. Heinze (ed.), Book series Advances in Polymer Science, Springer. DOI: 10.1007/b136816

El Mansouri, N.-E., and Salvado, J. (2007). "Analytical methods for determining functional groups in various technical lignins," Indust. Crops Prod. 26(2), 116-124. DOI: 10.1016/j.indcrop.2007.02.006

El-Molla, M. M., Badawy, N. A., AbdEl-Aal, A. Y., El-Bayaa, A. A., and El-Shaimaa, H. M. G. (2011). "Dyeability of cationised cotton and nylon 6 fabrics using acid dyes," Indian J. Fib. Text. Res. 36(1), 88-95.

El-Shafei, A., Hinks, E., and Freeman, H. X. (2011). "Molecular modeling and predicting dye properties," Handbook of Textile and Industrial Dyeing, Vol. 1, Principles, Processes and Types of Dyes, M. Clark (ed.), Woodhead Publ. Textiles, Issue 116, pp. 225-244. DOI: 10.1533/9780857093974.1.225

Eschrich, W., and Currier, H. B. (1964). "Identification of callose by its diachrome and fluorochrome reactions," Stain Technol. 39, 303-307. DOI: 10.3109/10520296409061248

Esteghlalian, A. R., Bilodeau, M., Mansfield, S. D., and Saddler, J. N. (2001). "Do enzymatic hydrolyzability and Simons' stain reflect the changes in the accessibility of lignocellulosic substrates to cellulase enzymes?” Biotech. Prog. 17(6), 1049-1054. DOI: $10.1021 / \mathrm{bp} 0101177$

Fardim, P., Holmbom, B., Ivaska, A., and Karhu, J. (2002). "Critical comparison and validation of methods for determination of anionic groups in pulp fibres," Nordic Pulp \& Paper Research Journal 17(3), 346-351. DOI: 10.3183/NPPRJ-2002-17-03p346-351

Farina, C., Santos, F. C., and Tort, A. C. (1999). "A simple way of understanding the nonadditivity of van der Waals dispersion forces," Amer. J. Phys. 67(4), 344-349. DOI: $10.1119 / 1.19260$ 
Fernando, D, and Daniel, G. (2010). "Characterization of spruce thermomechanical pulps at the fiber cell wall level: A method for quantitatively assessing pulp fiber development using Simons' stain," Tappi Journal 9(10), 47-55.

Fernando, D., Daniel, G., and Liden, J. (2005). "The state and spatial distribution of extractives during birch kraft pulping, as evaluated by staining techniques," Nordic Pulp Paper Res. J. 20(4), 383-391. DOI: 10.3183/NPPRJ-2005-20-04-p383-391

Fernando, D., Muhic, D., Engstrand, P., and Daniel, G. (2011). "Fundamental understanding of pulp property development under different thermomechanical pulp refining conditions as observed by a new Simons' staining method and SEM observation of the ultrastructure of fibre surfaces," Holzforschung 65(6), 777-786. DOI: $10.1515 / \mathrm{HF} .2011 .076$

Fester, T., Berg, R. H., and Taylor, C. G. (2008). "An easy method using glutaraldehydeintroduced fluorescence for the microscopic analysis of plant biotrophic interactions," J. Microsc. 231(2), 342-348. DOI: 10.1111/j.1365-2818.2008.01999.x

Feucht, W., Treutter, D., and Polster, J. (2012). "Flavanols in nuclei of tree species: Facts and possible functions," Trees - Structure and Function 26(5), 1413-1425. DOI: 10.1007/s00468-012-0725-4

Feuillet, C., Lauvergeat, V., Deswarte, C., Pilate, G., Boudet, A., and Grimapettenati, J. (1995). "Tissue-specific and cell-specific expression of a cinnamyl alcoholdehydrogenase promoter in transgenic poplar plants," Plant Molec. Biol. 27(4), 651667. DOI: 10.1007/BF00020220

Filonova, L., Gunnarsson, L. C., Daniel, G., and Ohlin, M. (2007). "Synthetic xylanbinding modules for mapping of pulp fibres and wood sections," BMC Plant Biology 7(1), 54. DOI: 10.1186/1471-2229-7-54

Filpponen, I., and Argyropoulos, D. S. (2010). "Regular linking of cellulose nanocrystals via click chemistry: Synthesis and formation of cellulose nanoplatelet gels," Biomacromol. 11(4), 1060-1066. DOI: 10.1021/bm1000247

Fowke, L. C., Attree, S. M., Binarova, P., Galway, M. E., and Wang, H. (1995). “Conifer somatic embryogenesis for studies of plant-cell biology," In Vitro Cellular \& Devel. Biol. - Plant 31(1), 1-7. DOI: 10.1007/BF02632218

Fowkes, F. M. (1990). "Quantitative characterization of the acid-base properties of solvents, polymers, and inorganic surfaces," Journal of Adhesion Science and Technology 4(1), 669-691. DOI: 10.1163/156856190X00595

Fowkes, F. M., and Mostafa, M. A. (1978). "Acid-base interactions in polymer adsorption," Industrial \& Engineering Chemistry Product Research and Development 17(1), 3-7. DOI: 10.1021/i360065a002

Frank, H. A., Desamero, R. Z. B., Chynwat, V., Gebhard, R., vanderHoef, I., Jansen, F. J., Lugtenburg, J., Gosztola, D., and Wasielewski, M. R. (1997). "Spectroscopic properties of spheroidene analogs having different extents of pi-electron conjugation," J. Phys. Chem. A 101(2), 149-157. DOI: 10.1021/jp9623731

Franke, W. (1993). Prüfung von Papier, Pappe, Zellstoff und Hoszstoff, Band 2, Springer Verlag, Berlin.

Fu, S., Hinks, D., Hauser, P., and Ankeny, M. (2013). "High efficiency ultra-deep dyeing of cotton via mercerization and cationization," Cellulose 20(6), 3101-3110. DOI: 10.1007/s10570-013-0081-6

Gärtner, H., and Schweingruber, F. H. (2013). Microscopic Preparation Techniques for Plant Stem Analysis, Verlag Dr. Kessel, Remagen-Oberwinter, pp. 78. 
Gatenholm, P. (2003). Hemicelluloses: Science and Technology, American Chemical Society, Washington, DC. DOI: 10.1021/bk-2004-0864

Ghinea, N. (1986). "Cationic heme undecapeptide as stain for detecting glycosaminoglycans on cellulose-acetate strips," Anal. Biochem. 155(1), 78-82. DOI: 10.1016/0003-2697(86)90227-7

Gimaker, M., and Wågberg, L. (2009). "Adsorption of polyallylamine to lignocellulosic fibres: Effect of adsorption conditions on localisation of adsorbed polyelectrolyte and mechanical properties of resulting paper sheets," Cellulose 16(1), 87-101. DOI: 10.1007/s10570-008-9240-6

Glasser, W. G., and Sarkanen, S. (eds.) (1989). Lignin: Properties and Materials, American Chemical Society, Washington, DC, pp. 545. DOI: 10.1021/bk-1989-0397

Goodrich, J. D., and Winter, W. T. (2007). " $\alpha$-Chitin nanocrystals prepared from shrimp shells and their specific surface area measurement," Biomacromol. 8(1), 252-257. DOI: $10.1021 / \mathrm{bm} 0603589$

Gourlay, K., Hu, J. G., Arantes, V., Penttila, M., and Saddler, J. N. (2015). "The use of carbohydrate binding modules (CBMs) to monitor changes in fragmentation and cellulose fiber surface morphology during cellulase- and swollenin-induced deconstruction of lignocellulosic substrates," J. Biological Chem. 290(5), 2938-2945. DOI: $10.1074 /$ jbc.M114.627604

Graff, H. H. (1935). "New stains and their uses for fiber identification," Paper Trade J. $100(16), 45$.

Graff, J. H. (1940). Color Atlas for Fiber Identification, Institute of Paper Chemistry, Appleton, WI.

Gram, K., and Jǿrgensen, E. (1951). "An easy, rapid and efficient method of counterstaining plant tissues and hyphae in wood sections by means of fast green or light green and safranin," Friesia 4, 262-266.

Grant, J. (1961). In: A Laboratory Handbook for Pulp and Paper Manufacture, $2^{\text {nd }}$ Ed., Edward Arnold, London, pp. 376.

Gray, P. (1954). The Microtomist's Formulary and Guide, Blakiston, New York, NY, pp. 794.

Green, H. V., and Yorston, F. H. (1952). "Identification of unbleached sulfite pulps in mixtures," Pulp Paper Mag. Canada 53(6), 133-134.

Green, J. W., Pearl, I. A., Hardacker, K. W., Andrews, B. D., and Haigh, F. C. (1977). "Peeling reaction in alkaline pulping," TAPPI 60(10), 120-125.

Griffiths, J. (1982). "Practical aspects of color prediction of organic dye molecules," Dyes Pigments 3(2-3), 211-233. DOI: 10.1016/0143-7208(82)80024-7

Grigsby, W. J., Thumm, A., and Kamke, F. A. (2005). "Determination of resin distribution and coverage in MDF by fiber staining," Wood Fiber Sci. 37(2), 258-269.

Guerriero, G., Fugelstad, J., and Vincent, B. (2010). "What do we really know about cellulose biosynthesis in higher plants," J. Integrative Plant Biol. 52(2), 161-175. DOI: $10.1111 / \mathrm{j} .1744-7909.2010 .00935 . \mathrm{x}$

Gurr, E. (1965). The Rational Use of Dyes in Biology and General Staining Methods, Williams \& Wilkins, Baltimore, MD, pp. 422.

Gutmann, M. (1995). "Improved staining procedures for photographic documentation of phenolic deposits in semithin sections of plant-tissue," J. Microscopy-Oxford 179, 277-281. DOI: 10.1111/j.1365-2818.1995.tb03642.x 
Hagege, R., Kassenbe, P., Meimoun, D., and Parisot, A. (1969). "Electron microscopy of cellulosic structures by inclusion of stainable unsaturated polymers," Textile Res. J. 39(11), 1015-1021. DOI: 10.1177/004051756903901104

Hall, D. M. (1976). Practical Fiber Identification, Auburn University, Auburn, AL, pp. 74.

Hamburger, D., Rezzonico, E., Petetot, J. M. C., Somerville, C., and Poirier, Y. (2002). "Identification and characterization of the Arabidopsis PHO1 gene involved in phosphate loading to the xylem," Plant Cell 14(4), 889-902. DOI:

$10.1105 /$ tpc. 000745

Hansen, C. M. (2007). Hansen Solubility Parameters: A User's Handbook, $2^{\text {nd }}$ Ed., CRC Press, Boca Raton, FL, USA. DOI: 10.1201/9781420006834

Harkin, J. M. (1972). "Wood and pulp chromophores - A critical review," TAPPI 55(7), 991-994.

Harrar, E. S. (1928). “A stain combination for phloem tissues of woody plants (with one figure)," Botanical Gazette 86, 111-112. DOI: 10.1086/333878

Harris, J. R. (1997). Negative Staining and Cryoelectron Microscopy: The Thin Film Techniques, BIOS Sci. Publ. in assoc. with the Royal Microscopical Soc, Oxford, UK, pp. 208.

Hartley, R. D., Akin, D. E., Himmelsbach, D. S., and Beach, D. C. (1990). "Microspectrophotometry of Bermudagrass (Cynodon dactylon) cell-walls in relation to lignification and wall biodegradability," J. Sci. Food Agri. 50(2), 179-189. DOI: 10.1002/jsfa.2740500206

Hartshorne, A. W., and Laing, D. K. (1987). "The definition of color for single textile fibers by microspectrophotometry," Forensic Sci. Intl. 34, 107-129. DOI: 10.1016/0379-0738(87)90090-9

Hashimoto, K., Imanishi, S. I., Okada, M., and Sumitomo, H. (1991). "Chemical modification of the reducing chain end in dextrans and trimethylsilylation of its hydroxyl groups," J. Polym. Sci. Part A - Polym. Chem. 29(9), 1271-1279. DOI: 10.1002/pola.1991.080290906

Hayat, M. A. (1975). Positive Staining for Electron Microscopy, Van Norstrand Reinhold Co., New York, NY, pp. 361.

He, P. J., Chai, L. N., Li, L., Hao, L. P., Shao, L. M., and Lu, F. (2013). "In situ visualization of the change in lignocellulose biodegradability during extended anaerobic bacterial degradation," RSC Advan. 3(29), 11759-11773. DOI: $10.1039 / \mathrm{c} 3 \mathrm{ra} 40654 \mathrm{~g}$

Heathcote, J. G., Washington, R. J., Haworth, C., and Bell, S. (1970). “An improved technique for analysis of amino acids and related compounds on thin layers of cellulose. 3. Detection and identification by selective staining," J. Chromatogr. 51(2), 267-275. DOI: 10.1016/S0021-9673(01)96863-3

Herrington, T. M., and Midmore, B. R. (1984). "Adsorption of ions at the cellulose/aqueous electrolyte interface. Part 2. Determination of the surface area of cellulose fibres," J. Chem. Soc. Faraday Trans 1: Phys. Chem. Condensed Phases 80, 1539-1552.

Herzberg, W. (1902). Papierprüfung: Eine Aneitung zum Untersuchen von Papier, zweite vollständig neubearbeitete Auflage, Julius Springer, Berlin. DOI: 10.1007/978-3-662$36418-5$

Herzberg, W. (1932). Papierprüfung, Julius Springer, Berlin. DOI: 10.1007/978-3-66232760-9 
Herzog, A, (1935). Mikrochemische Papieruntersuchung, Springer, Berlin. DOI: 10.1007/978-3-662-33893-3

Heyn, A. (1966). "The microcrystalline structure of cellulose in cell walls of cotton ramie and jute fibers as revealed by negative staining of sections," J. Cell Biol. 29(2), 181-

197. DOI: $10.1083 /$ jcb.29.2.181

Hieta, K., Kuga, S., and Usuda, M. (1984). "Electron staining of reducing ends evidences a parallel-chain structure in valonia cellulose," Biopolymers 23(10), 1807-1810. DOI: 10.1002/bip.360231002

Hildebrand, J. H., Prausnitz, J. M., and Scott, R. L. (1970). Regular and Related Solutions: The Solubility of Gases, Liquids, and Solids, Van Nostrand Reinhold Co.

Hillyer, M. B., and Gibb, B. C. (2016). "Molecular shape and the hydrophobic effect," Ann. Rev. Phys. Chem. 67, 307-329. DOI: 10.1146/annurev-physchem-040215112316

Hindeleh, A. M., and Johnson, D. J. (1974). "Crystallinity and crystallite size measurement in cellulose fibers. 2. Viscose rayon," Polymer 15(11), 697-705. DOI: 10.1016/0032-3861(74)90020-2

Ho, Y. S., and McKay, G. (1999). "Pseudo-second order model for sorption processes," Process Biochem. 34, 451-465. DOI: 10.1016/S0032-9592(98)00112-5

Hornatowska, J. (2005). Visualisation of Pectins and Proteins by Microscopy (Report no. 87/ 2005), STFI-Packforks.

Horobin, R. W. (1982). Histochemistry: An Explanatory Outline of Histochemistry and Biophysical Staining, G. Fischer, Stuttgart, pp. 310.

Horobin, R. W. (2002). Conn's Biological Stains: A Handbook of Dyes, Stains and Fluorochromes for Use in Biology and Medicine, $1^{\text {st }}$ Ed., BIOS Scientific Publ, Oxford. pp. 1-502.

Horvath, A. T., Horvath, A. E., Lindström, T., and Wågberg, L. (2008). "Adsorption of low charge density polyelectrolytes to an oppositely charged porous substrate," Langmuir 24(13), 6585-6594. DOI: 10.1021/la800274w

Hosoo, Y., Yoshida, M., Imai, T., and Okuyama, T. (2002). "Diurnal difference in the amount of immunogold-labelled glucomannans detected with field emission scanning electron microscopy at the innermost surface of developing secondary walls of differentiating conifer tracheids," Planta 215, 1006-1012. DOI: 10.1007/s00425-0020824-3

Houtman, C. J., Kitin, P., Houtman, J. C. D., Hammel, K. E., and Hunt, C. G. (2016). "Acridine orange indicates early oxidation of wood cell walls by fungi," PLOS ONE, 11(7), article no. e0159715. DOI: 10.1371/journal.pone.0159715.

Hubbe, M. A. (2014). "Zipping backwards the other way - Yet another unique aspect of cellulose," BioResources 9(3), 3759-3760. DOI: 10.15376/biores.9.3.3759-3760

Hubbe, M. A., Beck, K. R., O'Neal, W. G., and Sharma, Y. C. (2012a). "Cellulosic substrates for removal of pollutants from aqueous systems: A review. 2. Dyes," BioResources 7(2), 2592-2687. DOI: 10.15376/biores.7.2.2592-2687

Hubbe, M. A., Chen, H., and Heitmann, J. A. (2009). "Permeability reduction phenomena in packed beds, fiber mats, and wet webs of paper exposed to flow of liquids and suspensions: A review," BioResources 4(1), 405-451. DOI: 10.15376/biores.4.1.405451

Hubbe, M. A., Pawlak, J. J., and Koukoulas, A. A. (2008). "Paper's appearance: A review," BioResources 3(2), 627-665. DOI: 10.15376/biores.3.2.627-665 
Hubbe, M. A., and Rojas, O. J. (2008). "Colloidal stability and aggregation of lignocellulosic materials in aqueous suspension: A review," BioResources 3(4), 14191491.

Hubbe, M. A., Sundberg, A., Mocchiutti, P., Ni, Y., and Pelton, R. (2012b). "Dissolved and colloidal substances (DCS) and the charge demand of papermaking process waters and suspensions: A review," BioResources 7(4), 6109-6193. DOI: 10.15376/biores.7.4.6109-6193

Hunger, K., and Herbst, W. (2012). "Pigments, organic," in: Ullmann's Encyclopedia of Industrial Chemistry, Wiley-VCH, Weinheim. DOI: 10.1002/14356007.a20_371

Hutterer, C., Fackler, K., Schild, G., Ibl, V., and Potthast, A. (2017). "Xylan localization on pulp and viscose fiber surfaces," BioResources 12(3), 5632-5648. DOI: 10.15376/biores.12.3.5632-5648

Inglesby, M. K., and Zeronian, S. H. (1996). "The accessibility of cellulose as determined by dye adsorption," Cellulose 3(3), 165-181. DOI: 10.1007/BF02228799

Inglesby, M. K., and Zeronian, S. H. (2002). "Direct dyes as molecular sensors to characterize cellulose substrates," Cellulose 9, 19-29. DOI: 10.1023/A:1015840111614

Ingmanson, W. L., and Andrews, B. D. (1959). "The effect of beating on filtration resistance and its components of specific surface and specific volume," Tappi 42(1), 29-35.

Isenberg, I. H. (1967). Pulp and Paper Microscopy, $3^{\text {rd }}$ Ed., The Institute of Paper Chemistry, Appleton, WI.

Jablonsky, M., Dubinyova, L., Varga, S., Vizarova, K., Sima, J., and Katuscak, S. (2015). "Cellulose fibre identification through color vectors of stained fibre," BioResources 10(3), 5845-5862. DOI: 10.15376/biores.10.3.5845-5862

James, J. (1984). Histochemical Protein Staining Methods, Oxford Univ. Press, Oxford, UK, pp. 40.

Jansen, S., Kitin, P., De Pauw, H., Idris, M., Beeckman, H., and Smets, E. (1998). "Preparation of wood specimens for transmitted light microscopy and scanning electron microscopy," Belg. Journ. Bot. 131(1), 41-49.

Jayme, G., and Harders-Steinhauser, M. (1955). "Über die Erkennung von Dichteunterschieden in Cellulosefasern durch Doppelfärbung," Das Papier 9(21-22), 507-510.

Jensen, W. A. (1962). Botanical Histochemistry, W. H. Freeman and Co., San Francisco, CA, pp. 408.

Johansen, D. A. (1940). Plant Microtechnique, McGraw-Hill, New York, NY, pp. 523.

Jia, L. F., Yang, M., Liu, Y., and Sun, L. (2016). "Automatic identification of ramie and cotton fibers based on iodine blue reaction, Part I: The optimum conditions for the iodine blue reaction of cellulose," Textile Res. J. 86(88), 848-855. DOI: 10.1177/0040517515596970

Jiang, G. S., Huang, W. F., Li, L., Wang, X., Pang, F. J., Zhang, Y. M., and Wang, H. P. (2012). "Structure and properties of regenerated cellulose fibers from different technology processes," Carbohydr. Polymers 87(3), 2012-2018. DOI: 10.1016/j.carbpol.2011.10.022

Johnson, A., Patel, N. M., and Peters, R. H. (1974). "Sorption of mixtures of direct dyes by cellulose," J. Soc. Dyers Colourists 90(2), 50-54. DOI: 10.1111/j.1478-

4408.1974.tb03183.x 
Johnson, G. M., and Fairchild, M. D. (2003). "A top down description of S-CIELAB and CIEDE2000," Color Res. Appl. 28(6), 425-435. DOI: 10.1002/col.10195

Kadla, J. F., and Gilbert, R. D. (2000). "Cellulose structure: A review," Cellulose Chem. Technol. 34(3-4), 197-216.

Kameshwar, A. K. S., and Qin, W. (2018). "Structural and functional properties of pectin and lignin-carbohydrate complexes de-esterases: A review," Bioresources and Bioprocessing, 5(43), 1-16, DOI: 10.1186/s40643-018-0230-8

Kantrowitz, M. S., and Simmons, R. H. (1934). "Rapid method for the determination of bleached an unbleached fibers in pulp and paper," Paper Trade J. 98(10), 46-48.

Karst, D., and Yang, Y. Q. (2005). "Using the solubility parameter to explain disperse dye sorption on polylactide," J. Appl. Polym. Sci. 96(2), 416-422. DOI: 10.1002/app.21456

Kasten, F. H. (1989). "The origins of modern fluorescent microscopy and fluorescent probes," in: Cell Structure and Function by Microspectrofluorometry, E. Kohen and J. G. Hirschberg (eds.), Academic Press, San Diego, CA. pp. 3-5. DOI: 10.1016/B978-0-12-417760-4.50008-2

Khatri, A., White, M., Padhye, R., and Momin, N. H. (2014). “The use of reflectance measurements in the determination of diffusion of reactive dyes into cellulosic fiber," Color Res. Appl. 39(1), 63-69. DOI: 10.1002/col.21764

Kikuchi, S., Ohinata, A., Tsumuraya, Y., Hashimoto, R., Kaneko, Y., and Matsushima, H. (1991). "Production and characterization of antibodies to the beta- $(1 \rightarrow 6)$ galactotetraosyl group and their interaction with arabinogalactan-proteins," Planta 190, 525-535.

Kim, S. H., Lee, C. M., and Kafle, K. (2013). "Characterization of crystalline cellulose in biomass: Basic principles, applications, and limitations of XRD, NMR, IR, Raman, and SFG," Korean J. Chem. Eng. 30(12), 2127-2141. DOI: 10.1007/s11814-0130162-0

Kim, Y., Kim, C., Choi, I., Rengraj, S., and Yi, J. (2004). "Characterisation of the porosity of regenerated cellulosic fibres using classical dye adsorption techniques," Environmental Science and Technology 38, 924-931. DOI: 10.1021/es0346431

Kitamura, Y., and Kyoshi, H. (1971). "Dyeing properties of wood. I. Dyeing properties of wood and wood components," Mokuzai Gakkaishi 17, 292-297.

Kitin, P., Funada, R., Sano, Y., and Ohtani, J. (2000). “Analysis by confocal microscopy of the structure of cambium in the hardwood Kalopanax pictus," Ann. Bot. 6, 11091117. DOI: 10.1006/anbo.2000.1281

Kitin, P., Voelker, S. L., Meinzer, F. C., Beeckman, H., Strauss, S. H., and Lachenbruch, B. (2010). "Tyloses and phenolic deposits in xylem vessels impede water transport in low-lignin transgenic poplars: A study by cryo-fluorescence microscopy," Plant Physiol. 154(2), 887-898. DOI: 10.1104/pp.110.156224

Klemm, P. (1923). Handbuch der Papierkunde, $3^{\text {rd }}$ Ed., Grieben, Leipzig.

Knebel, W., and Schnepf, E. (1991). "Confocal laser scanning microscopy of fluorescently stained wood cells - A new method for 3-dimensional imaging of xylem elements," Trees - Structure and Function 5(1), 1-4. DOI: 10.1007/BF00225328

Koch, G., and Kleist, G. (2001). "Application of scanning UV microspectrophotometry to localise lignins and phenolic extractives in plant cell walls," Holzforschung 55(6), 563-567. DOI: 10.1515/HF.2001.091 
Kohnke, T., Lund, K., Brelid, H., and Westman, G. (2010). "Kraft pulp hornification: A closer look at the preventive effect gained by glucuronoxylan adsorption," Carbohydr. Polym. 81(2), 226-233. DOI: 10.1016/j.carbpol.2010.02.023

Kolb, H. (1991). "Anatomical pathways for color-vision in the human retina," Visual Neurosci. 7(1-2), 61-74. DOI: 10.1017/S0952523800010944

Korn, R., and Burgstaller, F. (eds.) (1953). Papier- und Zellstoff Prüfung, $2^{\text {nd }}$ Ed., Springer, Berlin. DOI: 10.1007/978-3-662-21989-8

Kovarik, A., Ondrkalova, M., Prachar, J., and Stofko, J. (1992). "Rapid and sensitive colloidal silver staining on cellulose-acetate membranes," Clinica Chimica Acta 208, 137-139. DOI: 10.1016/0009-8981(92)90033-M

Krauter, D. (1974). Mikroskopie im Alltag: eine Einfüring in die angewandte Mikroscopie auf enfacher Grundlage, Kosmos, Stuttgart.

Kronberg, B. (2016). "The hydrophobic effect," Curr. Opin. Colloid Interface Sci. 22, 14-22. DOI: 10.1016/j.cocis.2016.02.001

Kubelka, P., and Munk, F. (1931). "A contribution to the optics of colorant layers," $Z$. tech. Physik 12 (11A), 593-601.

Kuga, S., Hieta, K., and Usada, M. (1983). "Electron staining of reducing ends on cellulose microfibrils," Int. Symp. Wood \& Pulping Chem. (Japan), May 23-27, 1983, Vol. 1, pp. 38-41.

Kutscha, N. P. and Gray, J. R. (1972). "The suitability of certain stains for studying lignification in balsam fir, Abies balsamea (L.) Mill.," Univ. Maine Technical Bulletin 53, Life Sciences and Agriculture Experiment Station, University of Maine, Orono, pp. 50.

Kvien, I., Tanem, B. S., and Oksman, K. (2005). "Characterization of cellulose whiskers and their nanocomposites by atomic force and electron microscopy," Biomacromol. 6(6), 3160-3165. DOI: 10.1021/bm050479t

Kwok, T. T., Fogg, D. N., Realff, M. J., and Bommarius, A. S. (2017). “Applying Direct Yellow 11 to a modified Simons' staining assay," Cellulose 24(6), 2367-2373. DOI: 10.1007/s10570-017-1269-y

Lai, S. S. (2002). "Stain test for the fiber blending ratio of a polyester/cellulose nonwoven," Textile Res. J. 72(6), 499-503. DOI: 10.1177/004051750207200606

Landells, G., and Whewell, C. S. (1955). "The preparation and properties of regenerated cellulose containing vinyl polymers. 2 . Staining, swelling, and stiffness characteristics," J. Soc. Dyers Colourists 71(4), 171-174. DOI: 10.1111/j.14784408.1955.tb02078.X

Langan, P., Nishiyama, Y., and Chanzy, H. (2001). "X-ray structure of mercerized cellulose II at 1 angstrom resolution," Biomacromol. 2(2), 410-416. DOI: $10.1021 / \mathrm{mb} 005612 \mathrm{q}$

Langan, P., Sukumar, N., Nishiyama, Y., and Chanzy, H. (2005). "Synchrotron X-ray structures of cellulose I-beta and regenerated cellulose II at ambient temperature and 100 K," Cellulose 12(6), 551-562. DOI: 10.1007/s10570-005-9006-3

Langmuir, I. (1918). "The adsorption of gases on plane surface of glass, mica and platinum," J. Am. Chem. Soc. 40, 1361-1403. DOI: 10.1021/ja02242a004

Lawoko, M. (2013). "Unveiling the structure and ultrastructure of lignin carbohydrate complexes in softwoods," Intl. J. Biol. Macromol. 62, 705-713. DOI: 10.1016/j.ijbiomac.2013.10.022 
Lawoko, M., Berggren, R., Berthold, F., Henriksson, G., and Gellerstedt, G. (2004).

"Changes in the lignincarbohydrate complex in softwood kraft pulp during kraft and oxygen delignification," Holzforschung 58(6), 603-610. DOI: 10.1515/HF.2004.114

Lawoko, M., Henriksson, G., and Gellerstedt, G. (2005). "Structural differences between the lignin-carbohydrate complexes present in wood and in chemical pulps,"

Biomacromol. 6(6), 3467-3473. DOI: 10.1021/bm058014q

Lee, H. N. (1916). "The staining of wood fibers for permanent microscopic mounts," Botanical Gazette 62(4), 318-319. DOI: 10.1086/331928

Leite, C., and Pereira, H. (2017). "Cork-containing barks - A review," Frontiers Mater. 3, article no. UNSP 63. DOI: 10.3389/fmats.2016.00063

Lewis, P. R., and Knight, D. P. (1992). Cytochemical Staining Methods for Electron Microscopy, Elsevier, Amsterdam, 321 pp.

Lewis, S. W. (2009). "Analysis of dyes using chromatography," in: Identification of Textile Fibers, M. M. Houck (ed.), CRC Press, Ch. 11, pp. 203-223. DOI: 10.1533/9781845695651.2.203

Li, J. B., and Gellerstedt, G. (1998). "On the structural significance of the kappa number measurement," Nordic Pulp Paper Res. J. 13(2), 153-158. DOI: 10.3183/NPPRJ1998-13-02-p153-158

Li, K. C., and Reeve, D. W. (2004). "Fluorescent labeling of lignin in the wood pulp fiber wall," J. Wood Chem. Technol. 24, 169-181. DOI: 10.1081/WCT-200026572

Li., T.-Q., Hendriksson, H., and Ödberg, L. (1993). "Determination of pore sizes in wood cellulose fibers by ${ }^{2} \mathrm{H}$ and ${ }^{1} \mathrm{H}$ NMR," Nordic Pulp Paper Res. J. 8(3), 326-330. DOI: 10.3183/NPPRJ-1993-08-03-p326-330

Liebert, T., Hansch, C., and Heinze, T. (2006). "Click chemistry with polysaccharides," Macromol. Rapid. Commun. 27(3), 208-213. DOI: 10.1002/marc.200500686

Lillie, R. D. (1977). HJ Conn's Biological Stains: A Handbook on the Nature and Uses of the Dyes Employed in the Biological Laboratory, Sigma Chemical Company, St. Louis.

Liu, Y., Gustafson, R., Callis, J., and McKean, W. (1999). "Microspectroscopic analysis and kappa determination of single pulp fibres stained with acridine orange," J. Pulp Paper Sci. 25(10), 351-355.

Loeb, L., Giuffria, R., Cochran, S., and Schuck, R. O. (1964). “Adaptation of Simon staining technique to the quantitative assessment of wear in cotton fabric," Textile Res. J. 34(7), 611-616. DOI: 10.1177/004051756403400708

Lofton, B. E., and Merritt, M. F. (1921). "Test for unbleached sulfite and sulfate fibers," Technologic Paper No. 189, U. S. Bureau of Standards.

Luna, E., Pastor, V., Robert, J., Flors, V., Mauch-Mani, B., and Ton, J. (2011). "Callose deposition: A multifaceted plant defense response," Molec. Plant-Microbe Interact. 24(2), 183-193. DOI: 10.1094/MPMI-07-10-0149

Luterbacher, J. S., Moran-Mirabal, J. M., Burkholder, E. W., and Walker, L. P. (2015a). "Modeling enzymatic hydrolysis of lignocellulosic substrates using confocal fluorescence microscopy. I: Filter paper cellulose,” Biotech. Bioeng. 112(1), 21-31. DOI: $10.1002 /$ bit.25329

Luterbacher, J. S., Moran-Mirabal, J. M., Burkholder, E. W., and Walker, L. P. (2015b). "Modeling enzymatic hydrolysis of lignocellulosic substrates using fluorescent confocal microscopy. II: Pretreated biomass," Biotech. Bioeng. 112(1), 32-42. DOI: 10.1002/bit.25328 
Luterbacher, J. S., Walker, L. P., and Moran-Mirabal, J. M. (2013). “Observing and modeling BMCC degradation by commercial cellulase cocktails with fluorescently labeled Trichoderma reesei Cel7A through confocal microscopy," Biotech. Bioeng. 110(1), 108-117. DOI: 10.1002/bit.24597

Lux, A., Morita, S., Abe, J., and Ito, K. (2005). "An improved method for clearing and staining free-hand sections and whole-mount samples," Annals of Botany 96, 989996. DOI: $10.1093 / \mathrm{aob} / \mathrm{mci} 266$

Macrae, R., Dudley, R. J., and Smalldon, K. W. (1979). "Characterization of dyestuffs on wool fibers with special reference to microspectrophotometry," J. Forensic Sci. 24(1), 117-129.

Maekawa, M., Udaka, M., Sasaki, M., Tujii, Y., Yoshida, H., Kataoka, T., and Nango, M. (1989). "Diffusion mechanism of direct dyes into a cellulose membrane - The structural effect of direct dyes on the adsorption rate," J. Appl. Polymer Sci. 37(8), 2141-2152. DOI: 10.1002/app.1989.070370806

Mahapatra, N. N. (2016). Textile Dyes, CRC Press, Boca Raton, FL.

Marsh, J. T. (1942). Mercerising, D. van Norstrand, New York, NY, pp. 458.

Massonnet, G., Buzzini, P., Monard, F., Jochem, G., Fido, L., Bell, S., Stauber, M., Coyle, T., Roux, C., Hemmings, J., Leijenhorst, H., Van Zanten, Z., Wiggins, K., Smith, C., Chabli, S., Sauneuf, T., Rosengarten, A., Meile, C., Ketterer, S., and Blumer, A. (2012). "Raman spectroscopy and microspectrophotometry of reactive dyes on cotton fibres: Analysis and detection limits," Forensic Sci. Intl. 222, 200-207. DOI: 10.1016/j.forsciint.2012.05.025

Mathews, J., Gustafson, R., and Hodgson, K. (2004). "A method to determine the charge demand of single pulp fibers," Nordic Pulp Paper Res. J. 19(4), 453-459. DOI: 10.3183/NPPRJ-2004-19-04-p453-459

Matsumura, J., Booker, R. E., Donaldson, L. A., and Ridoutt, B. G. (1998). "Impregnation of radiata pine wood by vacuum treatment: Identification of flow paths using fluorescent dye and confocal microscopy," IAWA J. 19(1), 25-33. DOI: $10.1163 / 22941932-90000649$

Maurer, A., and Fengel, D. (1990). "A new process for improving the quality and lignin staining of ultrathin sections from wood tissue," Holzforschung 44(6), 453-460. DOI: 10.1515/hfsg.1990.44.6.453

McCartney, L., Blake, W. A., Flint, J., Bolam, D. N., Boraston, A. B., Gilbert, H. J., and Knox, J. P. (2006). "Differential recognition of plant cell walls by microbial xylanspecific carbohydrate-binding modules," Proc. Nat. Acad. Sci. 103(12), 4765-4770. DOI: 10.1073/pnas.0508887103

McDonough, T. J. (1993). "The chemistry of organosolv delignification," TAPPI J. 76(8), 186-193.

McKay, G., and Ho, Y. S. (1999). "Pseudo-second order model for sorption processes," Process. Biochem. 34, 451-465. DOI: 10.1016/S0032-9592(98)00112-5

McNeal, M. R., Nanko, H., and Hubbe, M. A. (2005). "Imaging of macromolecular events occurring during the manufacture of paper," Proc. $13^{\text {th }}$ Fundamental Research Symposium, Cambridge, UK, pp. 1225-1267.

Meng, X. Z., Foston, M., Leisen, J., DeMartini, J., Wyman, C. E., and Ragauskas, A. J. (2013). "Determination of porosity of lignocellulosic biomass before and after pretreatment by using Simons' stain and NMR techniques," Bioresour. Technol. 144, 457-476. DOI: 10.1016/j.biortech.2013.06.091 
Minick, M., Fotta, K., and Khan, A. (1991). "Polyiodine units in starch iodine complex INDO CI study of spectra and comparison with experiments," Biopolym. 31(1), 5763. DOI: 10.1002/bip.360310106

Mitra, P. P., and Loque, D. (2014). "Histochemical staining of Arabidopsis thaliana secondary cell wall elements," Jove - J. Visualized Exper. 87, article e51381. DOI: $10.3791 / 51381$

Mlynar, M. (1999). "Qualitative evaluation of nonwoven samples using Du Pont fiber Identification Stain No 4 and microscopy," TAPPI Nonwovens Conf., Proc., New Orleans, TAPPI Press, Atlanta, GA, pp. 243-247.

Molenaar, R., ten Bosch, J. J., and Zijp, J. R. (1999). "Determination of Kubelka-Munk scattering and absorption coefficients by diffuse illumination," Appl. Optics 38(10), 2068-2077. DOI: 10.1364/AO.38.002068

Mori, B., and Bellani, L. M. (1996). "Differential staining for cellulosic and modified plant cell walls," Biotech. Histochem. 71(2), 71-72. DOI: 10.3109/10520299609117136

Moser, C., Henriksson, G., and Lindstrom, M. E. (2016). "Specific surface area increase during cellulose nanofiber manufacturing related to energy input," BioResources 11(3), 7124-7132. DOI: 10.15376/biores.11.3.7124-7132

Mou, H. Y., Wu, S. B., and Fardim, P. (2016). "Applications of ToF-SIMS in surface chemistry analysis of lignocellulosic biomass: A review," BioResources 11(2), 55815599. DOI: 10.15376/biores.11.2.

Moulay, S. (2013). "Molecular iodine/polymer complexes," J. Polym. Eng. 33(5), 389443. DOI: $10.1515 /$ polyeng-2012-0122

Navarro, J. R. G., and Bergstrom, L. (2014). "Labelling of N-hydroxysuccinimidemodified rhodamine B on cellulose nanofibrils by the amidation reaction," $R S C$ Advan. 4(105), 60757-60761. DOI: 10.1039/c4ra06559j

Navarro, J. R. G., Conzatti, G., Yu, Y., Fall, A. B., Mathew, R., Eden, M., and Bergstrom, L. (2015). "Multicolor fluorescent labeling of cellulose nanofibrils by click chemistry,” Biomacromol. 16(4), 1293-1300. DOI: 10.1021/acs.biomac.5b00083

Neumann, P. M., Weissman, R., Stefano, G., and Mancuso, S. (2010). "Accumulation of xylem transported protein at pit membranes and associated reductions in hydraulic conductance," J. Exper. Bot. 61(6), 1711-1717. DOI: 10.1093/jxb/erq037

Niemelä, K. (1989). "Conversion of xylan, starch, and chitin into carboxylic acids by treatment with alkali," Carbohydr. Res. 204, 37-49. DOI: 10.1016/00086215(90)84019-Q

Nowak, K., Luniak, N., Meyer, S., Schulze, J., Mendel, R. R., and Hansch, R. (2004). "Fluorescent proteins in poplar: A useful tool to study promoter function and protein localization," Plant Biol. 6(1), 65-73. DOI: 10.1055/s-2004-815730

O'Brien, T. P., Feder, N., and McCully, M. E. (1964). "Polychromatic staining of plant cell walls by toluidine blue 0," Protoplasma 59(2), 368-373. DOI: 10.1007/BF01248568

O'Brien, T. P., and McCully, M. E. (1981). The Study of Plant Structure. Principles and Selected Methods, Thermacarphi Pty. Ltd, Melbourne, Australia, pp. 357.

Olmstead, J. A., and Gray, D. G. (1997). "Fluorescence spectroscopy of cellulose, lignin and mechanical pulps: A review," J. Pulp Paper Sci. 23(12), 571-581. 
Oparka, K. J., Duckett, C. M., Prior, D. A. M., and Fisher, D. B. (1994). "Real-time imaging of phloem unloading in the root-tip of Arabidopsis," Plant J. 6(5), 759-766. DOI: 10.1046/j.1365-313X.1994.6050759.x

Orelma, H., Filpponen, I., Johansson, L. S., Osterberg, M., Rojas, O. J., and Laine, J. (2012). "Surface functionalized nanofibrillar cellulose (NFC) film as a platform for immunoassays and diagnostics," Biointerphases 7, article no. 61. DOI: 10.1007/s13758-012-0061-7

Ougiya, H., Hioki, N, Watanabe, K., Morinaga, Y, Yoshinaga, F., and Samejima, M. (1998). "Relationship between the physical properties and surface area of cellulose derived from adsorbates of various molecular sizes," Biosci. Biotechnol. Biochem. 62, 1880-1884. DOI: $10.1271 /$ bbb.62.1880

Ozaki, Y., Bousfield, D. W., and Shaler, S. M. (2006). "Three-dimensional observation of coated paper by confocal laser scanning microscope," TAPPI J. 5(2), 3-8.

Paes, G., Habrant, A., Ossemond, J., and Chabbert, B. (2017). "Exploring accessibility of pretreated poplar cell walls by measuring dynamics of fluorescent probes," Biotech. Biofuels 10, article no. 15. DOI: 10.1186/s13068-017-0704-5

Pandey, J. L., Kiemle, S. N., Richard, T. L., Zhu, Y. M., Cosgrove, D. J., and Anderson, C. T. (2016). "Investigating biochemical and developmental dependencies of lignification with a click-compatible monolignol analog in Arabidopsis thaliana stems," Frontiers Plant Sci. 7, article no. 1309. DOI: 10.3389/fpls.2016.01309

Pandey, J. L., Wang, B., Diehl, B. G., Richard, T. L., Chen, G., and Anderson, C. T. (2015). "A versatile click-compatible monolignol probe to study lignin deposition in plant cell walls," Plos One 10(4), article no. e0121334. DOI:

10.1371/journal.pone.0121334

Paredez, A. R., Somerville, C. R., and Ehrhardt, D. W. (2006). "Visualization of cellulose synthase demonstrates functional association with microtubules," Science 312(5779), 1491-1495. DOI: 10.1126/science.1126551

Parham, R. A., and Gray, R. L. (1982). The Practical Identification of Wood Pulp Fibers, TAPPI Press, Atlanta, GA.

Park, B. D., Wi, S. G., Lee, K. H., Singh, A. P., Yoon, T. H., and Kim, Y. S. (2003). "Characterization of anatomical features and silica distribution in rice husk using microscopic and micro-analytical techniques," Biomass Bioenergy 25(3), 319-327. DOI: 10.1016/S0961-9534(03)00014-X

Park, S., Venditti, R. A., Jameel, H., and Pawlak, J. J. (2006). "Changes in pore size distribution during the drying of cellulose fibers as measured by differential scanning calorimetry," Carbohydr. Polym. 66(1), 97-103. DOI: 10.1016/j.carbpol.2006.02.026

Patel, S. K., and Varghese, J. (1983). "Preparatory treatments and their influence on dyeing of cotton - A review. 2. Mercerization and liquid-ammonia treatment," Colourage 30(5), 3-12.

Pearl, I. A. (1967). The Chemistry of Lignin, Dekker, New York, NY, pp. 339.

Pearce, R. B. (1986). "Chlorantine fast green-BLL as a stain for callose in oak phloem," Stain Technol. 61(1), 47-50. DOI: 10.3109/10520298609110705

Pereira, H. (2015). "The rationale behind cork properties: A review of structure and chemistry," BioResources 10(3), 6207-6229. DOI: 10.15376/biores.10.3.Pereira

Peters, R. H., and Ingamells, W. (1973). "Theoretical aspects of role of fiber structure in dyeing," Journal of the Society of Dyers and Colourists, 89, 397-405. DOI: 10.1111/j.1478-4408.1973.tb03109.x 
Peters, R. H., and Vickerstaff, T. (1948). "The adsorption of direct dyes on cellulose," Proc. Royal Soc. London, Ser. A - Math. Phys. Sci. 192(1029), 292-308.

Proksch, A., and Keser, D. (1970). "Paper and board testing practice no. 24: Fibermicroscopic differentiation according to pulping process and raw material (qualitative and quantitative)," Allgemeine Papier-Rundschau 3, 90-92.

Ramming, D. W., Hinrichs, H. A., and Richardson, P. E (1973). "Sequential staining of callose by aniline blue and lacmoid for fluorescence and regular microscopy on a durable preparation of the same specimen," Stain Technol. 48, 133-134. DOI: $10.3109 / 10520297309116601$

Ratee, I. D. (1974). "Dye-cellulose binding mechanism," Textile Res. J. 44(9), 728-730.

Righetti, P. G., Casero, P., and Delcampo, G. B. (1986). "Gold staining in celluloseacetate membranes," Clinica Chimica Acta 157(2), 167-174. DOI: 10.1016/00098981(86)90222-6

Robards, A. W., and Purvis, M. J. (1964). "Chlorazol Black E as stain for tension wood," Stain Technol. 39(5), 309-315. DOI: 10.3109/10520296409061249

Roberts, M. B. V., and King, T. J. (1987). Biology: A Functional Approach. Student's Manual, Nelson, Walton-on-Thames.

Ruzin, S. E. (1999). Plant Microtechnique and Microscopy, Oxford University Press, New York, NY, pp. 322.

Safa, Y., and Bhatti, H. N. (2010). "Factors affecting biosorption of direct dyes from aqueous solution," Asian J. Chem. 22(9), 6625-6639.

Sakakibara, A. (1980). "A structural model of softwood lignin,” Wood Sci. Technol. 14(2), 89-100. DOI: 10.1007/BF00584038

Sales, F. G., Maranhao, L. C. A., Lima Filho, N. M, and Abreu, C. A. M. (2006). "Kinetic evaluation and modeling of lignin catalytic wet oxidation to selective production of aromatic aldehydes," Indust. Eng. Chem. Res. 45(20), 6627-6631. DOI: 10.1021/ie0601697

SanchezRuiz, J. M. (1996). "Molecular-size corrections to the strength of the hydrophobic effect: A critical review," Eur. Biophys. J. Biophys. Lett. 24(4), 261-274.

Sass, J. E. (1958). Botanical Microtechnique, $3^{\text {rd }}$ Ed., Iowa State University Press, Ames, IA, pp. 228.

Schmidt, J. A., and Heitner, C. (1993). "Use of UV visible diffuse reflectance spectroscopy for chromophore research on wood fibers - A review," TAPPI J. 76(2), 117-123.

Schneider, H. (1960). "Sectioning and staining pathological phloem," Stain Technol. 35(3), 123-127. DOI: 10.3109/10520296009114727

Schuerch, C. (1952). "The solvent properties of liquids and their relation to the solubility, swelling, isolation and fractionation of lignin," J. Amer. Chem. Soc. 74(20), 50615067. DOI: 10.1021/ja01140a020

Scott, J. E. (1972), "Lies. damned lies - and biological stains," Histochem. 1(4), 387-389. DOI: $10.1007 / \mathrm{BF} 01012529$

Sebela, M., Luhova, L., Brauner, F., Galuszka, P., Radova, A., and Pec, P. (2001). "Light microscopic localisation of aminoaldehyde dehydrogenase activity in plant tissues using nitroblue tetrazolium-based staining method," Plant Physiol. Biochem. 39(10), 831-839. DOI: 10.1016/S0981-9428(01)01304-3

Seibert, G. R., Benjaminson, M. A., and Hoffman, H. (1978). "Conjugate of cellulase with fluorescein isothiocyanate-specific stain for cellulose," Stain Technol. 53(2), 103-106. DOI: 10.3109/10520297809111450 
Sevastyanova, O., Li, J. B., and Gellerstedt, G. (2006). "Influence of various oxidizable structures on the brightness stability of fully bleached chemical pulps," Nordic Pulp Paper Res. J. 21(1), 49-53. DOI: 10.3183/NPPRJ-2006-21-01-p049-053

Shi, B. Y., Li, G. H., Wang, D. S., Feng, C. H., and Tang, H. X. (2007). "Removal of direct dyes by coagulation: The performance of preformed polymeric aluminum species," J. Hazard. Mater. 143(1-2), 567-574. DOI: 10.1016/j.jhazmat.2006.09.076

Shi, J. L., and Li, T. (2013). "Technical investigation of $15^{\text {th }}$ and $19^{\text {th }}$ century Chinese paper currencies: Fiber use and pigment identification," J. Raman Spectros. 44(6), 892-898. DOI: $10.1002 /$ jrs.4297

Simons, F. L. (1950). “A stain for use in the microscopy of beaten fibers," Tappi J. 33, 312-314.

Sindall, R. W. (1906). Paper Technology: An Elementary Manual on the Manufacture, Physical Qualities and Chemical Constituents of Paper and Paper-making Fibers, Charles Griffin and Company, London.

Singer, M. (1952). "Factors which control the staining of tissue sections with acid and basic dyes," Intl. Rev. Cytolog. A Survey Cell Biol. 1, 211-255. DOI: 10.1016/S00747696(08)60012-1

Sjöström, E. (1993). Wood Chemistry: Fundamentals and Applications, $2^{\text {nd }}$ Ed., Academic Press, San Diego, CA, pp. 293.

Smith, G. S. (2005). "Human color vision and the unsaturated blue color of the daytime sky," Amer. J. Phys. 73(7), 590-597. DOI: 10.1119/1.1858479

Smith, M. M., and McCully, M. E. (1978). "A critical evaluation of the specificity of aniline blue induced fluorescence," Protoplasma 95, 229-254. DOI: 10.1007/BF01294453

Son, Y. A., Hong, J. P., and Kim, T. K. (2004). "An approach to the dyeing of polyester fiber using indigo and its extended wash fastness properties," Dyes Pigments 61(3), 263-272. DOI: 10.1016/j.dyepig.2003.11.001

Soukup, A. (2014). "Selected simple methods of plant cell wall histochemistry and staining for light microscopy," in: Plant Cell Morphogenesis: Methods and Protocols, Book ser.: Methods in Molecular Biology, Vol. 1080, Ch. 2, pp. 25-40. DOI: 10.1007/978-1-62703-643-6_2

Speranza, M., Martinez, M. J., Gutierrez, A., del Rio, J. C., and Martinez, A. T. (2002). "Eucalypt wood and pulp localization of sterols involved in pitch deposition using filipin fluorescent staining," J. Pulp Paper Sci. 28(9), 292-297.

Srebotnik, E., and Messner, K. (1994). "A simple method that uses differential staining and light-microscopy to assess the selectivity of wood delignification by white-rot fungi," Appl. Environ. Microbiol. 60(4), 1383-1386.

Stein, B. D., Klomparens, K. L., and Hammerschmidt, R. (1992). "Comparison of bromine and permanganate as ultrastructural stains for lignin in plants infected by the fungus Colletotrichum lagenarium," Microscopy Res. Techn. 23(3), 201-206. DOI: 10.1002/jemt.1070230302

Stockert, J. C., Canete, M., and Colman, O. D. (1984). "Histological mechanism for the orthochromatic staining and fluorescence reaction of lignified tissues," Cell. Mol. Biol. 30, 503-508.

Stone, J. E., and Scallan, A. M. (1966). "Influence of drying on the pore structures of the cell wall," in: Consolidation of the Paper Web, Trans. Symp. Cambridge, Sept. 1965, F. Bolam (ed.), Tech. Sec. British Paper and Board Makers' Assoc. Inc, London, Vol. $1,145-174$. 
Stone, J. E., and Scallan, A. M. (1968). "A structural model for the cell wall of waterswollen wood pulp fibers based on their accessibility to macromolecules," Cellulose Chem. Technol. 2(3), 343-358.

Strassburger, E., and Koernicke, M. W. (1923). Das botanische Praktikum, Anleitung zum Selbststudium der mikroskopischen Botanik für Anfänger und Geübtere, zugleich ein Handbuch der mikroskopischen Technik, G. Fischer, Jena. DOI: 10.5962/bhl.title. 18420

Suess, H. U. (2010). Pulp Bleaching Today, De Gruyter, New York, NY, pp. 310. DOI: $10.1515 / 9783110218244$

Sutermeister, E. (1920). Chemistry of Pulp and Papermaking, John Wiley, New York, NY.

Svensson, P. H., and Kloo, L. (2003). "Synthesis, structure, and bonding in polyiodide and metal iodide-iodine systems," Chem. Rev. 103(5), 1649-1684. DOI: $10.1021 / \mathrm{cr} 0204101$

Swanson, M. A. (1948). "Studies on the structure of polysaccharides. 4. Relation of the iodine color to the structure," J. Biol. Chem. 172(2), 825-837.

Swofford, R. L., Long, M. E., and Albrecht, A. C. (1976). "C-H vibrational-states of benzene, naphthalene, and anthracene in visible region by thermal lensing spectroscopy and local mode model," J. Chem. Phys. 65(1), 179-190. DOI: $10.1063 / 1.432815$

Szewczyk, B. (1983). "A sensitive staining method for detecting acidic polysaccharides in cellulose-acetate and agarose gels," Anal. Biochem. 130(1), 60-64. DOI: 10.1016/0003-2697(83)90649-8

TAPPI (1988). "Fiber analysis of paper and paperboard," TAPPI Test Method T 401 om88, pp. 12.

Tarbuk, A., Grancaric, A. M., and Leskovac, M. (2014). "Novel cotton cellulose by cationisation during the mercerisation process-part 1: Chemical and morphological changes," Cellulose 21(3), 2167-2179. DOI: 10.1007/s10570-014-0245-z

Tardif, J. C., and Conciatori, F. (2015). "Microscopic examination of wood: Sample preparation and techniques for light microscopy," in: Plant Microtechniques and Protocols, E. C. T. Yeung, C. Stasolla, M. J. Sumner, and B. Q. Huang (eds.), Springer International Publishing, Switzerland, pp. 373-415.

Thomaneck, U., Vienken, J., Waldschlager, U., Diamantoglou, M., Schutt, W., Falkenhagen, D., and Klinkmann, H. (1991). "Detection of charges and their distribution on dialysis membranes with cationic anionic dyes using confocal laser scanning microscopy," Intl. J. Artific. Organs 14(11), 686-690. DOI: $10.1177 / 039139889101401102$

Thomas, J., Idris, N. A., and Collings, D. A. (2017). "Pontamine fast scarlet 4B bifluorescence and measurements of cellulose microfibril angles," J. Microsc. 268(1), 13-27. DOI: $10.1111 /$ jmi.12582

Togo, H., and Iida, S. (2006). "Synthetic use of molecular iodine for organic synthesis," Synlett 14, 2159-2175. DOI: 10.1055/s-2006-950405

Tolivia, D., and Tolivia, J. (1987). "Fasga: A new polychromatic method for simultaneous and differential staining of plant tissues," J. Microsc. 148, 113-117. DOI: 10.1111/j.1365-2818.1987.tb02859.x

Truernit, E., Bauby, H., Dubreucq, B., Grandjean, O., Runions, J., Barthelemy, J., and Palauqui, J. C. (2008). "High-resolution whole-mount imaging of three-dimensional tissue organization and gene expression enables the study of phloem development and 
structure in Arabidopsis," Plant Cell 20(6), 1494-1503. DOI:

10.1105/tpc.107.056069

Ulrychova, M., Petru, E., and Pazourkova, Z. (1976). "Permanent staining of callose in plant material by ponceau S," Stain Technol. 51, 272-275. DOI:

$10.3109 / 10520297609116718$

Ursache, R., Andersen, T. G., Marhavy, P., and Geldner, N. (2018). "A protocol for combining fluorescent proteins with histological stains for diverse cell wall components," Plant J. 93(2), 399-412. DOI: 10.1111/tpj.13784

van de Ven, T. G. M., Saint-Cyr, K., and Allix, M. (2007). "Adsorption of toluidine blue on pulp fibers," Colloids Surf. A - Physicochem. Eng. Aspects 294(1-3), 1-7. DOI: 10.1016/j.colsurfa.2006.07.040

van Velzen, S. T. J. (2018). The Universe Between Felt and Wire. A New Look into the Typology of Western Made Paper, Ph.D. Dissertation, Amsterdam School of Historical Studies, The Netherlands.

Varriano-Marston, E., and Cheeseman, H. (1986). "8-Hydroxyquinoline as a stain for determining the distribution of alum in paper," TAPPI J. 69(6), 116-117.

Vaughn, S. F., and Lulai, E. C. (1991). "Suberin stains comparison of fluorescent stains for the detection of suberin in potato periderm," Amer. Potato J. 68(10), 667-674.

DOI: $10.1007 / \mathrm{BF} 02853742$

Vazquez-Cooz, I., and Meyer, R. W. (2002). "A differential staining method to identify lignified and unlignified tissues," Biotechnic Histochem. 77(5-6), 277-282. DOI: $10.1080 / 714028215$

Venkataraman, K. (1952). The Chemistry of Synthetic Dyes, Academic Press, New York, NY.

Verbelen, J. P., and Kerstens, S. (2000). "Polarization confocal microscopy and Congo Red fluorescence: A simple and rapid method to determine the mean cellulose fibril orientation in plants," J. Microsc. - Oxford 198, 101-107. DOI: 10.1046/j.13652818.2000.00691.x

Verhertbruggen, Y., Walker, J. L., Guillon, F., and Scheller, H. V. (2017). “A comparative study of sample preparation for staining and immunodetection of plant cell walls by light microscopy," Frontiers in Plant Science 8, article 1505. DOI: 10.3389/fpls.2017.01505

Vétillart, M. (1876). Études sur les Libres Végétales Textiles Employées dans l'Industrie, Firmin Didot et Cie, Paris.

Vishwanath, S. J., Delude, C., Domergue, F., and Rowland, O. (2015). "Suberin: Biosynthesis, regulation, and polymer assembly of a protective extracellular barrier," Plant Cell Reports 34(4), 573-586. DOI: 10.1007/s00299-014-1727-z

Von Arx, G., Crivellaro, A., Prendin, A. L., Čufar, K., and Carrer, M. (2016). "Quantitative wood anatomy - Practical guidelines," Frontiers in Plant Science 7, article 781.

Walstra, P. (1993). "Principles of emulsion formation," Chem. Eng. Sci. 48(2), 333-349. DOI: 10.1016/0009-2509(93)80021-H

Weber, W. J., and Morris, J. C. (1963). "Equilibrium and capacities for adsorption on carbon,” J. Sanit. Eng. Div. ASCE 89, 31-59.

Weise, U. (1998). "Hornification - Mechanisms and terminology," Paperi Puи 80(2), 110-115.

Weise, U. and Paulapuro, H. (1999). "Effect of drying and rewetting cycles on fiber swelling," J. Pulp Paper Sci. 25(5), 163-166. 
Whipple, W. L., and Maltesh, C. (2000). "Visualizing flocculation and adsorption processes in papermaking using fluorescence microscopy," Langmuir 16(7), 31243132. DOI: 10.1021/la991076f

Wick, H. L. (1970). Lignin Staining - A Limited Success in Identifying Kao Growth Rings, US Dept. Agriculture, Forest Service, Pacific Southwest Forest and Range Experiment Station, Berkeley, CA.

Willats, W. G. T., Steele-King, C. G., McCartney, L., Orfila, C., Marcus, S. E., and Knox, J. P. (2000). "Making and using antibody probes to study plant cell walls," Plant Physiol. \& Biochem. 38, 27-36. DOI: 10.1016/S0981-9428(00)00170-4

Williams, A. G. (1983). "Staining reactions for the detection of hemicellulose-degrading bacteria," FEMS Microbiol Let. 20(2), 253-258. DOI: 10.1111/j.15746968.1983.tb00127.x

Willis, H. F., Warwicker, J. O., Standing, H. A., and Urquhart, A. R. (1945). "The dyeing of cellulose with direct dyes. 2. The absorption of chrysophenine by cellulose sheet," Trans. Faraday Soc. 41(8-9), 506-541. DOI: 10.1039/tf9454100506

Woo, J. Y. (1970). Techniques for Sectioning and Staining Tissue Cultures of Western White Pine, US Dept. Agriculture, Forest Service, Intermountain Forest \& Range Experiment Station, Ogden, UT.

Wood, P. J. (1980). "Specificity in the interaction of direct dyes with polysaccharides," Carbohydr. Res. 85, 271-287. DOI: 10.1016/S0008-6215(00)84676-5

Woodings, C. (ed.) (2001). Regenerated Cellulose Fibres, CRC Press, Boca Raton, FL, pp. 336. DOI: $10.1533 / 9781855737587$

Woodward, J. H. (2002). "Stain for the determination of paper components and paper defects," Microscs. Microanal. 8(2), 196-197. DOI 10.1017.S1431927602102303

Wu, G. X., Heitz, M, and Chornet, E. (1994). "Improved alkaline oxidation process for the production of aldehydes (vanillin and syringaldehyde) from steam-explosion hardwood lignin," Indust. Eng. Chem. Res. 33(3), 718-723. DOI: 10.1021/ie00027a034

Wu, N., Hubbe, M. A., Rojas, O. J., and Park, S. (2009). "Permeation of polyelectrolytes and other solutes into the pore spaces of water-swollen cellulose: A review," BioResources 4(3), 1222-1262. DOI: 10.15376/biores.4.3.1222-1262

Xiao, Y., Kreber, B., and Breuil, C. (1999). "Localisation of fungal hyphae in wood using immunofluorescence labelling and confocal laser scanning microscopy," Intl. Biodeter. Biodegrad. 44(4), 185-190. DOI: 10.1016/S0964-8305(99)00076-1

Yamagishi, Y., and Oye, R. (1981). "Influence of recycling on wood pulp fibers Changes in properties of wood pulp fibers with recycling," Japan Tappi J. 35(9), 787797. DOI: $10.2524 /$ jtappij.35.787

Yamane, C., Aoyagi, T., Ago, M., Sato, K., Okajima, K., and Takahashi, T. (2006). "Two different surface properties of regenerated cellulose due to structural anisotropy," Polymer J. 38(8), 819-826. DOI: 10.1295/polymj.PJ2005187

Yang, D., Moran-Mirabal, J. M., Parlange, J. Y., and Walker, L. P. (2013). "Investigation of the porous structure of cellulosic substrates through confocal laser scanning microscopy," Biotech. Bioeng. 110(11), 2836-2845. DOI: 10.1002/bit.24958

Yang, Q. A., and Pan, X. J. (2010). "A facile approach for fabricating fluorescent cellulose," J. Appl. Polym. Sci. 117(6), 3639-3644. DOI: 10.1002/app.32287

Yang, Y. Y., Wang, G. A., Wang, B., Li, Z. L., Jia, X. M., Zhou, Q. F., and Zhao, Y. H. (2011). "Biosorption of Acid Black 172 and Congo Red from aqueous solution by nonviable Penicillium YW 01: Kinetic study, equilibrium isotherm and artificial 
neural network modeling," Bioresour. Technol. 102(2), 828-834. DOI:

10.1016/j.biortech.2010.08.12533

Yasuma, A., and Itchikawa, T. (1953). "Ninhydrin-Schiff and alloxan-Schiff staining. A new histochemical staining method for protein," J. Lab.Clin.Med., 41, 296-299.

Yu, X. C., and Atalla, R. H. (1998). "A staining technique for evaluating the pore structure variations of microcrystalline cellulose powders," Powder Technol. 98(2), 135-138. DOI: 10.1016/S0032-5910(98)00024-2

Yu, X., Minor, J. L, and Atalla, R. H. (1995). "Mechanism of action of Simons' stain," Tappi J. 78(6), 175-180.

Zelko, I., Lux, A., Sterckeman, T., Martinka, M., Kollarova, K., and Liskova, D. (2012). "An easy method for cutting and fluorescent staining of thin roots," Ann. Botany 1100(2), 475-478. DOI: 10.1093/aob/mcs046

Zhang, Y., Legay, S., Barriere, Y., Mechin, V., and Legland, D. (2013). “Color quantification of stained maize stem section describes lignin spatial distribution within the whole stem," J. Agric. Food Chem. 61(13), 3186-3192. DOI: $10.1021 / \mathrm{jf} 400912 \mathrm{~s}$

Zollinger, H. (1991). Color Chemistry: Synthesis, Properties, and Applications of Organic Dyes and Pigments, $2^{\text {nd }}$ Ed., Weinheim, New York, NY, pp. 496. 


\section{APPENDIX}

This appendix contains two tables. Table A lists key information about dye compounds that are widely used for the analytical staining of materials related to lignocellulose. Table B provides information about some of the most-used staining procedures.

Table A. Widely Used Analytical Stains for Cellulosic Materials

\begin{tabular}{|c|c|c|c|c|}
\hline $\begin{array}{l}\text { Dye name and } \\
\text { the class of } \\
\text { dye }\end{array}$ & Molecular structure and approximate color & $\begin{array}{l}\text { Lignocellulose } \\
\text { component } \\
\text { stained }\end{array}$ & Important details & $\begin{array}{l}\text { Selected } \\
\text { citations }\end{array}$ \\
\hline $\begin{array}{l}\text { Acid fuchsin } \\
\text { Acid dye }\end{array}$ & & Water & $\begin{array}{l}\text { The dye was used to } \\
\text { reveal water-filled } \\
\text { passages. In such an } \\
\text { application, high water } \\
\text { solubility and low affinity } \\
\text { for surfaces can be an } \\
\text { advantage. }\end{array}$ & $\begin{array}{l}\text { Kitin et al. } \\
2010\end{array}$ \\
\hline $\begin{array}{l}\text { Acridine orange } \\
\text { Basic dye }\end{array}$ & & Lignin & $\begin{array}{l}\text { The fluorescence } \\
\text { intensity of stained pulp } \\
\text { was correlated to the } \\
\text { lignin content. }\end{array}$ & $\begin{array}{l}\text { Li \& Reeve } \\
2004\end{array}$ \\
\hline $\begin{array}{l}\text { Alcian blue, } \\
\text { Basic }\end{array}$ & & Cellulose & $\begin{array}{l}\text { Staining of plant cell } \\
\text { walls. }\end{array}$ & Benes 1968 \\
\hline
\end{tabular}




\begin{tabular}{|c|c|c|c|c|}
\hline Analine blue & & Cell walls & $\begin{array}{l}\text { Used in two-step } \\
\text { treatment after staining } \\
\text { with safranin, rinsing, } \\
\text { then treatment with a } \\
\text { solution of picric acid an } \\
\text { ananline blue. }\end{array}$ & $\begin{array}{l}\text { Strassburger } \\
\text { \& Koernicke } \\
\text { 1923; } \\
\text { Cartwright } \\
\text { 1929; } \\
\text { Ramming et } \\
\text { al. } 1973\end{array}$ \\
\hline Anilinium sulfate & & $\begin{array}{l}\text { Mechanical } \\
\text { pulp }\end{array}$ & $\begin{array}{l}\text { Used to indicate } \\
\text { mechanical pulp fibers, } \\
\text { which stain deeply. }\end{array}$ & $\begin{array}{l}\text { Herzberg } \\
1902\end{array}$ \\
\hline Astra blue FM & & $\begin{array}{l}\text { Cellulose in the } \\
\text { absence of } \\
\text { lignin }\end{array}$ & & $\begin{array}{l}\text { Srebotnik \& } \\
\text { Messner } 1994\end{array}$ \\
\hline Auramine $\mathrm{O}$ & $\mathrm{HCl}$ & $\begin{array}{l}\text { Unsaturated } \\
\text { waxes }\end{array}$ & Fluorescent & $\begin{array}{l}\text { Ursache et al. } \\
2018\end{array}$ \\
\hline
\end{tabular}




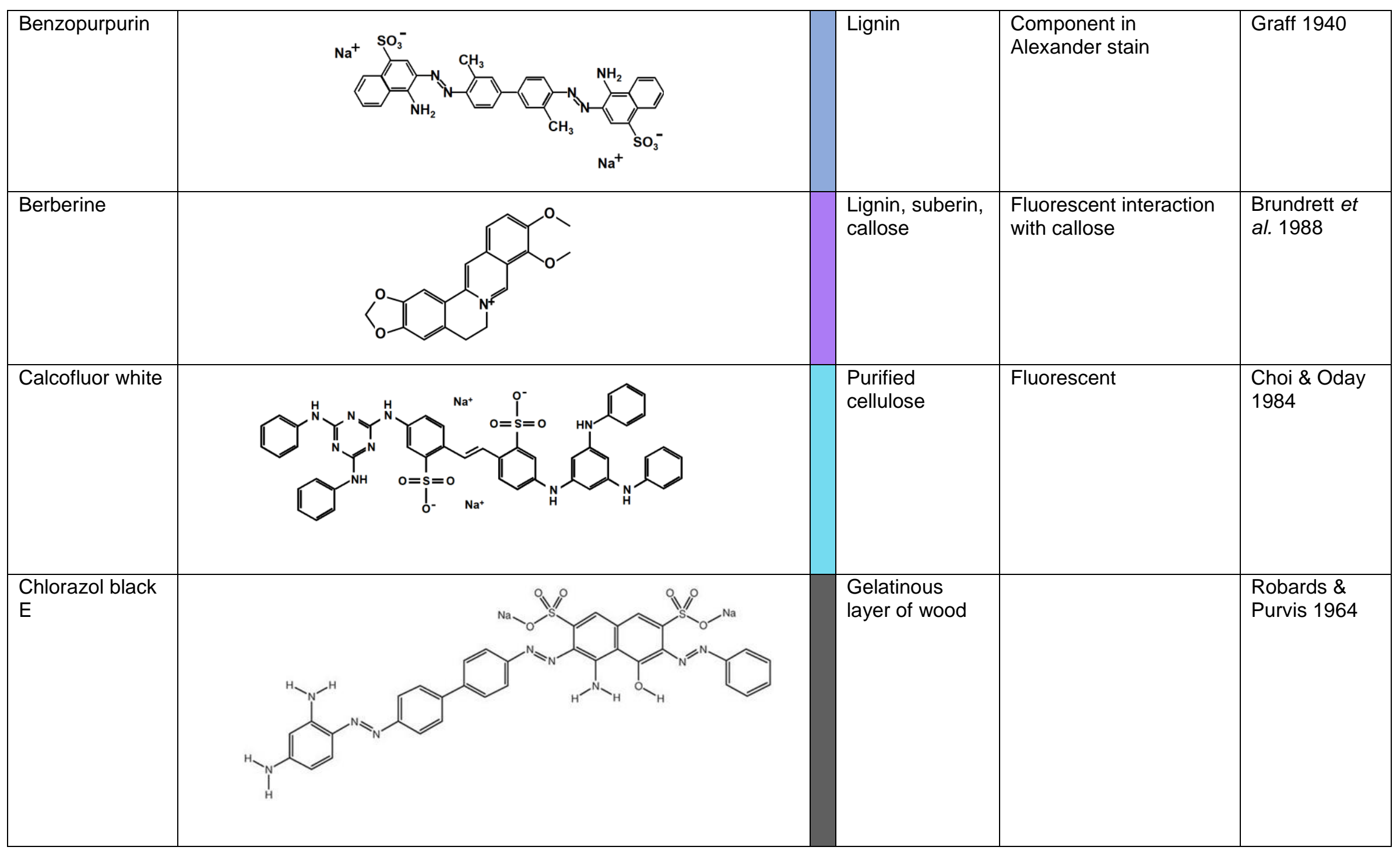




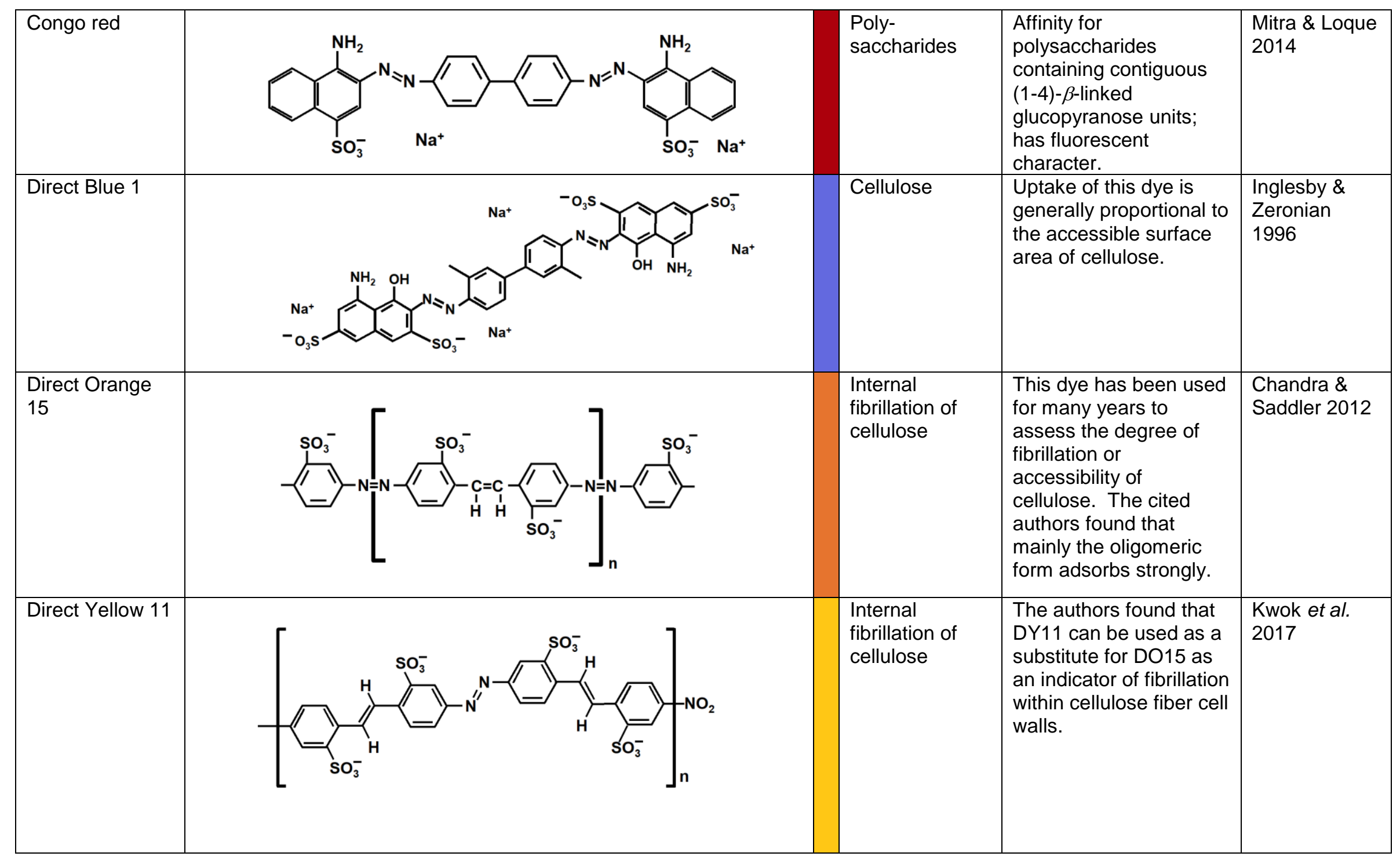




\begin{tabular}{|c|c|c|c|c|}
\hline Fluorinol yellow & & Extractives & $\begin{array}{l}\text { Note the relative } \\
\text { absence of polar groups } \\
\text { in this dye, suggesting } \\
\text { good affinity for } \\
\text { oleophobic substances. }\end{array}$ & $\begin{array}{l}\text { Brundrett et } \\
\text { al. } 1991\end{array}$ \\
\hline Hematoxylin & (1) & Phloem & $\begin{array}{l}\text { The hematoxylin was } \\
\text { applied after fixing with } \\
\text { ferric ammonium } \\
\text { sulfate, and it was } \\
\text { followed by lachmoid. } \\
\text { Lignin became blue, } \\
\text { cellulose of living cells } \\
\text { purplish black, and } \\
\text { nonliving cells brown to } \\
\text { purplish black with the } \\
\text { combination. }\end{array}$ & $\begin{array}{l}\text { Schneider } \\
1960\end{array}$ \\
\hline $\begin{array}{l}\text { Herzberg } \\
\text { reagent }\end{array}$ & Zinc, chlorine, and iodide preparation & $\begin{array}{l}\text { Tension wood } \\
\text { severity }\end{array}$ & See also Table B. & $\begin{array}{l}\text { Dogu \& } \\
\text { Grabner } 2010\end{array}$ \\
\hline Indigo & $\mathbf{H}$ & Polyester & $\begin{array}{l}\text { Useful to discriminate } \\
\text { between polyester and } \\
\text { various cellulose-based } \\
\text { fibers, including cotton. }\end{array}$ & $\begin{array}{l}\text { Son et al. } \\
2004\end{array}$ \\
\hline
\end{tabular}




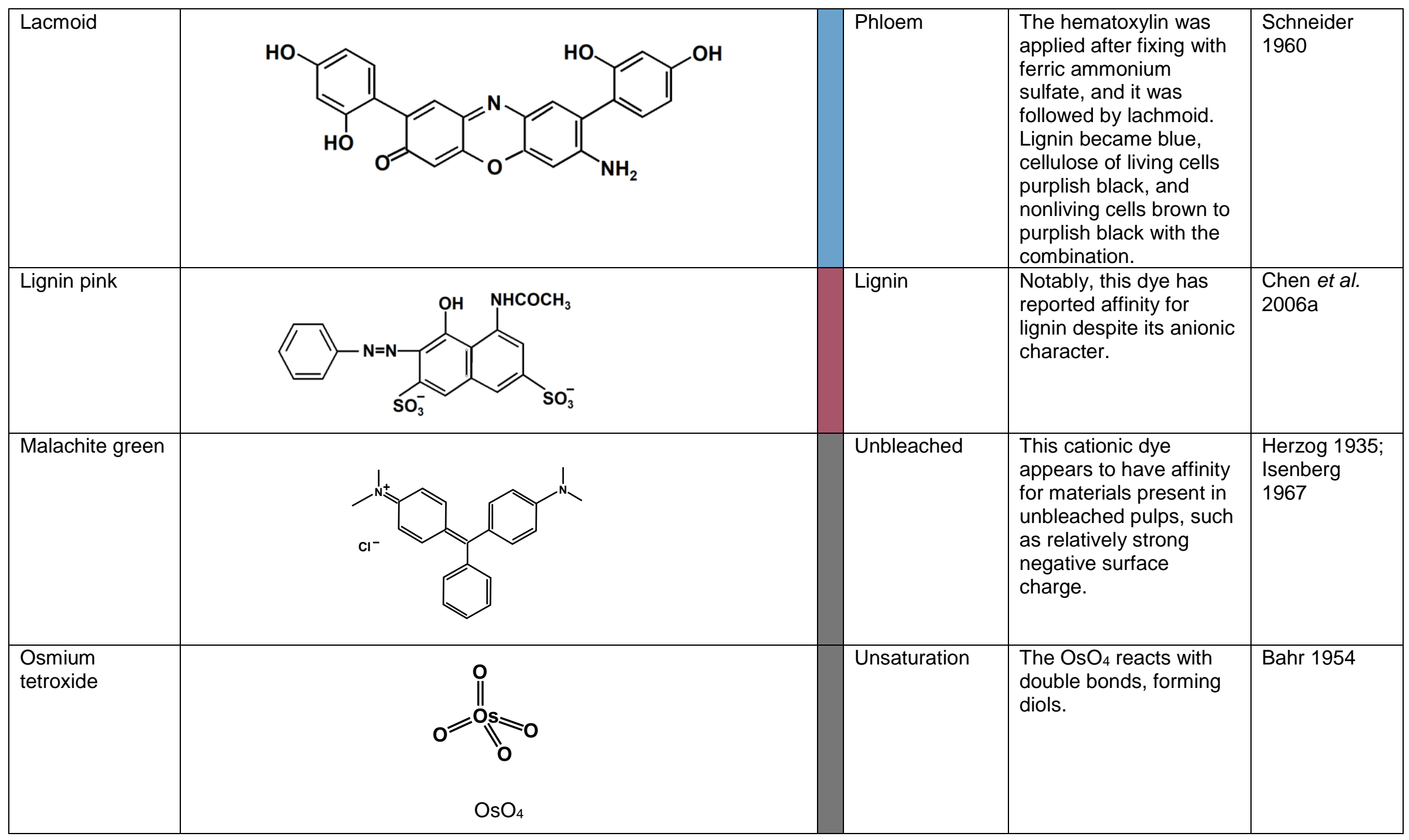




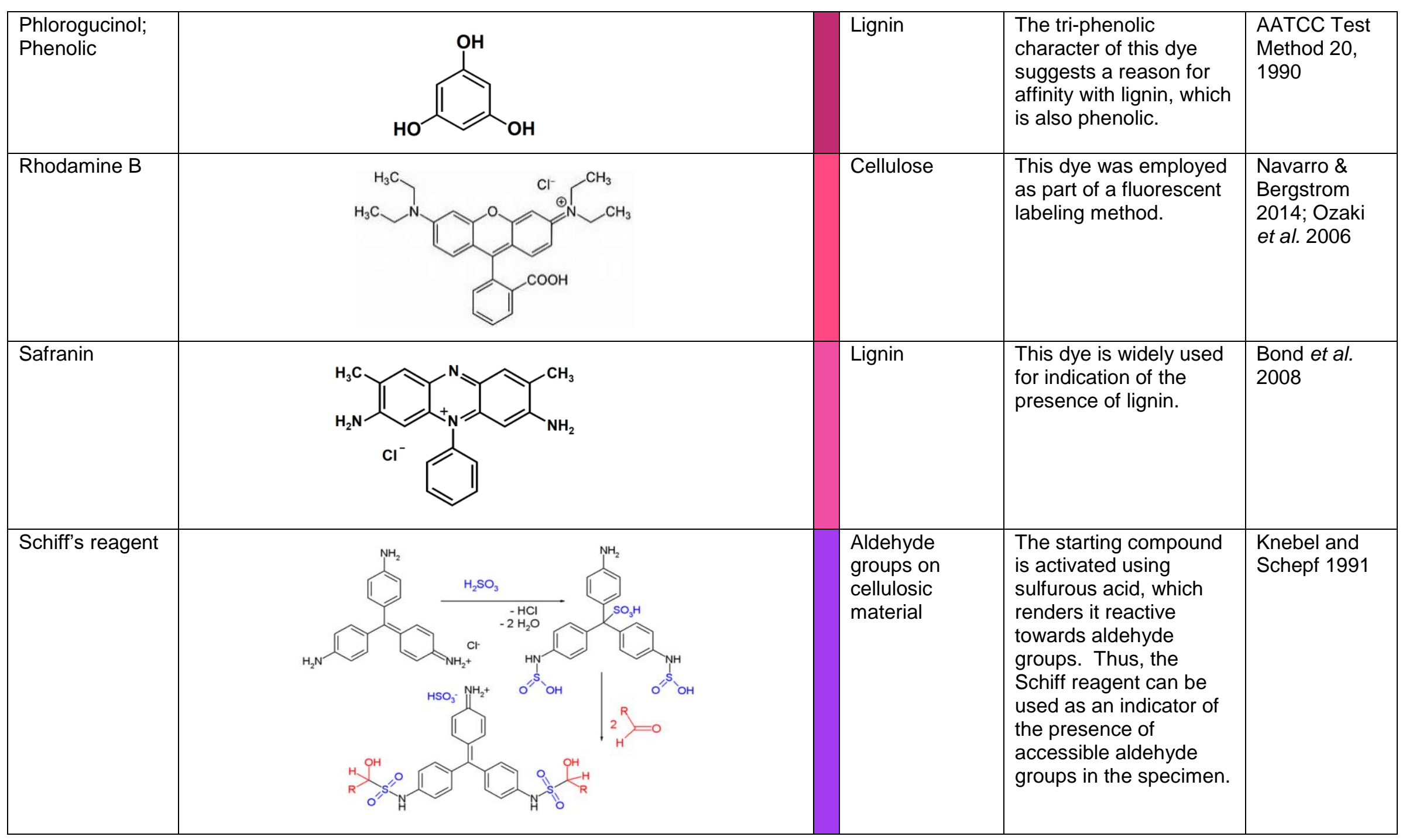




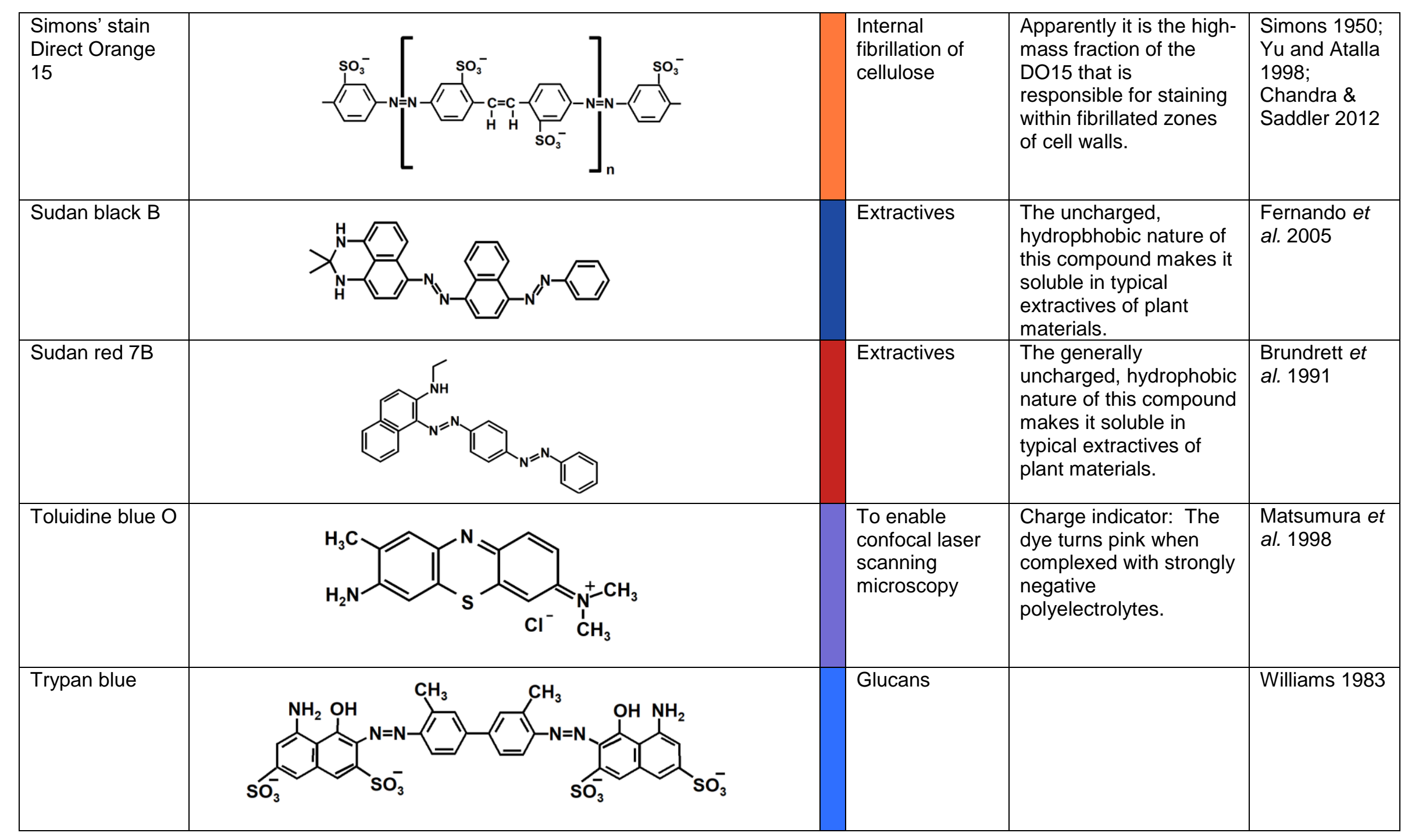


Table B. Widely Used Analytical Staining Procedures for Cellulosic Materials

\begin{tabular}{|c|c|c|c|}
\hline $\begin{array}{l}\text { Name of } \\
\text { procedure }\end{array}$ & Purpose of the procedure & Procedural steps & Selected citations \\
\hline Alexander stain & $\begin{array}{l}\text { Degree of cooking } \\
\text { (bleachability) }\end{array}$ & $\begin{array}{l}\text { Solution (a): } 2.7 \mathrm{~g} \mathrm{FeCl} 3 \text { in } 100 \mathrm{~cm}^{3} \text { water. } \\
\text { Solution (b): } 3.29 \mathrm{~g} \mathrm{~K} \text { ferricyanide in } 100 \mathrm{~cm}^{3} \text { water. } \\
\text { Solution (c): } 0.5 \mathrm{~g} \text { crude benzopurpurin } 4 \mathrm{~B} \text { in } 100 \mathrm{~cm}^{3} \text { hot } 50 \% \text { alcohol. } \\
\text { 1. Place } 1.5 \mathrm{~g} \text { of paper or pulp (dry basis) in } 50 \mathrm{~cm}^{3} \text { of a mixture of } \\
\text { equal parts of (a) and (b). } \\
\text { 2. Strain. } \\
\text { 3. Wash. } \\
\text { 4. Place in } 50 \mathrm{~cm}^{3} \text { of solution (c). } \\
\text { Chemical pulps from conifers: reddish; others: blue; groundwood: } \\
\text { yellow }\end{array}$ & $\begin{array}{l}\text { Graff 1940; } \\
\text { Isenberg } 1967\end{array}$ \\
\hline $\begin{array}{l}\text { Alexander } \\
\text { modification } \\
\text { stain }\end{array}$ & $\begin{array}{l}\text { Differentiate softwood from } \\
\text { hardwood pulp }\end{array}$ & $\begin{array}{l}\text { Solution A: Calcium nitrate solution } \\
\text { Solution B: Herzberg zinc chloride-iodine solution } \\
\text { Conifers: reddish; Other: blue }\end{array}$ & $\begin{array}{l}\text { Herzberg 1932; } \\
\text { Franke } 1993\end{array}$ \\
\hline $\begin{array}{l}\text { Anilinium sulfate } \\
\text { stain }\end{array}$ & $\begin{array}{l}\text { Presence of mechanical pulp } \\
\text { or esparto }\end{array}$ & $\begin{array}{l}\text { Aqueous solution made acidic with sulfuric acid. } \\
\text { Mechanical wood fibers: deep yellow }\end{array}$ & Herzberg 1902 \\
\hline $\begin{array}{l}\text { Astra blue- } \\
\text { safranin stain }\end{array}$ & $\begin{array}{l}\text { Differentiate rags, chemical, } \\
\text { and mechanical pulps }\end{array}$ & $\begin{array}{l}\text { Solution A: Astra blue Cl } 480480.5 \mathrm{~g}, 2 \mathrm{~g} \text { tartaric acid, } 97.5 \mathrm{~mL} \text { water } \\
\text { Solution B: Safranin, } \mathrm{Cl} 50240,99 \mathrm{~mL} \text { water } \\
\text { Solution C: } 37 \% \mathrm{HCl}, 0.5 \mathrm{~mL} ; 10 \% \text { ethanol, } 100 \mathrm{~mL} \\
\text { Wood-containing: red; wood-free: blue }\end{array}$ & Krauter 1974 \\
\hline $\begin{array}{l}\text { Behrens bast } \\
\text { fiber stain }\end{array}$ & Differentiation of bast fibers & $\begin{array}{l}\text { Solution A: Malachite green, } 1 \mathrm{~g} \text { with } 25 \mathrm{~mL} \text { water } \\
\text { Solution B: Acetic acid, } 2 \mathrm{~mL} \text { with } 98 \mathrm{~mL} \text { water } \\
\text { Solution C: Benzopurpurin } 10 \mathrm{~B} \mathrm{Cl} 241000.5 \mathrm{~g} \text { with } 100 \mathrm{~mL} \text { water } \\
\text { Protoplasm in lumen: green; hemp: bright green-blue and violet; } \\
\text { groundwood: green }\end{array}$ & Herzog 1935 \\
\hline Behrens stain & $\begin{array}{l}\text { Differentiate bleached } v s \text {. } \\
\text { unbleached sulfite pulps }\end{array}$ & $\begin{array}{l}\text { Solution A: Malachite green, } 1 \mathrm{~g} \text { with } 25 \mathrm{~mL} \text { water } \\
\text { Solution B: } 2 \mathrm{~mL} \text { acetic acid with } 98 \mathrm{~mL} \text { water } \\
\text { Unbleached: blue green to green; semibleached: sky blue; } \\
\text { bleached: no color }\end{array}$ & Isenberg 1967 \\
\hline Boast stain & $\begin{array}{l}\text { Differentiate rag, bleached, } \\
\text { unbleached sulfate, bleached } \\
\text { soda, and mechanical pulps }\end{array}$ & $\begin{array}{l}\text { Solution A: } 1.7 \mathrm{~g} \text { iron(III) chloride with } 100 \mathrm{~mL} \text { water } \\
\text { Solution B: } 3.29 \mathrm{~g} \text { potassium hexacyanoferrate(III) in } 100 \mathrm{~mL} \text { water } \\
\text { Solution C: } 0.8 \mathrm{~g} \mathrm{KI} \text { and } 0.1 \mathrm{~g} \mathrm{I} \text { in } 9 \mathrm{~mL} \text { water } \\
\text { Rag: wine red; unbleached sulfite: blue; bleached sulfite: rose; } \\
\text { bleached hardwood soda pulp: violet; groundwood: green-yellow }\end{array}$ & Franke 1993 \\
\hline
\end{tabular}




\begin{tabular}{|c|c|c|c|}
\hline Bright stain & $\begin{array}{l}\text { Differentiate bleached and } \\
\text { unbleached pulps }\end{array}$ & $\begin{array}{l}\text { Solution A: } 2.7 \mathrm{~g} \text { iron(III) chloride in } 100 \mathrm{~mL} \text { water. } \\
\text { Solution B: } 3.29 \mathrm{~g} \text { potassium hexacyanoferrate(III) in } 100 \mathrm{~mL} \text { water } \\
\text { Solution C: } 0.4 \mathrm{~g} \text { benzopurpurin and } 0.1 \mathrm{~g} \text { oxamine brilliant red BX in } \\
100 \mathrm{~mL} \text { of water } \\
\text { Unbleached (lignified): blue; bleached (lignin-free): red }\end{array}$ & Bright 1917 \\
\hline Bucher stain & $\begin{array}{l}\text { Differentiate chemical and } \\
\text { mechanical pulps }\end{array}$ & $\begin{array}{l}\text { Solution A: } 1 \mathrm{~g} \text { Malachite green in } 99 \mathrm{~mL} \text { water } \\
\text { Solution B: } 65 \mathrm{~g} \text { of tin(IV) chloride in } 35 \mathrm{~mL} \text { water } \\
\text { Solution C: } 1 \mathrm{~g} \text { of iodine in } 99 \mathrm{~mL} \text { of ethanol } \\
\text { Solution D: Herzberg zinc chloride-iodine, } 2 \text { drops, with acetic acid } 2 \\
\text { drops } \\
\text { Wood-containing: brown; wood-free cellulose: blue }\end{array}$ & Franke 1993 \\
\hline Cold soda stain & $\begin{array}{l}\text { Fluorescence of soda and } \\
\text { mechanical pulps }\end{array}$ & $\begin{array}{l}\text { Rhodamine } 6 \mathrm{GO}, \mathrm{Cl} 45160 \\
\text { Cold soda pulps fluoresce a bright orange } \\
\text { Groundwood pulp fluoresces a yellow-green }\end{array}$ & Isenberg 1967 \\
\hline $\begin{array}{l}\text { Cross \& Bevan } \\
\text { ferric ferri- } \\
\text { cyanide stain }\end{array}$ & $\begin{array}{l}\text { Demonstrate presence of } \\
\text { lignin }\end{array}$ & $\begin{array}{l}\text { Solution A: } 16.2 \mathrm{~g} \text { iron(III) chloride } \\
\text { Solution B: } 33 \mathrm{~g} \text { potassium hexacyanoferrate(III) } \\
\text { Lignocellulose and other samples with unsaturation and oxidizable } \\
\text { groups: Deep blue }\end{array}$ & Cross \& Bevan 1907 \\
\hline $\begin{array}{l}\text { Du Pont general } \\
\text { stain }\end{array}$ & $\begin{array}{l}\text { Differentiate rags.cellulose, } \\
\text { hardwood soda/sulfite, } \\
\text { softwood sulfite/sulfate and } \\
\text { mechanical pulps }\end{array}$ & $\begin{array}{l}\text { Solution A: } 50 \mathrm{~g} \text { chloride stain no. } 3 \text { zinc chloride } \& 15 \mathrm{~g} \text { calcium } \\
\text { chloride in } 100 \mathrm{ml} \text { water } \\
\text { Solution B (modified Herzberg stain): } 6 \mathrm{~g} \text { potassium iodide and } 1.5 \mathrm{~g} \mathrm{l} 2 \\
\text { in } 100 \mathrm{~mL} \text { water } \\
\text { Soda pulp, hardwood: blue; sulfite: weak gray; softwood: gray; } \\
\text { groundwood: yellow }\end{array}$ & Isenberg 1967 \\
\hline $\begin{array}{l}\text { Ferric chloride - } \\
\text { ferricyanide } \\
\text { calcium nitrate } \\
\text { stain }\end{array}$ & $\begin{array}{l}\text { Differentiate rags, bleached/ } \\
\text { unbleached sulite, bleached } \\
\text { hardwood soda, and } \\
\text { mechanical pulps }\end{array}$ & $\begin{array}{l}\text { Solution A: } 2.7 \mathrm{~g} \text { iron(III) chloride in } 100 \mathrm{~mL} \text { water } \\
\text { Solution B: } 3.29 \mathrm{~g} \text { potassium hexacyanoferrate(III) in } 100 \mathrm{~mL} \text { water } \\
\text { Solution C: } 100 \mathrm{~g} \text { calcium nitrate in } 50 \mathrm{~mL} \text { water } \\
\text { Solution D: } 8 \mathrm{~g} \mathrm{KI} \text { in } 90 \mathrm{ML} \text { water, then add } 1 \mathrm{~g} \mathrm{I} \\
\text { Equal volumes: Bleached sulfite stains pink; unbleached sulfite, blue; } \\
\text { bleached hardwood soda, violet; groundwood greenish, yellow; rag, } \\
\text { wine red }\end{array}$ & $\begin{array}{l}\text { Sindall 1906; } \\
\text { Isenberg } 1967\end{array}$ \\
\hline Graff "A" stain & $\begin{array}{l}\text { Differentiate softwood kraft } \\
\text { and sulfite fibers. }\end{array}$ & $\begin{array}{l}\text { Mix } 5 \mathrm{~cm}^{3} \text { of solution (a) and } 45 \mathrm{~cm}^{3} \text { of solution }(\mathrm{b}) . \\
\text { Solution (a): } 100 \mathrm{~g} \mathrm{CaCl} \text { in } 150 \mathrm{~cm}^{3} \text { water. } \\
\text { Solution (b): } 0.9 \mathrm{~g} \mathrm{KI} \text { and } 0.65 \mathrm{~g} \text { dry } \mathrm{I}_{2} \text { in } 50 \mathrm{~cm}^{3} \text { water. } \\
\text { Compare resulting colors with a chart }\end{array}$ & $\begin{array}{l}\text { Graff 1940; } \\
\text { Isenberg } 1967\end{array}$ \\
\hline
\end{tabular}




\begin{tabular}{|c|c|c|c|}
\hline Graff "C" stain & & $\begin{array}{l}\text { Solution A: } 40 \mathrm{~g} \text { aluminum chloride in } 100 \mathrm{~mL} \text { water } \\
\text { Solution B: } 100 \mathrm{~g} \text { calcium chloride in } 150 \mathrm{~mL} \text { water } \\
\text { Solution C: } 50 \mathrm{~g} \text { zinc chloride in } 25 \mathrm{~mL} \text { water } \\
\text { Solution D: } 0.9 \mathrm{~g} \text { potassium iodide and } 0.65 \mathrm{~g} \text { iodine in } 50 \mathrm{~mL} \text { water } \\
\text { Add } 20 \mathrm{~mL} \mathrm{~A}, 10 \mathrm{~mL} \text { B, } 10 \mathrm{~mL} \text { C; agitate, then add } 12.5 \mathrm{~mL} \text { of } \mathrm{D} \text {; then } \\
\text { agitate and leave to stand in the dark for } 12-24 \text { hours. Collect } \\
\text { supernatant and add a leaf of iodine. Compare colors with chart. }\end{array}$ & Graff 1940 \\
\hline Graff F stain & $\begin{array}{l}\text { Differentiate rags, bleached } \\
\text { soda, sulfite, \& sulfate pulps }\end{array}$ & $\begin{array}{l}\text { Solution A: } 40 \mathrm{~g} \text { aluminum chloride in } 100 \mathrm{~mL} \text { water } \\
\text { Solution B: } 100 \mathrm{~g} \text { calcium chloride in } 150 \mathrm{~mL} \text { water } \\
\text { Solution C: } 50 \mathrm{~g} \text { zinc chloride in } 25 \mathrm{~mL} \text { water } \\
\text { Solution } \mathrm{D}: 0.9 \mathrm{~g} \text { potassium iodide and } 0.65 \mathrm{~g} \text { iodine in } 50 \mathrm{~mL} \text { water } \\
\text { Add } 20 \mathrm{~mL} \text { A, } 6.5 \mathrm{~mL} \text { B, } 6.5 \mathrm{~mL} \text { C; agitate, then add } 1.5 \mathrm{~mL} \text { of } \mathrm{D} \text {; then } \\
\text { agitate and leave to stand in the dark for } 12-24 \text { hours. Collect } \\
\text { supernatant and add a leaf of iodine. Compare colors with chart. }\end{array}$ & Isenberg 1967 \\
\hline $\begin{array}{l}\text { Green-Yorston } \\
\text { stain }\end{array}$ & $\begin{array}{l}\text { Differentiate bleach } v s \text {. } \\
\text { unbleached sulfite pulp }\end{array}$ & $\begin{array}{l}15 \mathrm{mg} p \text {-phenyl azodimethylaniline, } 100 \mathrm{~mL} \text { glacial acetic acid, and } 300 \\
\mathrm{~mL} \text { water } \\
\text { Unbleached sulfite: strongly red; well-cooked pulps: pink with only } \\
\text { bordered pits strongly stained }\end{array}$ & $\begin{array}{l}\text { Isenberg 1967; } \\
\text { Jayme \& Harders- } \\
\text { Steinhäuser } 1955\end{array}$ \\
\hline Herzberg stain & $\begin{array}{l}\text { Fiber identification by } \\
\text { comparison with examples. }\end{array}$ & $\begin{array}{l}\text { Solution A: Dilute } 50 \mathrm{~g} \text { dry } \mathrm{ZnCl}_{2} \text { with water to make } 40 \mathrm{~cm}^{3} \text {. } \\
\text { Solution } \mathrm{B} \text { : Add } 5.25 \mathrm{~g} \text { dry } \mathrm{KI} \text { and } 0.25 \mathrm{~g} \mathrm{dry} \mathrm{I}_{2} \text { in } 12.5 \mathrm{~cm}^{3} \text { of water. } \\
\text { 1. Add iodine solution (solution } \mathrm{B} \text { ) with } \mathrm{ZnCl} \text { (solution } \mathrm{A} \text { ). } \\
\text { 2. Allow precipitate to form and settle. } \\
\text { 3. Treat the specimen. } \\
\text { Mix } \mathrm{A} \text { and } \mathrm{B} \text {, allow sedimentation, add of flake of iodine. } \\
\text { Lignocellulose: yellow; Lignin-free: blue or wine-red }\end{array}$ & $\begin{array}{l}\text { Herzberg 1902; } \\
\text { Graff } 1940\end{array}$ \\
\hline $\begin{array}{l}\text { lodine- potas- } \\
\text { sium iodide } \\
\text { Lugal stain }\end{array}$ & $\begin{array}{l}\text { Presence of starches or } \\
\text { dextrin }\end{array}$ & $\begin{array}{l}2.6 \mathrm{~g} \text { Potassium iodide, } 0.13 \mathrm{~g} \text { iodine, and } 5 \mathrm{~mL} \text { water stock solution; } \\
\text { dilute with } 92.27 \mathrm{~mL} \text { water for test solution. } \\
\text { Brown color indicates the presence of starch, etc. }\end{array}$ & Browning 1977 \\
\hline $\begin{array}{l}\text { lodine- } \\
\text { potassium } \\
\text { iodide stain }\end{array}$ & $\begin{array}{l}\text { Presence of starches or } \\
\text { dextrin and differentiation of } \\
\text { rags, chemical, mechanical } \\
\text { pulps }\end{array}$ & $\begin{array}{l}3 \mathrm{~g} \text { potassium iodide, } 1.15 \mathrm{~g} \text { iodine, } 2 \mathrm{~mL} \text { glycerin, in } 20 \mathrm{~mL} \text { water; } \\
\text { Cotton, linen, bleached hemp: brown; } \\
\text { Unbleached jute, straw, mechanical wood pulp: yellow to yellow-brown } \\
\text { Bleached jute and straw, chemical wood pulps: colorless to gray }\end{array}$ & Herzberg 1902 \\
\hline $\begin{array}{l}\text { Isenberg non- } \\
\text { wood stain }\end{array}$ & $\begin{array}{l}\text { Differentiation of cotton, flax, } \\
\text { hemp, and jute fibers }\end{array}$ & $\begin{array}{l}\text { Equal parts of neutral safranin, alkaline chrysophenine, and } \\
\text { benzoazurine in solution. } \\
\text { Cotton: Yellow with red spots; flax: white; hemp: dark brick red; jute: } \\
\text { red; wood: crimson red }\end{array}$ & Isenberg 1967 \\
\hline
\end{tabular}




\begin{tabular}{|c|c|c|c|}
\hline Jenke stain & $\begin{array}{l}\text { Differentiate rags, straw, } \\
\text { mechanical pulps }\end{array}$ & $\begin{array}{l}26.2 \mathrm{~g} \text { magnesium chloride, } 50 \mathrm{~mL} \text { water, } 2.3 \mathrm{~g} \text { potassium iodide, } 1.5 \mathrm{~g} \\
\text { iodine, and } 20 \mathrm{~mL} \text { water. } \\
\text { Cotton, linen: brown; straw cellulose pulp: blue-violet; wood-derived } \\
\text { cellulose: colorless to faint red; wood pulp: yellow }\end{array}$ & $\begin{array}{l}\text { Klemm 1923; } \\
\text { Herzberg } 1932 \\
\text { Isenberg } 1967\end{array}$ \\
\hline $\begin{array}{l}\text { Kantrowitz- } \\
\text { Simmons stain }\end{array}$ & $\begin{array}{l}\text { Amount of lignin present in } \\
\text { pulp fibers }\end{array}$ & $\begin{array}{l}\text { Solution A: } 2.7 \mathrm{~g} \text { iron(III) chloride, } 100 \mathrm{~mL} \text { water } \\
\text { Solution B: } 3.29 \mathrm{~g} \text { potassium hexacyanoferrate(III) in } 100 \mathrm{~mL} \text { water } \\
\text { Solution C: } 0.5 \mathrm{~g} \text { benzopupurin } 4 \mathrm{~B}, \mathrm{Cl} 23500 \text { in } 100 \mathrm{~mL} \text { water } \\
\text { Mix equal parts of A and B and apply to fibers for } 1 \text { minutes; wash; then } \\
\text { stain with C for } 2 \text { minutes } \\
\text { Well-cooked: red; poorly cooked: blue }\end{array}$ & ASTM D 1030-95 \\
\hline Klemm stain & $\begin{array}{l}\text { Differentiate hardwood vs. } \\
\text { softwood in mechanical pulp }\end{array}$ & $\begin{array}{l}\text { Solution } \mathrm{A}: 1 \mathrm{~g} \text { anilin sulfate in } 50 \mathrm{~mL} \text { water } \\
\text { Solution } \mathrm{B}: 10 \mathrm{mg} \text { methylene blue in } 50 \mathrm{~mL} \text { water } \\
\text { Use solution } \mathrm{A} \text {, apply vacuum, the use solution } \mathrm{B} \\
\text { Mechanical pulp: yellow; unbleached chemical pulp: intense blue }\end{array}$ & Korn \& Burgstaller 1953 \\
\hline $\begin{array}{l}\text { Klemm Sudan } \\
\text { stain }\end{array}$ & $\begin{array}{l}\text { Presence of ray cells in } \\
\text { chemical pulps; presence of } \\
\text { resins and fats }\end{array}$ & $\begin{array}{l}\text { Solution A: Ethanol, } 3 \text { parts; water, } 1 \text { part; saturated solution of Sudan } \\
\text { red II, CI } 261002 \text { parts } \\
\text { Rosin and related compounds: red }\end{array}$ & Herzog 1935 \\
\hline Kratochvil stain & $\begin{array}{l}\text { Differentiation of beached vs. } \\
\text { unbleached chemical pulp } \\
\text { and mechanical pulp }\end{array}$ & $\begin{array}{l}\text { Solution A: 4-nitroaniline } 2 \mathrm{~g} \text { in } 100 \mathrm{~mL} \text { water } \\
\text { Solution B: Herzberg zinc chloride-iodine, } 1 \text { drop } \\
\text { Dry the fibers on a slide; add solution A for } 20-30 \mathrm{~s} \text {; vacuum up the } \\
\text { liquid and apply solution B. } \\
\text { Unbleached groundwood: orange-yellow; unbleached semichemical: } \\
\text { brown-green to gray-green; bleached semichemical as well as } \\
\text { bleached or unbleached chemical pulps: blue-violet to deep purple }\end{array}$ & Franke 1993 \\
\hline Laughlin stain & $\begin{array}{l}\text { Differentiate bleached, } \\
\text { unbleached sulfite and sulfate } \\
\text { pulp and soda pulp }\end{array}$ & $\begin{array}{l}\text { Solution A: } 0.665 \mathrm{~g} \text { Basic orange } 3 \mathrm{RN} \text { in } 50 \mathrm{~mL} \text { water } \\
\text { Solution B: } 1 \text { drop of } 0.5 \mathrm{M} \text { hydrochloric acid } \\
\text { Solution C: } 3 \text { drops of Herzberg zinc chloride-iodine solution } \\
\text { Solution D: } 50 \mathrm{~g} \text { zinc chloride \& } 15 \mathrm{~g} \text { calcium chloride in } 100 \mathrm{~mL} \text { water } \\
\text { Place fiber suspension on slide; remove the water; apply A for one } \\
\text { minute; remove water with filter paper; apply B; after pressing apply C } \\
\text { for } 30 \mathrm{~s} \text {; vacuum away the solution; apply D and cover glass. } \\
\text { Sulfite pulp, unbleached: orange; sulfite, bleached: light brown; sulfite } \\
\text { highly bleached: light blue, changing to brown } \\
\text { Sulfate pulp, unbleached: gray to bluish; sulfate, bleached: medium } \\
\text { blue; sulfate highly bleached: weak to medium blue } \\
\text { Soda pulp, bleached: dark blue }\end{array}$ & Franke 1993 \\
\hline
\end{tabular}




\begin{tabular}{|c|c|c|c|}
\hline Lignin pink stain & Show presence of lignin & $\begin{array}{l}0.5 \mathrm{~g} \text { lignin pink, } \mathrm{Cl} 18050 \\
0.5 \mathrm{~g} \text { chlorozol black } \mathrm{E}, \mathrm{Cl} 30235 \\
100 \mathrm{~mL} \text { water; Lignin: Bright carmine; Other tissues: black }\end{array}$ & Gurr 1965 \\
\hline $\begin{array}{l}\text { Lofton-Merrit } \\
\text { stain }\end{array}$ & $\begin{array}{l}\text { Differentiate sulfite and } \\
\text { sulfate pulps }\end{array}$ & $\begin{array}{l}\text { Solution A: } 2 \% \text { malachite green } \\
\text { Solution B: } 1 \% \text { basic fuchsin } \\
\text { Sulfate fibers: blue to blue-green; sulfite: purple or lavender }\end{array}$ & Lofton \& Merritt 1921 \\
\hline $\begin{array}{l}\text { Lofton-Merrit } \\
\text { Wisbar } \\
\text { modification }\end{array}$ & $\begin{array}{l}\text { Differentiate sulfite, sulfate, } \\
\text { and mechanical pulps }\end{array}$ & $\begin{array}{l}\text { Solution A: } 10 \mathrm{~g} \text { malachite green, } 100 \mathrm{~mL} 95 \% \text { ethanol, } 400 \mathrm{~mL} \text { water } \\
\text { Solution B: } 5 \mathrm{~g} \text { fuchsin red, } 100 \mathrm{~mL} \text { ethanol, } 400 \mathrm{~mL} \text { water } \\
\text { Solution C: } 0.09 \mathrm{~mL} \text { of } 37 \% \text { hydrochloric acid } \\
\text { Unbleached sulfate: blue to green; unbleached sulfite: purple }\end{array}$ & Herzberg 1932 \\
\hline Mäule stain & $\begin{array}{l}\text { Differentiate hardwood vs. } \\
\text { softwood }\end{array}$ & $\begin{array}{l}\text { Solution A: } 1 \text { g, sodium permanganate, } 99 \mathrm{~mL} \text { water } \\
\text { Solution B: } 2 \text { drops } 6 \mathrm{~N} \text { hydrochloric acid } \\
\text { Solution C: } 1 \text { drop ammonium hydroxide and } 5 \text { drops water } \\
\text { Hardwood groundwood: red; softwood groundwood: brownish }\end{array}$ & Isenberg 1967 \\
\hline Noll's stain & $\begin{array}{l}\text { Differentiate bleached } v s \text {. } \\
\text { unbleached and mechanical } \\
\text { pulps }\end{array}$ & $\begin{array}{l}\text { Solution A: } 0.1 \mathrm{~g} \text { methylene blue, } 25 \mathrm{~mL} \text { methyl glycol, } 25 \mathrm{~mL} \text { water } \\
\text { Solution B: } 1 \mathrm{~g} \text { aniline sulfate, } 24 \mathrm{~mL} \text { water } \\
\text { Groundwood: yellow; unbleached pulp: blue; bleached: colorless }\end{array}$ & Korn \& Burgstaller 1953 \\
\hline Noll-Hahn stain & $\begin{array}{l}\text { Show presence of ray cells, } \\
\text { resins, and fat in sulfite or } \\
\text { sulfate pulps }\end{array}$ & $\begin{array}{l}0.1 \mathrm{~g} \text { sudan orange; } 0.1 \mathrm{~g} \text { indophenol; } 0.1 \mathrm{~g} \text { Sudan black } \mathrm{B}, 20 \mathrm{~mL} \\
96 \% \text { ethanol, } 20 \mathrm{~mL} 31 \text { Bé glycerin, } 10 \mathrm{~mL} \text { water } \\
\text { Rosin in bordered pits: red to black }\end{array}$ & Korn \& Burgstaller 1953 \\
\hline $\begin{array}{l}p \text {-Nitroaniline } \\
\text { stain }\end{array}$ & $\begin{array}{l}\text { Show presence of bleached } \\
\text { or unbleached sulfite and } \\
\text { mechanical pulps }\end{array}$ & $\begin{array}{l}\text { Solution A: } 20 \mathrm{~g} \text { p-nitroaniline, } 80 \mathrm{~mL} \text { water, } 20 \mathrm{~mL} \text { sulfuric acid } \\
\text { Solution B: } 4.3 \mathrm{~g} \text { ammonium molybate, } 100 \mathrm{~mL} \text { water } \\
\text { Mechanical woodpulp: bright reddish-orange to brick red } \\
\text { Unbleached sulfite pulp: Faint dull orange or faint brown to full orange } \\
\text { Bleached sulfite pulp: Yellow or colorless }\end{array}$ & Isenberg 1967 \\
\hline Schiff reaction & $\begin{array}{l}\text { Detect and localize aldehyde } \\
\text { groups in a specimen. }\end{array}$ & $\begin{array}{l}\text { The starting compound is activated using sulfurous acid, which renders } \\
\text { it reactive towards aldehyde groups. Thus, the Schiff reagent can be } \\
\text { used as an indicator of the presence of accessible aldehyde groups in } \\
\text { the specimen. }\end{array}$ & Knebel \& Schnepf 1991 \\
\hline Schultz's stain & Show presence of cellulose & $\begin{array}{l}\text { Solution A: } 110 \mathrm{~g} \text { zinc metal, } 300 \mathrm{~mL} \text { conc. hydrochloric acid, evaporate } \\
\text { Solution B: } 10 \mathrm{~g} \text { potassium iodide, } 7.14 \mathrm{~mL} \text { water } \\
\text { Cellulose: purple }\end{array}$ & Roberts and King 1987 \\
\hline Schultze stain & $\begin{array}{l}\text { Differential chemical and } \\
\text { mechanical pups }\end{array}$ & $\begin{array}{l}\text { Solution A: } 1 \mathrm{~g} \text { Brilliant Congo Blue RRW CI } 23745 \text { in } 70 \mathrm{~mL} \text { water } \\
\text { Solution B: } 1 \mathrm{~g} \text { Cotton Brown N, CI } 20090 \text { in } 70 \mathrm{~mL} \text { water } \\
\text { Solution C: } 6 \mathrm{~g} \text { Sodium sulfate in } 94 \mathrm{~mL} \text { distilled water } \\
\text { Delignified pulp: bright blue, changing to violet } \\
\text { Groundwood: maroon }\end{array}$ & Herzberg 1932 \\
\hline
\end{tabular}




\begin{tabular}{|c|c|c|c|}
\hline Schwalbe stain & $\begin{array}{l}\text { Differentiate sulfite from } \\
\text { sulfate pulps }\end{array}$ & $\begin{array}{l}0.05 \mathrm{~N} \text { ferric chloride, } 1 \% \text { sulfuric acid, and solution of } 2 \mathrm{~g} \text { potassium } \\
\text { ferrocyanide in } 98 \mathrm{~mL} \text { water } \\
\text { Sulfite: deep blue; unbleached sulfate: weak yellow to green-brown; } \\
\text { bleached sulfate: colorless to very weak blue }\end{array}$ & Isenberg 1967 \\
\hline Selleger stain & $\begin{array}{l}\text { Differentiate rags, softwood } \\
\text { unbleach sulfite and sulfate, } \\
\text { straw, and mechanical pulps }\end{array}$ & $\begin{array}{l}\text { Solution A: } 100 \mathrm{~g} \text { calcium citrate in } 50 \mathrm{~mL} \text { water } \\
\text { Solution B: } 3 \mathrm{~g} \text { potassium iodide in } 80 \mathrm{~mL} \text { water } \\
\text { Combine with } 1 \mathrm{~g} \text { of solid iodine } \\
\text { Manilla and hemp: deep red } \\
\text { Bleached coniferous wood: Pale rose-red } \\
\text { Linen and cotton: dirty red } \\
\text { Hardwoods and straw: reddish blue to violet } \\
\text { Soda pulps: esparto, straw, some woods: blue } \\
\text { Unbleached or low-beached wood pulps: pale yellow } \\
\text { Lignified pulps: Deep yellow }\end{array}$ & $\begin{array}{l}\text { Grant } 1961 \\
\text { Isenberg } 1967\end{array}$ \\
\hline Shaffer's stain & $\begin{array}{l}\text { Differentiate bleached sulfite } \\
\text { and sulfate pulps }\end{array}$ & $\begin{array}{l}1 \mathrm{~g} \text { C.P. brazilin, Cl } 75280 ; 1 \mathrm{~g} \text { sodium carbonate, } 175 \mathrm{~mL} \text { water } \\
\text { Bleached sulfite: wine red; bleached sulfate; purple }\end{array}$ & Isenberg 1967 \\
\hline Simons' stain & $\begin{array}{l}\text { Estimate the extent of } \\
\text { fibrillation and the } \\
\text { accessibility of cellulase to } \\
\text { cellulose }\end{array}$ & $\begin{array}{l}\text { Solution A: } 1 \mathrm{~g} \text { Direct Blue } 1 \text { and } 100 \mathrm{~mL} \text { water } \\
\text { Solution } \mathrm{B}: 1 \mathrm{~g} \text { Direct Orange } 15 \mathrm{in} 100 \mathrm{~mL} \text { water } \\
\text { 1. Add the specimen ( } 10 \mathrm{mg} \text { ) to phosphate buffer solution. } \\
\text { 2. Allow to sit over night. } \\
\text { 3. Add the DB1 and DO15 dyes. } \\
\text { Direct Orange } 15 \text { preparation: Isolate the high-mass fraction (> } 100 \\
\mathrm{kDa} \text { ) by dialysis starting with } 10 \mathrm{mg} / \mathrm{mL} \text { stock solution. } \\
\text { Unbeaten fibers: blue; increasing beating shifts color to orange. }\end{array}$ & $\begin{array}{l}\text { Simons 1950; Yu and } \\
\text { Attala 1998; Chandra \& } \\
\text { Saddler } 2012\end{array}$ \\
\hline $\begin{array}{l}\text { Sulfanilic acid } \\
\text { stain }\end{array}$ & $\begin{array}{l}\text { Differentiation of chemical } \\
\text { and mechanical pulp }\end{array}$ & $\begin{array}{l}20 \mathrm{~g} \text { sulfanilic acid, } 40 \mathrm{~g} \text { urea, } 40 \mathrm{~g} \text { glycerin, and } 900 \mathrm{~mL} \text { water } \\
\text { Groundwood: intense yellow }\end{array}$ & Isenberg 1967 \\
\hline $\begin{array}{l}\text { Sutermeister } \\
\text { stain }\end{array}$ & $\begin{array}{l}\text { Differentiate rags, jute- } \\
\text { manilla, and bleached/ } \\
\text { unbleached sulfite, bleached } \\
\text { straw-esparto-hardwood } \\
\text { sulfate and mechanical pulps } \\
\text { (Alternative to Herzberg stain) }\end{array}$ & $\begin{array}{l}\text { Solution A: } 1.3 \mathrm{~g} \text { iodine, } 1.8 \mathrm{~g} \text { potassium iodide, and } 100 \mathrm{~mL} \text { water } \\
\text { Solution B: } 74 \mathrm{~g} \text { calcium chloride and } 100 \mathrm{~mL} \text { water } \\
\text { Cotton, linen, hemp, and ramie: red to brownish red } \\
\text { Bleached soda pulps from hardwoods: dark blue } \\
\text { Bleached sulfite or low-yield sulfite: bluish or reddish violet } \\
\text { Jute, manila and more lignified sulfite fibers: greenish } \\
\text { Groundwood: yellow }\end{array}$ & Sutermeister 1920 \\
\hline $\begin{array}{l}\text { Toluidine blue B } \\
\text { stain }\end{array}$ & Show the presence of lignin & $\begin{array}{l}\text { Solution A: } 0.05 \mathrm{~g} \text { toluidine blue } \mathrm{O} \text { with } 99.95 \mathrm{~mL} \text { water } \\
\text { Solution B: } 1.38 \mathrm{~g} \text { sodium orthophosphate di-H in } 100 \mathrm{~mL} \text { water (buffer) } \\
\text { Solution C: } 2.65 \mathrm{~g} \text { sodium orthophosphate mono-H in } 100 \mathrm{~mL} \text { water } \\
\text { Lignified secondary wall: blue-green; lignified middle lamella: red purple }\end{array}$ & O’Brien et al. 1964 \\
\hline
\end{tabular}




\begin{tabular}{|c|c|c|c|}
\hline Vétillart stain & $\begin{array}{l}\text { Differentiate rags, cellulose, } \\
\text { and mechanical pulp }\end{array}$ & $\begin{array}{l}\text { Solution A: } 1.0 \mathrm{~g} \text { potassium iodide, } \sim 0.1 \mathrm{~g} \text { iodine, } 100 \mathrm{~mL} \text { water } \\
\text { Solution B: } 3 \text { parts } 66^{\circ} \text { sulfuric acid, } 2 \text { parts glycerin, } 1 \text { part water } \\
\text { Cotton, linen, hemp, bleached jute: red violet or wine red } \\
\text { Well-bleached wood cellulose: pure blue or gray blue } \\
\text { Poorly cooked wood or straw pulps: little iodine adsorbed } \\
\text { Strongly lignified fibers: dark yellow }\end{array}$ & Vétillart 1876 \\
\hline Wiesner stain & Show the presence of lignin & $\begin{array}{l}\text { Solution A: } 5 \mathrm{~g} \text { phloroglucinol and } 95 \mathrm{~mL} \text { water } \\
\text { Solution B: } 37 \% \text { hydrochloric acid, } 1 \text { drop } \\
\text { Lignified cells: red; not lignified: colorless }\end{array}$ & Dodge 1897 \\
\hline Wilson stain & $\begin{array}{l}\text { Differentiate rags, bleached, } \\
\text { unbleached sulfite, sulfate, } \\
\text { straw and mechanical pulps }\end{array}$ & $\begin{array}{l}0.8 \mathrm{~g} \text { iodine, } 35 \mathrm{~g} \text { cadmium iodide, } 50 \mathrm{~mL} \text { water, } 90 \mathrm{~mL} \text { water, } 7 \mathrm{~mL} \\
37 \% \text { formaldehyde, } 10 \mathrm{~g} \text { calcium nitrate }\left(4 \mathrm{H}_{2} \mathrm{O}\right), 20 \mathrm{~g} \text { cadmium } \\
\text { chloride }\left(2.5 \mathrm{H}_{2} \mathrm{O}\right) \text {. } \\
\text { Cotton: red; linen: rose; unbleached sulfite wood pulp (softwood): } \\
\text { colorless to gray; (hardwood): light purple; bleached softwood sulfite: } \\
\text { lavender-blue; hardwood: weak purple; unbleached groundwood: } \\
\text { yellow }\end{array}$ & Isenberg et al. 1967 \\
\hline Wisbar stain & $\begin{array}{l}\text { Differentiation of rag vs. } \\
\text { chemical pulps }\end{array}$ & $\begin{array}{l}\text { Solution A: } 0.1 \mathrm{~g} \text { iodine, } 0.5 \mathrm{~g} \text { potassium iodide, and } 1 \mathrm{~mL} \text { water } \\
\text { Solution B: } 90 \text { tin(II) chloride with } 100 \mathrm{~mL} \text { water } \\
\text { Rag fibers: rose; Delignified wood pulps: blue of various intensity }\end{array}$ & Franke 1993 \\
\hline Wisbar II stain & $\begin{array}{l}\text { Differentiation of rag, sulfite, } \\
\text { sulfate, and mechanical pulps }\end{array}$ & $\begin{array}{l}\text { Solution A: } 0.1 \mathrm{~g} \text { iodine, } 0.5 \mathrm{~g} \text { potassium iodide, and } 1 \mathrm{~mL} \text { water } \\
\text { Solution B: } 6.291 \mathrm{~g} \text { sat. solution of aluminum chloride \& } 9 \mathrm{~mL} \text { water } \\
\text { Solution C: } 1 \text { drop of Herzberg zinc chloride-iodine solution } \\
\text { Notes that even the best iodine-type stain systems mainly can clearly } \\
\text { differentiate just between rag, groundwood, and sulfite pulps. }\end{array}$ & Isenberg et al. 1967 \\
\hline Wurster di-stain & Show presence of lignin & $\begin{array}{l}\text { Dimethyl-paraphenylene-diamine } \\
\text { Woody fibers: orange-red, changing to crimson } \\
\text { Rosin-containing: pale pink }\end{array}$ & Herzberg 1932 \\
\hline
\end{tabular}

